\title{
DISSERTATION
}

\section{THE ROLE OF CHIEF EXECUTIVE OFFICER}

\author{
Submitted by \\ Margaret B. Glick \\ School of Education \\ In partial fulfillment of the requirements \\ For the Degree of Doctor of Philosophy \\ Colorado State University \\ Fort Collins, Colorado \\ Spring 2011
}

Doctoral Committee:

Advisor: Thomas J. Chermack

Gene W. Gloeckner

Susan A. Lynham

Jennifer K. Bond 
Copyright by Margaret B. Glick 2011

All Rights Reserved 


\section{ABSTRACT OF DISSERTATION \\ THE ROLE OF CHIEF EXECUTIVE OFFICER}

The purpose of this study was to address the gap between what is reported in the literature and what is known in current practice on the role of CEO. Research on the role of CEO is conflicting and outdated, and the theory deduced by Mintzberg in the 1970s has not been continually refined and updated, a necessary process for maintaining the usefulness of a theory (Lynham, 2002). A major goal of this research was to use the insights provided by CEOs to improve our general understanding of the major roles played by CEOs and how they generally allocate their time in various critical functions. CEOs are known for being a difficult population to research, yet this study has shown they are not inaccessible.

This research was also intended to serve those responsible for identifying CEO candidates, recruiting CEOs, coaching CEOs, sustaining an organization's leadership system, and developing performance matrices for Boards of Directors who are ultimately responsible for making sure the $\mathrm{CEO}$ is effective and efficient.

To investigate the role of CEO a survey instrument was developed based on 31 roles identified in the literature. The survey was sent to CEOs selected from a purchased database by e-mail. The study focused on three research questions with the purpose of understanding the role of $\mathrm{CEO}$, how CEOs allocate their time to roles, and what new 
roles are identified by CEOs. Eight research hypotheses were tested to understand the impact of gender, company ownership status, age, years in current job, years as CEO, and company size, on the roles agreed with and time allocations. There were a number of statistically significant findings with small effect sizes. The most significant differences were among company sizes, defined by number of employees. Because the survey instrument was developed specifically for this study it does not have a consistent or lengthy track record of valid and reliable survey scores, however, results from a factor analysis reveal high initial scores and a good basis for further instrument refinement and development.

This study had implications for CEO role theory. The results provide evidence for adjusting Mintzberg's prior theorizing about the role of CEO, and in this study, many of the roles Mintzberg found were strongly supported, yet some were not. The roles of other researchers and new roles suggested by study participants add depth to Mintzberg's work and serve to update his theory for modern times. The impact of industry on the role of CEO may provide help to CEOs who change industries during their careers. Finally, this study provides implications for practice by providing benchmark data for working CEOs about what their role is and how other CEOs allocate their time to these roles. 


\section{ACKNOWLEDGEMENTS}

For Pearl, you have been a constant and faithful companion on this journey.

For Scott, you are the love of my life and I thank God for you every day.

For my late dad, Tom Frisby and my mom, Sadie Frisby, who taught me I could do

anything I set my mind to, and for my late father-in-law Randall, and mother-in-law

Doris Glick, thank you for being my extra set of parents.

I am deeply thankful for a graduate committee that was supportive of my research project as well as my personal goals:

My advisor, Tom Chermack, I can't thank you enough for everything you have done. I am deeply grateful for your wisdom and support.

My methodologist, Gene Gloeckner, thanks for your help and encouragement. You are like family to Scott and me.

Susan Lynham, you are an inspiration to me. Thank you for believing in me, being a mentor, and a friend.

Jennifer Bond, thanks for stepping in and being there with your wisdom about surveying CEOs.

Thank you to Mike Thoren, an inspiring CEO, and a wonderful friend.

Thank you to Stephanie Mace and Wendy Bodwell for your friendship and support.

Thank you to Dr. Henry Mintzberg for a lifetime of work on this topic and for responding to my e-mails. 
TABLE OF CONTENTS

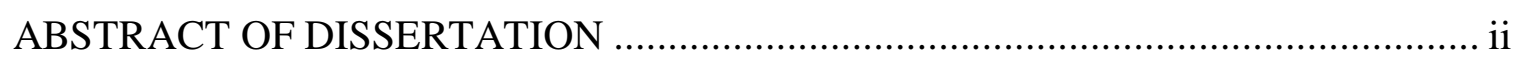

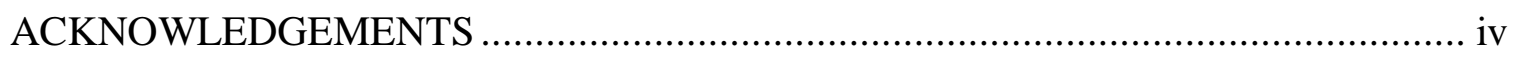

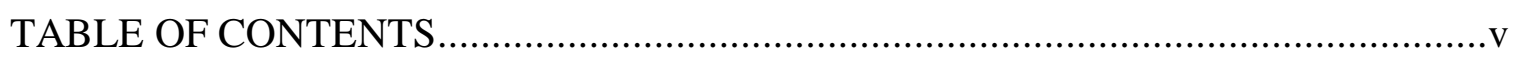

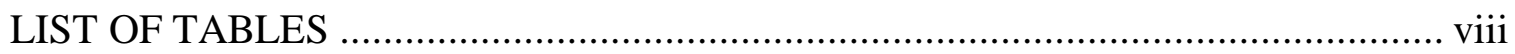

CHAPTER ONE: INTRODUCTION AND BACKGROUND .....................................

The Problem and the Need for This Study .................................................................

The Problem Description and Statement ...........................................................

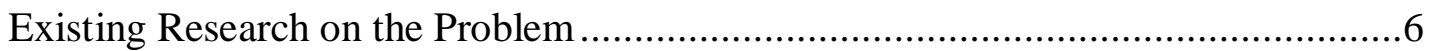

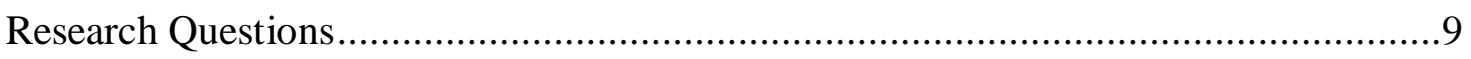

Study Purpose and Significance ............................................................................10

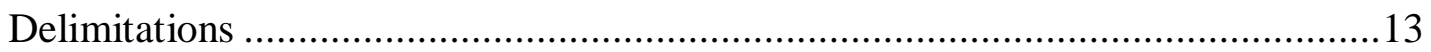

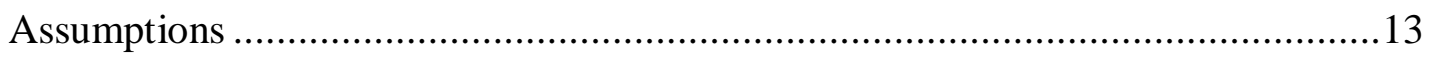

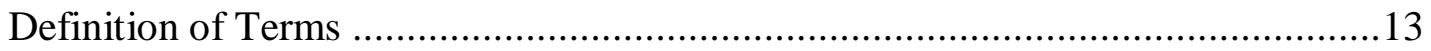

Researcher's Perspective .............................................................................15

CHAPTER TWO: REVIEW OF THE LITERATURE ..............................................16

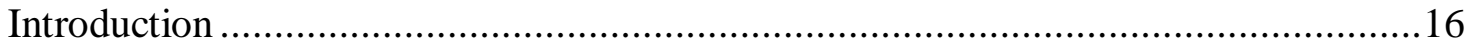

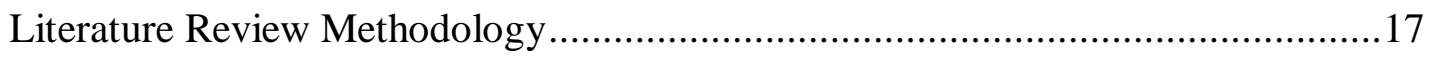

Part One: An Overview of the History of CEOs .....................................................18

Part Two: Theoretical Foundations for Studying The Role of CEO ............................21

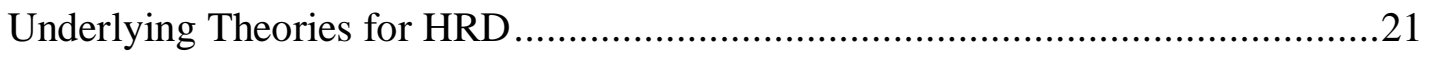

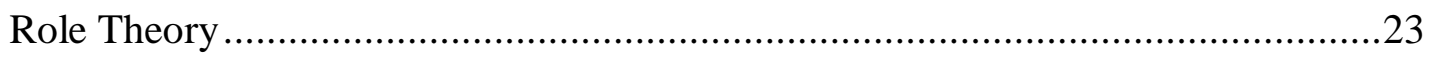

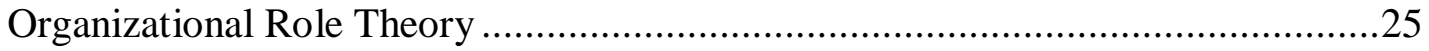

The Contribution of Role Theory in Informing Research on the Role of CEO ........27

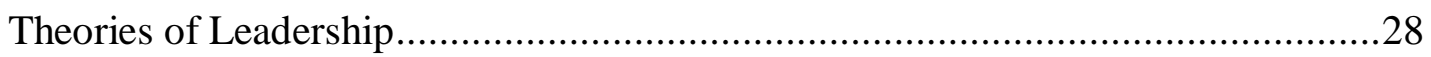

Strategic Leadership Theory ........................................................................29 


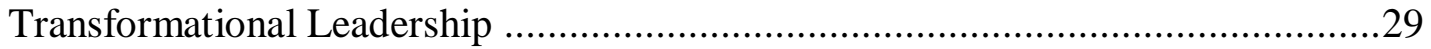

Theories of Responsible Leadership for Performance ............................................30

The Contribution of Leadership Theories in Informing Research on the Role of CEO .31

The Seminal Research of Mintzberg: A Theory of the Role of CEO ............................32

Mintzberg's Methodology: Structured Observation ..................................................33

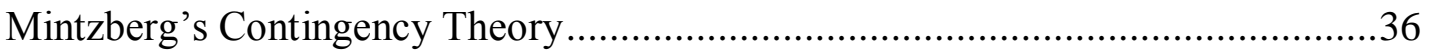

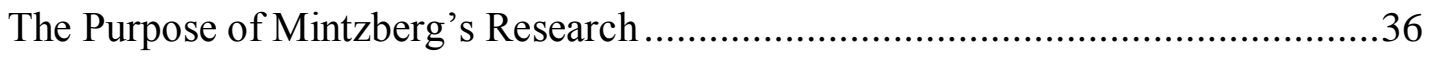

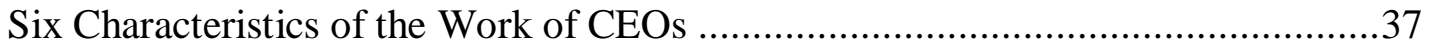

Part Three: Research on the Role of CEOs: The Emergence of Six Categories of Roles

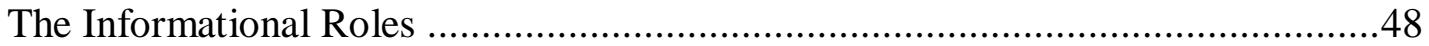

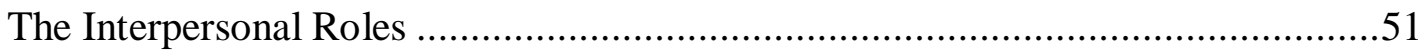

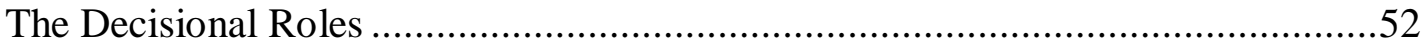

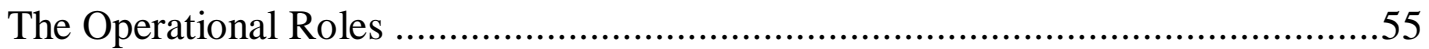

The Strategic Roles ..........................................................................................5

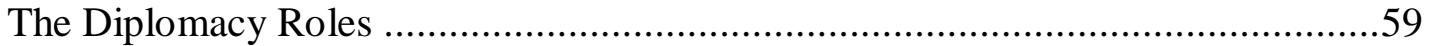

Contemporary Research: External Complexities and Their Impact on The Role of CEO

Changes in the External Environment ..............................................................64

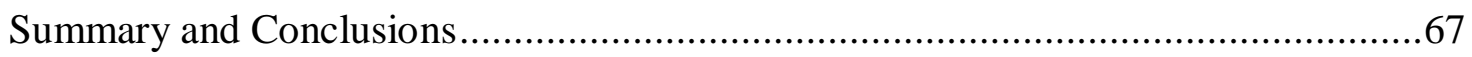

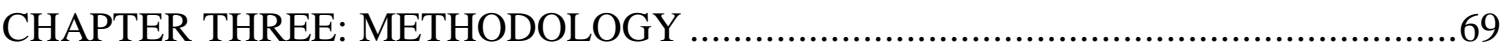

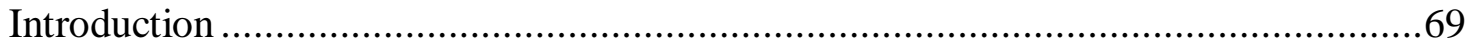

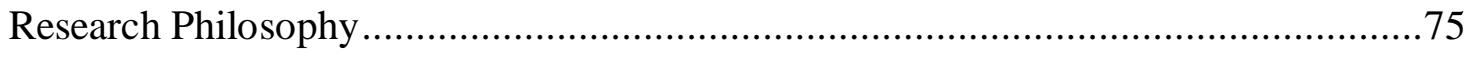

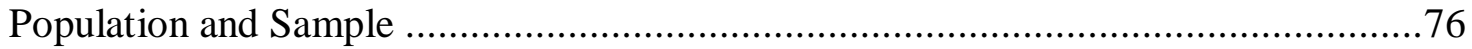

Sampling Procedures and External Validity ……………...................................

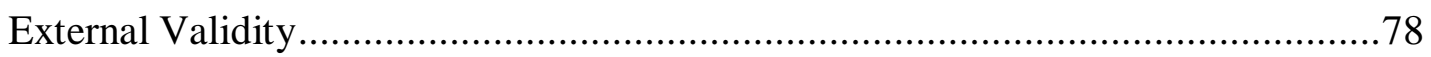

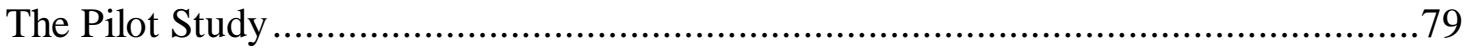

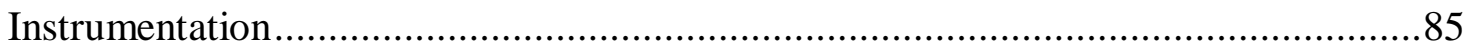

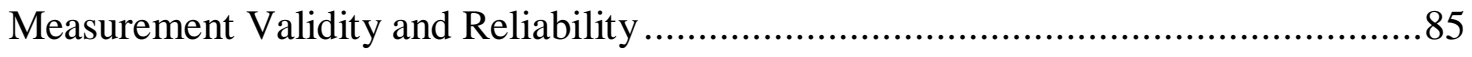

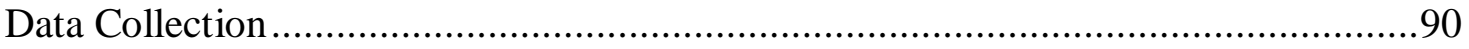




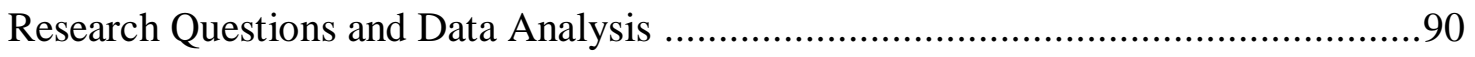

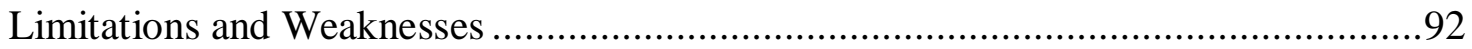

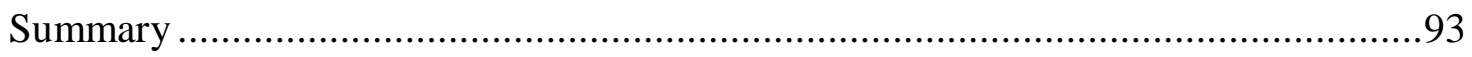

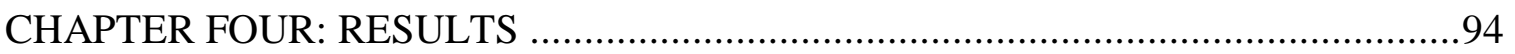

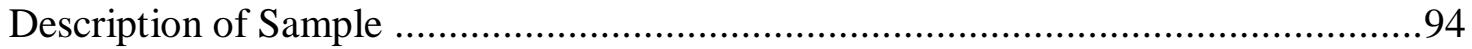

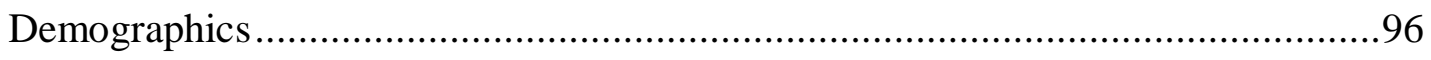

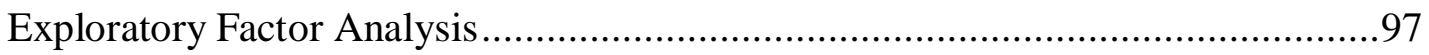

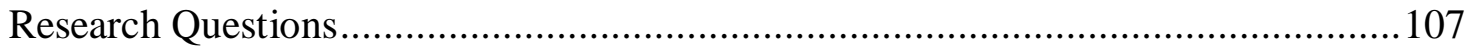

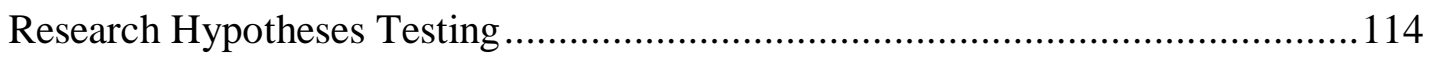

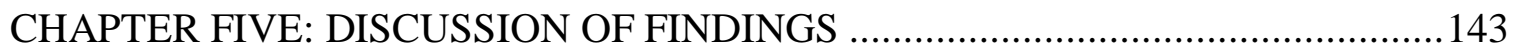

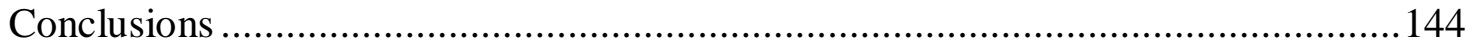

Discussion - Three Research Questions ................................................ 144

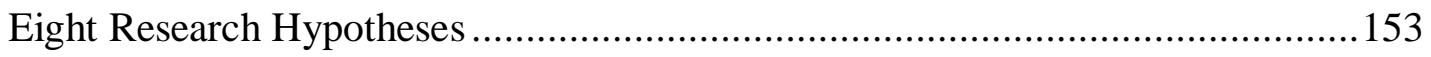

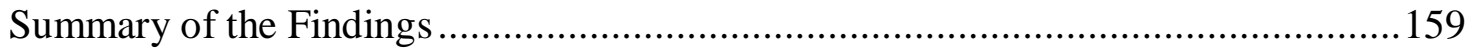

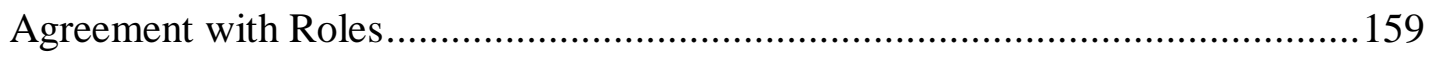

Time Allocated to the Role Categories .................................................... 160

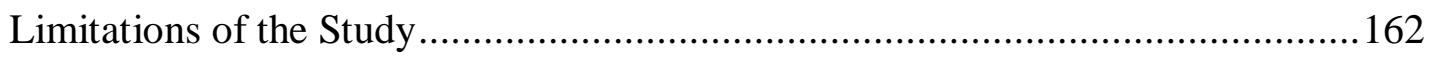

Implications and Recommendations for Future Research ................................ 164

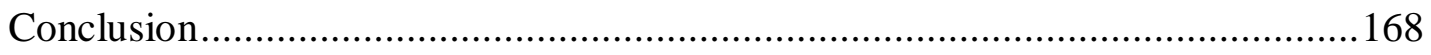

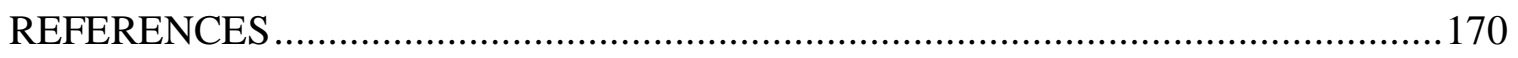

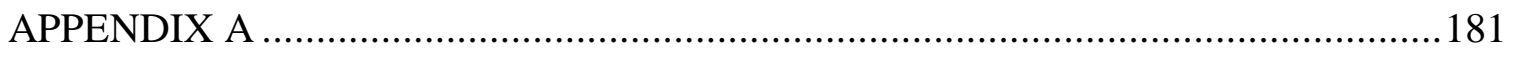

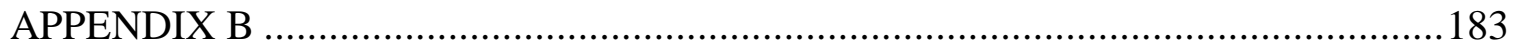

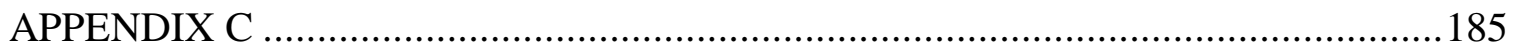

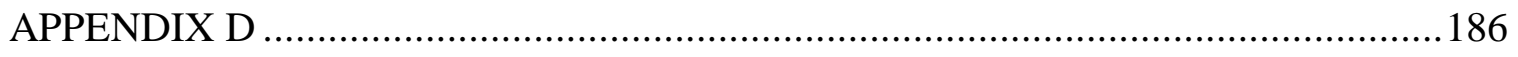

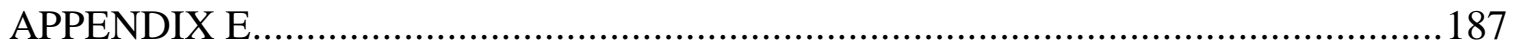

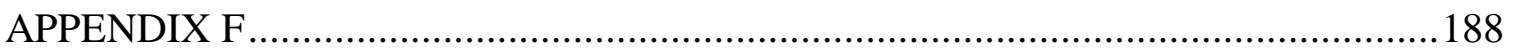

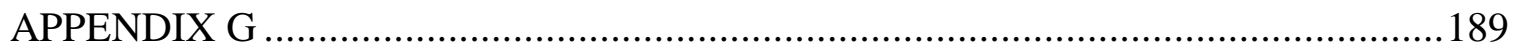




\section{LIST OF TABLES}

Table 1. Example Activities that Describe Mintzberg's 10 CEO Roles, Adapted from

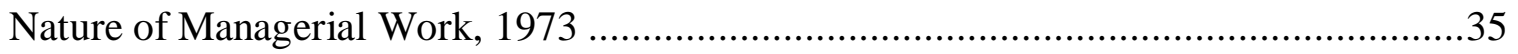

Table 2. Summary of 20 Studies Using Mintzberg's Theory for the Conceptual

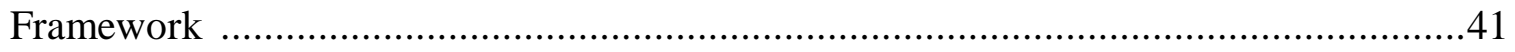

Table 3. Research Questions, Variables, and Appropriate Statistics for Analysis............72

Table 4. Research Conducted on the Role of CEO: Sample Size ...............................80

Table 5. Frequency Table - Responses to Operational Roles......................................84

Table 6. Role of CEO as Described by Previous Studies ........................................86

Table 7. Six Role Categories Described Through Constant Comparative Analysis .........88

Table 8. Role of CEO Survey Response Rates ...............................................95

Table 9. Demographic Data Provided by Survey Respondents ................................98

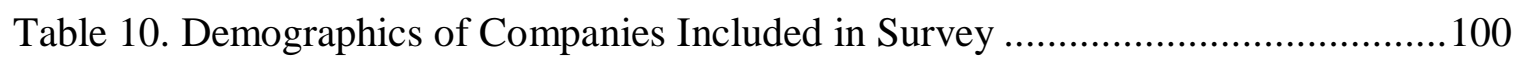

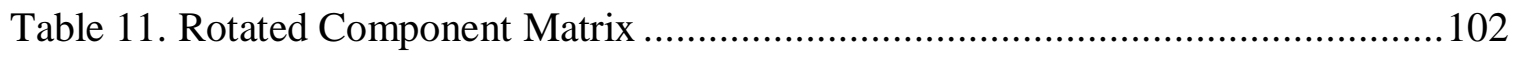

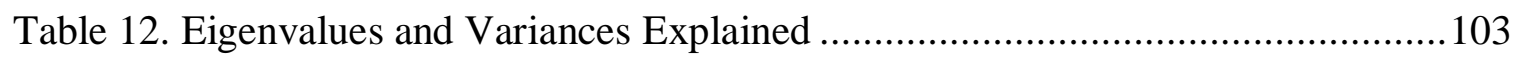

Table 13. Component Means, Standard Deviations, Reliabilities, Variances, and Item

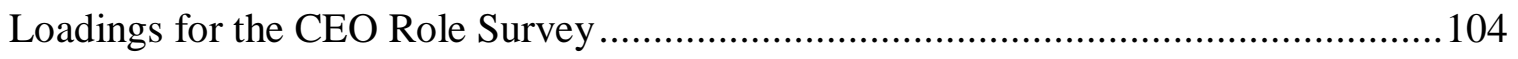

Table 14. Agreement with Informational Role Categories ..................................... 107

Table 15. Agreement with Interpersonal Role Categories ..................................... 108

Table 16. Agreement with Decisional Role Categories.......................................... 108

Table 17. Agreement with Operational Role Categories ....................................... 109 
Table 18. Agreement with Strategic Role Categories 110

Table 19. Agreement with Diplomacy Role Categories 110

Table 20. Agreement With the Six Roles Eliminated Through Factor Analysis

Table 21. Descriptive Statistics, Agreement With 31 Roles.

Table 22. Frequencies - Hours Reported in the Six Role Categories During an Average

Week 113

Table 23. Descriptive Statistics: Hours Reported in Six Role Categories During an

Average Week

Table 24. Differences between Males and Females on Role Agreement

Table 25. Differences between Male and Female CEOs in Terms of Time Spent in Six

Role Categories

Table 26. Majority of Time Spent in the Role Categories - Males and Females

Table 27. Majority of Time Approximations in the Role Categories - Private Versus

Public Companies

Table 28. Means and Standard Deviations Comparing Four Degree Majors or Industry Focus of CEO Participants and Agreement with Role Categories 121

Table 29. One-Way Analysis of Variance Summary Table Comparing a CEOs Degree Major or Industry Background on Agreement with Six Role Categories

Table 30 .Differences between CEOS With and Without Other C-levelEexecutives and their Approximations of Time in the Six Role Categories 124

Table 31. Means, Standard Deviations, and Intercorrelations for the Informational Roles and Predictor Variables $(\mathrm{N}=934)$ 125 
Table 32. Simultaneous Multiple Regression Analysis Summary for Age, Yrs. In Current Job, Yrs. As CEO, Last Degree Earned, and Company Size in Predicting Agreement with the Informational Role Category. .126

Table 33. Means, Standard Deviations, and Intercorrelations for the Interpersonal Roles and Predictor Variables $(\mathrm{N}=944)$

Table 34. Simultaneous Multiple Regression Analysis Summary for Age, Yrs. In Current Job, Yrs. As CEO, Last Degree Earned, and Company Size in Predicting Agreement with the Interpersonal Role Category. 128 Table 35. Means, Standard Deviations, and Intercorrelations for the Strategic Roles and Predictor Variables $(\mathrm{N}=908)$.

Table 36. Simultaneous Multiple Regression Analysis Summary for Age, Yrs. In Current Job, Yrs. As CEO, Last Degree Earned, and Company Size in Predicting Agreement with the Strategic Role Category 130

Table 37. Means, Standard Deviations, and Intercorrelations for the Diplomacy Roles and Predictor Variables $(\mathrm{N}=937)$

Table 38. Simultaneous Multiple Regression Analysis Summary for Age, Yrs. In Current Job, Yrs. As CEO, Last Degree Earned, and Company Size in Predicting Agreement with the Diplomacy Role Category.

Table 39. Differences between CEOs From Private versus Public Companies on Role Agreement. 133

Table 40. Differences between Private and Public Company CEOs on Time Spent in the Six Role Categories 134 
Table 41. Differences between CEOs from the Random versus Convenience Sample on

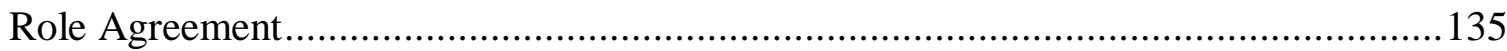

Table 42. Differences Between CEOs from the Random versus Convenience Sample on

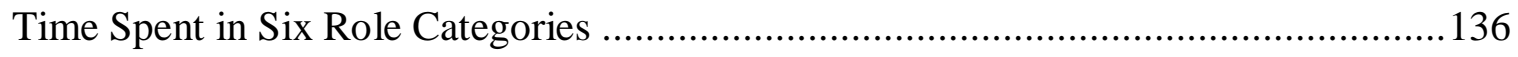

Table 43. Means and Standard Deviations Comparing Three Levels of Company Size 139

Table 44. One-Way Analysis of Variance Summary Table Comparing a CEOs Company

Size on Agreement with Six Role Categories ................................................. 140

Table 45. Comparison Data: Time Allocations to Role Categories .............................. 161 


\section{CHAPTER ONE: INTRODUCTION AND BACKGROUND}

This chapter introduces the problem statement that is the focus of this study. Additionally, this chapter: 1) provides evidence of the problem and the need for this study; 2) introduces the problem statement; 3) briefly discusses research on the problem; 4) presents the research questions that are the foundation for the study; and 5) describes the purpose and the significance of the study. Finally, definitions of key terms and the researcher's perspective are provided.

\section{The Problem and the Need for This Study}

One of the most important and influential roles in any organization is that of Chief Executive Officer (CEO), yet research on this role remains ambiguous, conflicted, and outdated. It is ambiguous to the extent the role is still uncertain and remains unsubstantiated by empirical research (Edersheim, 2007; Hales, 1986; Lafley, 2009). It is conflicted by contradicting research and by authors of popular literature claiming to know what the role is (Ireland \& Hitt, 1999), but with no empirical evidence supporting the claims (Edersheim, 2007; Hales, 1986; Lafley, 2009). Finally, it is outdated in the sense we continue to rely on models and theories from the late 1960s and early 1970s to guide scholarly research on the role of CEO, seemingly ignoring the complexities of business today and how these complexities have changed the world of work (Breene, Nunes, \& Shill, 2007; Hales, 1986). 
During a 2003 interview, Peter Drucker commented that "the role of CEO needed to be the next focus of management research" and former CEO of Proctor and Gamble, A. G. Lafley referred to the CEO role as "Drucker's unfinished chapter" (Edersheim, 2007, p. 40). Much of the focus on CEOs during the past ten years has been negative due to the widely-publicized failures of WorldCom, Enron, Arthur Andersen, and Tyco (Matsumura \& Shin, 2005; Zhang \& Wiersema, 2009). These scandals were associated in the press with CEO compensation, bringing executive compensation into the limelight. Critics of CEO compensation packages suggest the pay is too high, it has no link to organizational performance, and that the relative increases in compensation are immoral and unethical (Matsumara \& Shin, 2005). The bailout of banking and automotive manufacturers during 2009 and 2010 continued to place CEOs and their compensation packages in the news. In the turmoil of today's economy and in light of the tainted reputation of CEOs, understanding the role of CEOs and how they spend their time seems a worthy research topic.

CEOs may lead companies with extremely significant economies (Edersheim, 2007). Not only can these CEOs influence the course of their companies, employees, and markets, in some cases they also influence the course of entire countries and regions of the world (Boatright, 2009; Edersheim, 2007; Lynham \& Cunningham, 2006). During 2006 it was estimated that "of the hundred largest economic entities in the world, 46 were countries, and 54 were companies" (Edersheim, 2007, p. 40). As manufacturing and service centers have shifted off-shore the CEO role has also shifted to that of a global leader. While there is much negative focus on CEO compensation, companies spend hundreds of thousands of dollars in recruitment fees to hire these individuals, creating a 
tension between public perception and corporate boards (Case, 2009; Matsumara \& Shin, 2005).

Each of us is impacted by organizations and the CEOs who lead them. From our basic needs for a safe food supply, clean water, and shelter to our desire for highdefinition televisions, I-Phones, and designer jeans, all of these needs are produced or manufactured by corporations and organizations that are led by CEOs and Boards of Directors (Kleiner, 2008). We support corporations with the purchasing power of both our discretionary and non-discretionary spending, and our investment in retirement accounts, yet little is known about the role of these leaders or how they focus their time (Edersheim, 2007; Hales, 1999; Lafley, 2009).

Organizations and the CEOs who lead them have numerous stakeholders. These stakeholders may be impacted significantly by decisions made by CEOs and Boards of Directors. The list of stakeholders includes but is not limited to, consumers, suppliers, investors, employees, including HR directors and other C-level executives, and Boards of Directors. The need for this study is rooted in the need for CEOs to understand what their roles are and how they should spend their time. Existing research is outdated and does not provide CEOs with updated roles or time allocations. The resulting data from this study may serve HR Directors who create job descriptions, performance appraisals, and succession plans for CEOs. It may serve Boards of Directors, responsible for hiring and evaluating CEOs. It may also serve the CEOs by helping them to understand their existing roles and how time might best be allocated to major categories of roles. A CEOs understanding of their own role may serve them well in meeting the needs of the 
remaining stakeholders, including their employees, consumers, suppliers, investors, and Boards of Directors.

\section{The Problem Description and Statement}

Popular literature offers an abundance of how-to-be a CEO advice, yet the advice tends not to be based on empirical research (Hales, 1986). Little is known about the impact popular literature has on the ability of CEOs to lead their organizations. However failure to perform in the role results in the frequent churn (turnover) we see in CEO positions (Jacovitz, 2006). One-third of all CEOs in charge of U.S. organizations are terminated from their jobs, voluntarily or involuntarily, within three years of being hired (Coyne \& Rao, 2005). In 2006 the number of CEOs changing jobs was 2,088 in the U.S., an increase of over 47\% from 2005 (Jacovitz, 2006). According to a 2006 study by Booz Allen Hamilton Inc. turnover rates for CEOs in 2006 were 16.2\% (Mooney, Dalton, Dalton, \& Certo, 2007). CEOs may be forced out of their jobs by their Board of Directors for a variety of reasons including poor performance and poor fit with the organization, yet these are seldom reasons made public (Charan, 2005). Accounting irregularities, insider trading, and other unethical or illegal acts are more apt to make headlines and get the attention of the public, eroding a company's reputation quickly (Ertugrul \& Krishnan, 2011). Additionally, ignoring customers, tolerating low performers, denying the reality of bad news, and failing to execute programs critical to organizational success are reasons CEOs lose their jobs (Murphy, 2005).

During 2008 it was estimated that 1,484 CEOs left their jobs, an average of 6 each business day. The turnover rate for CEOs stabilized in 2009 at 14.3\% (Favaro, Karlsson, \& Neilson, 2010). CEOs unable to perform leave companies with the financial burden of 
expensive severance packages and recruitment costs (Walsh, 2008). Ineffective CEOs who are not dismissed have the potential for creating even more financial burden on organizations, earning high salaries without return for the organization, its stakeholders, and society.

Turnovers are expensive and eventually investors and consumers pay the price (Jensen \& Murphy, 1990). High CEO salaries, stock option plans, extravagant bonuses, and pricey severance packages frequently make the news, a result of recent government bailouts of the banking and automobile industries (Walsh, 2008). The ratio of pay between CEOs and typical workers has increased from 100 times in 1990 to between 350 and 570 times in 2009, primarily a result of an increase in stock options in CEO compensation packages (Hall \& Murphy, 2003; Harris, 2009). Changes in the way CEOs are compensated, that is an increase in equity-based pay, may be explained in part by the ever-changing environment in which companies conduct business.

The external business environment has been described as volatile, uncertain, complex, and ambiguous (Johansen, 2007; IBM Institute for Business Value, 2010). With unemployment in the U.S. over 9\% during July, 2010 (U.S. Bureau of Labor Statistics), the country is struggling for economic recovery. CEOs play an especially vital role, as they are expected to provide leadership that produces jobs, quality products and services, and return on investment to shareholders (Boatright, 2009; Case, 2009). CEOs are therefore expected to be efficient and effective leaders with significant impact on the performance of the organizations they lead (Boatright, 2009).

The business environment has changed dramatically since the 1970s; technology has changed the way companies do business; the economy is more globalized; and the 
workforce has changed and continues to change in ways that no one could have imagined. Leading through this organizational "permanent white water" (Vaill, 1996, p. 10) may be one of the most important roles a CEO must play. A study conducted in 2002 examined whether the rhetorical claims about the emergence of new and different managerial work could be substantiated by empirical evidence (Tengblad, 2006). The research suggests that the role of CEO has changed from an administrative/desk-work job to the job of institutional and global leader. However a change in the role of CEO conflicts with early research by Mintzberg in 1973 suggesting the roles of CEO and of managers in general, were "timeless" (Tengblad, 2006, p. 1452).

During the 1980s and 1990s research on CEOs shifted its focus to research on CEO compensation, succession plans, corporate social responsibility, and the separation of the CEO and Chairman of the Board roles. This shift in focus is due largely to increased regulatory pressures faced by CEOs along with strong criticism from the public of their compensation packages (Boatright, 2009; Matsumura \& Shin, 2005). The need to study and understand the role of CEO is more important today than it has ever been, yet extant theory and research informing understanding and practice on the role of CEO is outdated and ill-suited to the task. This results in the problem that is the focus of this study, namely: that the research on the role of CEO is conflicting and outdated.

Existing Research on the Problem Initial work on the roles of managers began in 1916 by Henri Fayol and was followed by other authors of the classical school who approached management as a science (Mintzberg, 1973). The role of CEO was detailed in Mintzberg's book The Nature of Managerial Work. Mintzberg utilized methods of the work activity school 
whereby the detailed activities of CEOs were analyzed into three role categories comprised of 10 roles. In contrast to the notion of management as science and considered a seminal work on the role of CEOs, this research became the basis for many studies on the work of all managers, not just executives or CEOs. However, the significance of the differences between managers and CEOs is evidenced not only in the work they do, but in

the conceptions they hold, deep in their psyches, of chaos and order. Managers embrace process, seek stability and control, and instinctively try to resolve problems quickly ... Leaders, in contrast, tolerate chaos and lack of structure and are willing to delay closure in order to understand the issues more fully (Zaleznik, 1977, p. 74).

While Mintzberg's landmark study provides a conceptual framework for extensive research into the work of managers in general, the research was specifically conducted on the work, in the forms of roles and variables, of five CEOs. Although the majority of studies on managerial roles in organizations have focused on middle and lower-level managers, the focus of this study is specifically on the role of CEOs and is not intended to address the role of other managerial positions.

Following are three role categories and corresponding 10 roles induced by Mintzberg's (1973) research:

1) interpersonal roles: figurehead, liaison, and leader;

2) informational roles: monitor, disseminator, and spokesperson; and

3) decisional roles: entrepreneur, disturbance handler, resource allocator, and negotiator. 
In addition to the 10 roles, Mintzberg developed a Contingency Theory of Managerial Work in which he determined the work of CEOs is influenced by four variables, namely, the environment, the job, the person, and the situation.

Mintzberg's research was the impetus and framework for many studies on the work, the role, and the characteristics of CEOs (Carter, 1982; Howe, 1988; Kurke \& Aldrich, 1983; Lau, Pavett, \& Newman, 1979; Snyder \& Wheelen, 1981; Whitely, 1978). Some studies utilized and expanded upon the original model and some put forth new models to explain the role of CEO (Hart \& Quinn, 1993; Howe, 1988; Lau et al., 1979; Snyder \& Wheelen, 1981; Tengblad, 2006). Some claim that Mintzberg "got it [the role of CEO] right" (Kurke \& Aldrich, 1983, p. 975) and Mintzberg's theory of roles is “timeless" (Tengblad, 2006, p. 1452). Others suggest further development of Mintzberg's theory is necessary to fully understand the role of CEO and how CEOs spend their time (Hales, 1986; Hart \& Quinn, 1993). Furthermore, social and applied theory is contextual and temporal, and as a result requires continuous refinement, re-development, and reconfirmation (Lynham, 2002):

in order for the theoretical framework to evoke trust and confidence, the initial explanation of the phenomenon, problem, or issue embedded in the framework must be applied to and empirically confirmed in the world in which the phenomenon, issue, or problem occurs (p. 232).

The context of the world in which we do business has changed dramatically, thus we are left with a substantial gap in our theory about the role of CEO and how CEOs spend their time. Managing has been referred to as a "theory in search of evidence" (Hales, 1999, p. 339). While Mintzberg's research provided a framework for studying and understanding the role of CEO in the 1970s and 1980s, the theory and much of the informing research is now 30 - 40 years old. Research conducted to support Mintzberg's 
theory has been described as "richly descriptive and insightful, but largely self-contained, studies" (Hales, 1999, p. 337). It has also been criticized for numerous limitations and omissions, failure to find similarities while focusing only on differences, data that are only descriptive, identification of variations that still require explanation, and rarely going beyond demonstrating correlation with other variables to advance possible substantive causal connections (Hales, 1999; Martinko \& Gardner, 1985). These deficiencies help further illuminate definition of research questions that are the foundation of this study.

\section{Research Questions}

To gain an understanding of how working CEOs perceive their roles the overarching research question was:

1) What is the role of CEO in the U.S.?

To gain an understanding about how CEOs allocate their time, the following question was asked:

2) How much time do CEOs estimate they spend in six categories of roles?

On the survey participants were asked to add roles that were missing in order to explore the following question:

3) What roles are identified by CEOs that were not identified in the literature on the role of CEO?

In addition to the three research questions, the following hypotheses were tested:

H1) There is no difference between gender, agreement with the 31 role descriptions, and time allocated to the six role categories. 
HIa) Female CEOs will report they spend more time in interpersonal roles than their male counterparts.

HIb) Female CEOs will report they spend less time in operational roles than their male counterparts.

H2) CEOs from public companies will report they spend less than $10 \%$ of their time in strategic role categories.

H3) Agreement with and time spent in the role categories will not differ depending upon the CEOs degree major or industry background.

H4) There will be no difference in the way CEOs spend their time between CEOs with other C-level executives working for them, and those without C-level executives. H5) There will be an association between age, years in current job, years as a CEO, last degree earned, company size and agreement with each role category.

H6) There will be no difference in the responses on role agreement and time spent in the role categories between CEOs from privately-held versus publicly-held companies. H7) There will be no difference in the responses on role agreement and time allocations to role categories between a convenience sample of CEOs and a random sample of CEOs.

H8) There will be no difference in the responses on role agreement and time allocations between CEOs from small companies and CEOs from large companies.

Study Purpose and Significance

Given the informing problems and guiding research questions and hypotheses, the purpose of this study was to address the gap between what is reported in the literature and 
what is known in current practice on the role of CEO. It was hoped insights provided by CEOs would improve understanding of their role. Additionally, it was hoped Mintzberg's (1973) theory of the role of CEO would be informed by this research project; theories generally require a constant process of refinement and development to inform them (Lynham, 2002). There is a gap in research and literature on the role of CEO and the intent of this research project was to inform the gap with current research.

It seems possible that gaps exist due to lack of access to working CEOs or the fear CEOs will be unresponsive to requests for survey responses or interviews (Beggs \& Doolittle, 1988). Access issues have made it difficult to study CEOs from a variety of disciplines, not just Human Resource Development (HRD), and provided many challenges to this research project (Rosser, 2005; Thomas, 1995; Useem, 1995). Some studies on CEOs utilized biographies or autobiographies, public information provided in proxy statements and annual reports, surveys of employees, CEO job advertisements, and information from public interviews and speeches as methods to access information about CEOs (Ahmed, 2005; Steiner, Kunin, \& Kunin, 1981; Wood \& Vilkinas, 2003). Much of Jim Collins' (2001) research on CEOs utilized data from publicly traded companies widely available to the general public from the Securities and Exchange Commission website. A successful research project on working CEOs may encourage future research on a population that seems very inaccessible.

Data collected from CEOs may bridge a knowledge gap between research and practice by providing the CEOs' perspective about what the role of CEO really is (Ruona \& Lynham, 2004). This research will serve HRD practitioners who may be responsible for the process of identifying CEO candidates, coaching CEOs, sustaining an 
organization's leadership system, and developing performance matrices for Boards of Directors who are ultimately responsible for ensuring effective and efficient CEO role behavior in the form of productivity, achievement, and goal attainment.

The ability of CEOs to perform effectively in the role has significant implications for the organizations they lead (Edersheim, 2007; Hales, 1996; Hart \& Quinn, 1993; Lafley, 2009; Matsumura \& Shin, 2005; Mintzberg, 1973). Organizations are relied upon to meet not only the wants and desires of society, but also the most basic needs including food, water, and shelter. The success of CEOs has direct impact on the financial performance of organizations and financial performance has a direct impact on the stock market, the banking industry, and financial markets overall. In some cases CEOs may lead organizations with economies larger than small countries, so the potential impact they have in their role can be substantial (Edersheim, 2007; Hales, 1996; Hart \& Quinn, 1993; Lafley, 2009; Lynham \& Cunningham, 2006; Matsumura \& Shin, 2005; Mintzberg, 1973).

Human Resource (HR) directors and vice presidents can strategically impact and influence the direction of their organizations by emphasizing the importance of selecting and hiring the right CEO (Allgood \& Farrell, 2003; Torraco \& Swanson, 1995). For Boards of Directors, clarity of role provides tools for evaluating CEO quality and performance. For CEOs, understanding role expectations and focusing on the most productive roles will improve both individual and organizational performance in a chaotic business environment. Additionally, knowledge of what other CEOs consider important roles and how they allocate time to these roles could provide strategic insight for benchmarking performance against other CEOs and the organizations they lead. 


\section{Delimitations}

This study was delimited to CEOs randomly selected from a list of companies with U.S. mailing addresses and accessed from a purchased database. Because of the focus on CEOs, and the selection of a database with U.S. addresses, the study cannot be considered applicable to middle or lower-level managers or to CEOs in other countries.

\section{Assumptions}

The following assumptions are important to this study:

1) A valid and reliable instrument will be utilized to gather data.

2) A sample of CEOs will be willing to complete a survey and return it.

3) CEOs will be able to provide an accurate representation of their roles and the amount of time spent in each role.

4) The study is confidential, that is, who responds to the survey will not be known.

5) Honesty in time estimations will not be known.

6) Differences in time allocation and actual effort will not be known.

\section{Definition of Terms}

This study utilizes definitions derived from the review of literature. A list of terms and the working definitions applicable to this particular study are presented below.

Chief Executive Officer (CEO): The top person in an organization's hierarchy.

C-Executives: Chief Executive Officer, Chief Financial Officer (CFO), Chief

Operations Officer (COO), Chief Information Officer (CIO), or Chief Technology

Officer (CTO). 
Equity-based compensation: Stock options and restricted stock frequently received by executives as part of their total compensation package.

Human resource development: "a process of developing and unleashing expertise for the purpose of improving individual, team, work process, and organizational system performance" (Swanson \& Holton, 2009, p. 4).

This study uses the following definitions of variables presented by Kahn, Wolf, Quinn, \& Snoek, (1964, pp. 12-26) in their book titled Organizational Stress: - Studies in Role

\section{Conflict and Ambiguity:}

Office: the place where business roles are carried out

Role: a set of activities, behaviors

Role set: the other people impacted by a particular role, other employees or supervisor

Focal person: the person carrying out the specific role

Role senders: collectively, they constitute the role set and they provide expectations to the focal person

Role pressures: role senders' expectations for role performance

Role conflict: when expected role behaviors are inconsistent, five different types of role conflict may occur: 1) intrasender conflict (inconsistent expectations from one person in a role set); 2) intersender conflict (inconsistent expectations from two or more persons in a role set); 3 ) interrole conflict (inconsistent expectations from members of two or more role sets); 4) person-role conflict (inconsistent expectations between one or more persons from a role set and expectations within the focal person's subjective role); and 5) other complex forms, including role overload.

Role ambiguity: when a role lacks clarity or adequate information for the individual to understand the expected role behavior; types of role ambiguity are: 1) task ambiguity (unclear job description, job goals or methods to achieve); and 2) ambiguity regarding the impact one's job has on the effectiveness of self, the role set or the entire organization 


\section{Researcher's Perspective}

My experience working in the roles of Controller, Chief Accounting Officer, and Chief Financial Officer afforded me the unique opportunity to work closely with, and sometimes directly for, CEOs of the organizations that employed me. I have witnessed extremely hard-working and dedicated CEOs resurrect businesses that seemed doomed to fail and make them successful enough to engage in initial public offerings. I have watched CEOs in struggling start-ups take huge personal risks to keep their employees working and their own dreams alive. I have watched CEOs agonize over difficult personnel decisions and I have also seen them show little regard for their employees. I have witnessed CEOs struggle through mergers, acquisitions, and liquidations. I have been personally and deeply impacted by those always willing to do the right thing, even at a personal cost, and those that asked me to do the wrong thing, from whom I walked away. These unique experiences influence my perspective of what roles the CEO plays, what impacts those roles, and what qualities of character make for the most effective CEOs. As a researcher, I seek to learn what CEOs perceive about their roles and I hope that this project will, in some small way, provide a deeper understanding for CEOs, for HRD professionals, for the organizations they lead and serve, and for the stakeholders. 


\section{CHAPTER TWO: REVIEW OF THE LITERATURE}

\section{Introduction}

The purpose of this study was to address the gap between extant informing research and literature and what is known in current practice on the role of CEO. Chapter two begins with the methodology employed to conduct the literature review. Part one explores the history of CEOs and introduces the importance of their positions in business today. Part two begins with a brief explanation of the underlying theories for HRD. It is suggested there is a gap in these theories related to role theory, thus, HRD may benefit from research on roles and the theories that support the role of CEO. A review of literature on role theory defines what role theory is and describes its evolution and importance in informing the role of CEO and its study. A brief review of organizational role theory provides further delineation of the importance of roles within organizations. Finally, the seminal research to induce a theory about the role of CEO performed by Mintzberg $(1968 ; 1973)$ is presented in detail as the starting framework for the roles and role categories that are the focus of this study. Part three introduces six categories of CEO roles and 31 specific roles, supported by research conducted on the CEO to date. Throughout part two and three the research questions and hypotheses emerge. Part three ends with a discussion of the most recent research conducted using Mintzberg's framework to study the impact of complexities in the external business environment on the role of CEO. Finally, the importance of this chapter is the introduction of the gap in 
both the early and current literature which supports the problem statement from Chapter One, namely, that the research on the role of CEO is conflicting and outdated.

\section{Literature Review Methodology}

The review of literature was conducted to find the most recent knowledge on the role of CEO. The methodology included a search of electronic databases including Digital Dissertations, Business Source Premier, Academic Search Premier, Google Scholar, Psyc Info, and Web of Science from the Morgan Library at Colorado State University. The search included "Chief Executive Officer", "CEO", and "role", or "role theory" in the keywords fields. The name "Mintzberg" was used as a title search. A title search was conducted on "Chief Executive Officer" or "CEO" producing over 8,000 results. This search was narrowed by including the phrases "self reflection", "themselves", and "reflection". With the assistance of a research librarian at Morgan Library at Colorado State University these phrases were selected to narrow the focus to the role of CEO from the perception of CEOs.

Digital dissertations contained 21 dissertations with "Mintzberg" in the title. After a review of the abstracts for additional details, the search was narrowed to 10 possible dissertations for review. These dissertations were either downloaded from Proquest or were requested in hard copy using inter-library loan. The dissertations not selected for detailed review were not available, were written in a language other than English, or were not specific to CEOs. A more detailed review of the 10 dissertations resulted in a final selection of four dissertations that were focused specifically on CEOs or on executives at the top of the organization. Mintzberg's dissertation from 1968 was added to this list. 
Dissertations with a focus on middle or lower-level managers were excluded from this literature review.

The database search resulted in 250 journal articles with relevance to the topics of the history of CEOs, the role of $\mathrm{CEO}$, changes to the role of $\mathrm{CEO}$, and role theory informing the role of CEO. A few additional articles were selected for their applicability to $\mathrm{CEO}$ turnover, $\mathrm{CEO}$ succession planning, CEO compensation, corporate social responsibility, and the impact of these variables on the role of CEO. Over 60 refereed journal articles were selected for their relevance to the role of CEO and are presented in this review of literature.

Role theory is a mature topic researched by practitioners in psychology, sociology, social psychology, and anthropology. The role of executives in organizations also has a long history. A search of books at the Morgan Library at Colorado State University resulted in several seminal books on the topics of role theory and the history of executives in organizations utilized in this literature review. Additional books or book chapters were selected for their applicability to the role of CEO and the implications of this role in the study of HRD. These books provide a substantial base for understanding the discipline of HRD. The dissertations, journal articles, books, and book chapters were analyzed and synthesized to inform the review of literature that follows, beginning with a brief overview of the history of CEOs.

\section{Part One: An Overview of the History of CEOs}

The process of studying the role of CEOs should begin with an understanding of who these individuals are and how their roles have evolved. The robber barons or railroad magnates, of the late nineteenth century are considered the earliest CEOs in the 
U.S. While mostly viewed as a group of thugs, there was an air of romance about these individuals who created great wealth for themselves (Tedlow, Bettcher, \& Purrington, 2003). Descriptions include terms like "parvenus," however, "they were also men of heroic audacity and magnificent exploitive talents—shrewd, energetic, aggressive, rapacious, domineering, insatiable" (Hofstadter, 1948, p. 213.) It has been implied that the mold was broken after this group of executives retired or died, and that their successors, CEOs of the 1920s, came from a much smaller mold, perhaps suggesting successor CEOs were not as exciting or as interesting as their predecessors had been (Wiebe, 1962, as cited in Tedlow et al., 2003). Most CEOs were referred to as "President" until the 1940s when the Chief Executive Officer title became vogue (Galambos, 1995, p. 189).

During the 1940s corporations moved away from a centralized structure and began to assume a multidivisional one, resulting in organizations that were more decentralized than those of the early 1900s (Galambos, 1995; Tedlow et al., 2003). Family ownership began to lose influence due to the aging of company founders, thus "professional CEOs, bred in new management schools, took the reins of corporate America" (Hawkins, 1997, p. 146). The structural change and ownership changes marked the beginning of a new type of relationship between the CEO and the organization, where the CEO was depended upon for strategic decision making and managing relationships with the Board of Directors and others outside the organization (Galambos, 1995). Increased organizational complexity required the addition of Chief Operating Officers (COOs) to the hierarchy to handle the day-to-day (as opposed to strategic) operations and decision making. The decentralized organization became the most common form of 
corporate structure in the U.S. following World War II. Its complexity constrained the CEO position as the responsibilities expanded at the same time authority was being restricted by increasing governmental rules and regulations (Galambos, 1995).

External events, too, impacted the role of the CEO when companies began to expand to the global marketplace after World War II. These events simultaneously increased responsibilities and reduced authority of CEOs. In the 1960s global competition began to squeeze U.S. corporations, while government regulations at home squeezed the CEOs' authority. State and federal regulations on interstate commerce became more restrictive and the concomitant ability of the government to provide for and take away from business became more evident (Galambos, 1995; Greenfeld, Winder, \& Williams, 1988). Taxes, subsidies, regulation, deregulation, anti-trust laws, environmental regulations, personnel regulations, and fixing prices—all potential governmental impacts now had to be managed by the CEO (Galambos, 1995; Greenfeld et al., 1988).

During the global expansion of corporations that began in the 1990s the complexity of business added to the complexity of the role of CEO. Over the course of four decades the role of the CEO has come under consecutive and significant pressurepressure which has resulted in successive changes in the nature of the role, and subsequent implications for its study and practice. The importance of the CEO position rests not only in the perceived power of this role, but in the actual power some individuals in this role have to impact economies and consumers that depend on them (Edersheim, 2007; Lafley, 2009). This exploration into the role of CEO begins with a description of the informing theories for the practice of HRD, role theory, its evolution to 
organizational role theory, Mintzberg's theory on the role of $\mathrm{CEO}$, and a discussion of how this body of theories help inform the topic.

Part Two: Theoretical Foundations for Studying The Role of CEO

Part two begins with a description of the underlying theories supporting the discipline of HRD. It follows with a description of role theory and organizational role theory and how these foundational theories inform research on the role of CEO. A brief exploration is made into leadership theories that inform this study. Finally, Mintzberg's seminal research describes his theory of the role of CEO.

\section{Underlying Theories for HRD}

$\mathrm{HRD}$ is "a process of developing and unleashing expertise for the purpose of improving individual, team, work process, and organizational system performance", and the purpose of HRD is to "focus on the resources that humans bring to the success equation—-both personal success and organizational system success" (Swanson \& Holton, 2009, p. 4). Three underlying theories provide the foundation for improved performance, and are the basis for Swanson's three legged stool. These include economic theory, systems theory, and psychological theory (Swanson \& Holton, 2009). The economic theory component includes scarce resource theory, sustainable resource theory, and human capital theory. The systems theory component includes general systems theory, chaos theory, and futures theory. The psychological theory component includes Gestalt psychology, behavioral psychology, and cognitive psychology. However it is suggested the psychology leg of Swanson's stool is missing the aspect of social psychology that includes role theory (Swanson \& Holton, 2009). Specifically Swanson's three-legged stool is lacking a theory about how roles are formed and developed. It could be argued 
organizational role theory needs both development and confirmation as a fundamental theory supporting the practice of HRD (Swanson \& Holton, 2009).

Swanson's Taxonomy of Performance (2007) suggests the foundation of performance is the ability to understand the language of an existing process or system. Once understanding is obtained operating the process or system is essential. Troubleshooting the process or system includes the ability to identify and alleviate problems in an existing process or system. Swanson's first three levels of performance, that is, understanding, operating, and troubleshooting, are considered the responsibility of managers. The next two levels in Swanson's taxonomy, improve and invent are considered the responsibility of leaders or CEOs. These levels exist to change processes or systems to make them more effective and to develop new processes or systems, improving the performance of the entire organization (Swanson, 2007). While Swanson's taxonomy (2007) suggests that there are significant differences in the roles of managers and leaders missing from the HRD foundation is a theory that explains how roles are developed and defined within organizations (Swanson \& Holton, 2009).

Role definition is important for individual and organizational performance because roles help define how work gets accomplished (Hart \& Quinn, 1993; Katz \& Kahn, 1966). One of the first steps in improving performance is the process of understanding the work design, including job descriptions and performance metrics within an organization (Gilley, Boughton, \& Maycunich, 1999). Furthermore, "findings show that the particular roles played by the top manager are important predictors of firm performance" (Hart \& Quinn, 1993, p. 569). Role definition for CEOs seems to have changed over time, influenced by changes in the business environment including changes 
in how CEOs are compensated, recruited, and replaced. Contemporary research indicates both internal and external factors influence all organizational roles including desires for work-life balance. This balance can be disrupted by the complexity of today's family structures, increased cultural, gender, and age diversity in the labor market, and the increased use of technology enabling workers to be connected to work 24 hours a day (Marginson \& Bui, 2009; Wickham \& Parker, 2006). It is likely that both internal and external pressures are impacting and shaping the role of CEO. These pressures on CEOs are complicated by the pressure for organizational and individual performance. The tension created by internal and external pressure further substantiates the need to study the role of CEO, helping these individuals make their efforts more focused and effective.

\section{Role Theory}

To understand the role of $\mathrm{CEO}$ and the importance of roles in organizations, it is important to understand the underlying theory informing the concept of role. The concept of role began in the theatre where participants each play a part or role. The social sciences adopted the concept of role and it evolved into a body of knowledge, a theory, a research endeavor, and a domain of study that included perspective and language (Biddle $\&$ Thomas, 1966). Whether or not role theory has continued to evolve and develop as a theory remains in question (Stryker \& Statham, 1985).

The word role is derived from the latin word rotula meaning the little wheel or round log. This round wheel was used for attaching sheets of paper or parchment creating a scroll. These scrolls were used in Greece and Rome to record the parts that prompters read to actors during a play. Towards the $16^{\text {th }}$ century when the modern stage emerged the parts of actors were read from roles. Each scene part became a role (Biddle \& 
Thomas, 1966). Role theory is defined as a set of behaviors or actions engaged in by individuals who "are members of social positions and hold expectations for their own behaviors and those of other persons" (Biddle, 1986, p. 67). For purposes of this study the role of CEO is not restricted to a single activity or behavior, but may be discovered by the research to be a series of activities and behaviors that comprise the role of CEO. To understand the role of CEO an exploration of role theory is helpful because "a theory simply explains what a phenomenon is and how it works" (Torraco, 1997, p. 115). Therefore, a theory about roles explains what they are (a set of behaviors and actions) and how they work (expectations for roles are established socially or organizationally). Role theory has origins in sociology, psychology, social psychology, and anthropology and dates as far back as 1893 to Durkheim's classic description of the division of labor, Sumner's differentiation of individual behaviors and community behaviors in 1906, and Piaget's description of the study of rules and rule compliant behaviors in 1932 (Biddle \& Thomas, 1966). It was during the 1930s that the term role began to emerge in technical writings as descriptions of role problems. Mead discussed the concept of role-taking in Mind, Self and Society, which was published in 1934. Linton (1936) strongly influenced the idea that there is a relationship between role performance and individual behavior and implied "role was one linkage between individual behavior and social structure" (Biddle \& Thomas, 1966, p. 7). As a theory, role theory has been described as a "theoretical approach" at best, or a "framework: directives for examining certain features of the empirical world that are likely to be significant in the development of an eventual theory" (Stryker \& Statham, 1985, p. 312). It is suggested role theory lacks "a set of assumptions or postulates with which one approaches some part of the empirical 
world, a set of concepts in terms of which this part of the world is described, and a set of propositions, emerging from the assumptions and relating the concepts, about the way this part of the world 'works' which are checked against observations of that world" (Stryker, 1959, p. 111).

Terminology that links roles in organizations began to appear in research after World War II, when role theory began to be more closely associated with occupational settings than with social settings (Biddle \& Thomas, 1966). More recently, the literature has classified role theory into five different views: functional, symbolic-interactionist, structural, organizational, and cognitive role theory (Biddle, 1986). Stryker and Statham (1985) believe that a combination of role theory and symbolic interactionism (in which roles are constructed as the play evolves) provides a more complete and integrated framework for discussing the concept of role within social settings- - however, a complete discussion on the history and development of role theory within social psychology is beyond the scope of this dissertation. Biddle (1986) suggests that the classification of role theory most useful in informing the role of CEO (or any individual within an organization) is organizational role theory.

\section{Organizational Role Theory}

Even if criticized as lacking full development as a theory (Stryker \& Statham, 1985), organizational role theory does provide a conceptual framework for understanding that roles emerge from specific hierarchical positions in an organization and are created by the "normative expectations" of the organization and its members (Biddle, 1986, p.73). The majority of research in the field of role theory has been generated due to the interest of researchers in roles within the settings of formal organizations. A formal 
organization is defined as a group of individuals who come together to achieve a common purpose (Biddle, 1986). This organizational view of role theory is centered on the definition that organizations are "preplanned, task-oriented, and hierarchical" (Biddle, 1986, p.73). While norms of behavior may vary, one of the limitations of organizational role theory is the lack of discussion about the evolution or changing of roles by "nonnormative expectations" (Biddle., 1986, p. 74). This limitation is bounded by the assumption that organizations are both static and logical (Biddle, 1986). Mintzberg attempted to address impacts on roles through his Contingency Theory of Managerial Work (which suggested certain variables impact the role of CEO). However he believed that the role of CEO and of managers in general, was timeless (Mintzberg, 1973). Mintzberg further described role as "a fuzzy concept" explaining that "program" would be a better concept to use in defining a job (p. 266).

Organizational role theory may have been first described by Gross, Mason, and McEachern (1958) and Kahn et al., (1964). In addition to expanding the theory with a dictionary of terms, Gross et al. (1958) suggested a theme common to many researchers: "role consensus" which he stated "exists on the expectations applied to the incumbents of particular social positions" (p. 21). Role consensus implies that roles from multiple stakeholders are not in conflict. However role conflict has been found to have a negative impact on job performance $(\rho<.01)$ and is an important construct in the research on organizational role theory, completely contradicting the idea that role consensus among multiple stakeholders exists (Marginson \& Bui, 2009).

Furthermore, it is unlikely role consensus in terms of the role of CEO exists. Some research purports there are 10 roles of the CEO (Mintzberg, 1973), others suggest 
four roles (Hart \& Quinn, 1993). Popular literature suggests there may be only one role of the CEO (Lafley, 2009; Steiner, et al., 1981). Lack of consensus on the meaning of the word role may account for some of this confusion as it is often confused with the word responsibility (Mintzberg, 1973). The dictionary of common language created by Gross et al. (1958) in terms of role theory was not necessarily agreed upon by all researchers. Kahn et al. (1964) focused on role dynamics, specifically the constructs of role conflict and role ambiguity, and their impact on organizational stress. Both constructs have been researched extensively with contradictory results (Fisher \& Gitelson, 1983; Jackson \& Schuler, 1985; Kahn et al., 1964; King \& King, 1990; Marginson \& Bui, 2009; Rizzo, House \& Lirtzman, 1970).

The Contribution of Role Theory in Informing Research on the Role of CEO

Even without common language to describe organizational role theory, most authors agree on three basic foundations supporting the theory. The basic theory about roles in organizations is: 1) individuals within a specific setting (organization), 2) exhibit specific behaviors (roles), 3) based on behaviors (roles) expected of them (Biddle, 1986;

Gross et al., 1958; Katz \& Kahn, 1966). Research supporting the theory suggests an individual's behavior at work is not random, is influenced by the expectations of others, by the individual's expectations of themselves, and by the individuals' own perception of their role. Research on roles provides evidence that when specific role expectations are not met a stressful situation ensues, termed role conflict for the focal person (Biddle, 1986; Gross, et al., 1958; Katz \& Kahn, 1966).

The importance of role theory to researching the role of CEO is the foundation it provides for understanding the hierarchy of roles within organizations and the problems 
that ensue when roles are misunderstood or misinterpreted. At the apex of the organization, the CEO is considered to be the organization's chief leader (Boal \& Hooijberg, 2001). In order to understand the leader role, a brief exploration of leadership theories specific to executives provides an additional framework for studying the role of CEO. It is beyond the scope of this dissertation to provide a thorough review of all theories of leadership, however there are a few foundational theories with importance to the study of CEOs. These theories are presented in the following section.

Theories of Leadership

The leadership role is believed to be one of the most important roles of a CEO with a reach that spans all other roles. This belief makes a brief description of leadership theories necessary for informing research on CEOs (Goleman, Boyatzis, \& McKee, 2002; Mintzberg, 1973; Steiner et al., 1981). CEOs perform in the upper echelon of the organizations they lead. Upper echelon theory helps to explain the influence of top leaders on organizational development, suggesting CEOs and other top leaders are able to reflect their thoughts and values into an organization. This ability is based on how much discretion these leaders have to act independently, that is, CEOs who act independently are more able to influence the organization (Boal \& Hooijberg, 2001; Hambrick \& Mason, 1984; Hiller, Resick, Weingarden, \& Whitman, 2009). Upper echelon theory evolved into strategic leadership theory, which suggests organizations are truly reflections of their top leaders. Taking these theories one step further, positive agency theory purports leaders act in their own best interests, as opposed to the best interests of the organization (Boal \& Hooijberg, 2001). To increase alignment between the goals of leaders and those of stakeholders, Boards of Directors use incentive systems tied to 
organizational performance to influence top leadership (Boal \& Hooijberg, 2001). Leadership theory in general describes leaders at all levels of an organization (not necessarily CEOs), however strategic leadership theory refers only to top organizational leaders (Vera \& Crossan, 2004).

Strategic Leadership Theory

Unique to strategic leadership theory are the concepts of adaptive capacity, or the ability to change (Cummings \& Worley, 2009), and absorptive capacity, or the ability to learn. Absorptive capacity requires that the individual constantly experiment, tolerate small failures, and engage in double-loop learning (Argyris \& Schon, 1978; Boal \& Hooijberg, 2001). Handling the rapid change and complexity of today's business environment suggests that leaders need to become ambidextrous, or to develop "the capacity to simultaneously implement diverse courses of action: incremental and discontinuous innovation, exploration and exploitation, flexibility and control, and feedforward and feedback learning” (Vera \& Crossan, 2004, p. 227). Bodwell and Chermack (2010) suggest "ambidexterity eliminates the need for organizations [or CEOs] to choose between opposites or to focus on "trade-offs"' (p. 197). From strategic leadership theory transformational leadership evolved, including the concepts of complexity and the ability to handle juxtaposing positions (Bass, 1985; 1998). The transformational leadership style is described in the following section.

Transformational Leadership

The transformational leader stands in stark contrast to the transactional leader who focuses on internal processes and managing others to get the job done (Bass, 1990; Vera \& Crossan, 2004). Instead, the transformational leader "asks followers to transcend 
their own self-interests for the good of the group, organization, or society; to consider their longer-term needs to develop themselves, rather than their needs of the moment; and to become more aware of what is really important" (Bass, 1990, p. 53). Transformational leaders are identified as being "charismatic, inspirational, intellectually stimulating, and individually considerate" (Vera \& Crossan, 2004, p. 224). Described as selfless or servant leadership, transformational leadership focuses on the development of all members of an organization into leaders (Bass, 1990). Emerging theories resulting from transformational leadership include the complexity theories of behavioral and cognitive complexity introduced by Hart and Quinn (1993) and explored in more detail by Zacarro (2001). Transformational leadership has a focus on integrity however integrity alone will not insure strong organizational performance. Leaders often struggle with the desire to do the right thing while at the same time making sure the organization performs financially. Lynham's $(1998,2000)$ theory of responsible leadership for performance addresses this tension.

Theories of Responsible Leadership for Performance

Ambiguity in theories of leadership calls for both firm performance and selflessness (Lynham, 1998). The selfishness of human nature conflicts with the ability to be a servant leader, especially when complicated by the demand for corporate performance from shareholders and boards of directors. It is not difficult to imagine how executives become tempted to force earnings when their personal wealth can be substantially influenced by a strong stock price (Boatright, 2009; Jensen \& Murphy, 1990). To resolve the conflict between selfish needs and the needs for performance, Lynham has suggested a new model of "Responsible Leadership for Performance" (1998, 
p. 208). The need for a new model stems from the leadership dilemma that remains in many organizations, lack of evidence that leadership development programs sustain real results, increased complexity in business, and increased rate of change in which leaders must act (Antonioni, 2003; Block, 1993; Lynham, 1998; Zaccaro, 2001).

Gone are the days of prescriptive recipes of leadership. Organizations will need leadership that is able to think and act fundamentally differently, able to integrate critical thinking with critical practice. Organizations will need to shift away from the pursuit of control, discrete boundaries and recognizable problems towards greater complexity, global competition, continuous quantum change and collaborative team orientations. These shifts herald an increasing gap between current leadership practices and future leadership needs. The competencies needed of and for leadership will be different. They will need to integrate the apparent paradox of performance demands and the realities of humanity - in other words, of people and performance (Lynham, 1998, p. 209).

Lynham (1998) also suggests that leadership systems should be developed to answer the problem of succession planning. It is not uncommon for organizations to undergo substantial changes due to the change of one individual at the top. This is disruptive and often very unproductive for the organization (Case, 2009). A recent article about the replacement of HP CEO Mark Hurd suggested that the CEO position should be a "team job" arguing that

A rotational CEO position would put boards in control of the CEO spot, rather than the other way around. Instead of paying huge sums to - and relying exclusively on - a single individual, boards would groom multiple individuals of diverse skills useful for finite durations, with paychecks to match. Investors would benefit knowing the company had several qualified and/or tested CEOs from which to choose. Perhaps, by failing to engage in adequate succession planning and to rein in pay, boards have, inadvertently, pointed us to a better, more cost-effective model at the top (Bloxham, 2010, p. 3).

The Contribution of Leadership Theories in Informing Research on the Role of CEO

The theories of leadership described in the literature suggest that the leadership role of CEOs is an evolving role. The newer models suggest CEOs are leaders not only 
within their organizations but also globally, and as global citizens the role is even more important (Antonioni, 2003; Matsumura \& Shin, 2005). It seems the need for these evolved models of leadership could not have been imagined by Mintzberg during the 1960s or 1970s. Furthermore, he could not have anticipated the magnitude of changes that would occur in the 40 years following his research on five CEOs, yet his study continues to provide a conceptual framework for contemporary research on the role of CEO. His work was an attempt to create a theory about the role of CEO by observing what CEOs did at work. A description of his research and the resulting theory on the role of CEO is presented in the following section.

The Seminal Research of Mintzberg: A Theory of the Role of CEO Mintzberg's work began as a result of his interest as a child in what his father did at the office. The purpose of his research was to determine what CEOs really do at work, not to theorize about what they should do to be effective. Mintzberg recognized a gap in the literature where generalities about the CEO's or manager's job were made, yet no empirical data informed the general theories about what the job was. A structured observational study of five CEOs resulted in Mintzberg's dissertation in 1968: The Manager at Work—Determining his activities, roles, and programs by structured observation. In 1973, after putting some time between himself and the research, Mintzberg released a book titled: Nature of Managerial Work. This book is considered a landmark study on the role of CEOs with impacts extending into the role of managers at all hierarchical levels. The following discussion details Mintzberg's methodology and research purpose and describes in detail the six characteristics of the work of CEOs. 
Mintzberg's Methodology: Structured Observation

Mintzberg's intention in applying the structured observation method was the inductive development of a theory about the role of managers (Mintzberg, 1973). Specifically, he observed five male CEOs: a chairman and chief executive from a major consulting firm, a president of a research and development firm engaged in high technology solutions for industry and the military, a director of a large urban hospital, a president of a manufacturing company producing consumer goods, and a superintendent of a large suburban school district (Mintzberg, 1973).

Each subject was observed for one week while at work. The observations resulted in a chronology record, a mail record, and a contact record. The chronology record summarized the amount of time each participant spent on desk work, telephone calls, scheduled meetings, unscheduled meetings, and tours. The mail record summarized the type and amount of mail each subject received and read at work during the week of observation. The contact record summarized the type of contacts: verbal, telephone, scheduled meeting, unscheduled meeting and who the contact was: subordinates, directors, clients, suppliers, peer/trade organizations, independents, and other. The purpose of the contact was categorized as organizational, scheduling, ceremony, board work, status requests and solicitations, action requests, manager requests, observational tours, receiving information, giving information, review, strategy, and negotiation. The total time was presented in hours and as a percentage of the total time worked.

The activities from each record were categorized, and from the process of categorization Mintzberg's 10 roles were delineated. Table 1 was adapted from 
Mintzberg's book to provide examples of how work activities were coded to create the 10 roles his theory describes.

Once the ten roles were identified, Mintzberg categorized the roles into three major categories:

The interpersonal roles:

1) Figurehead, the CEO represents the organization in all formal matters.

2) Liaison, the CEO interacts with peers and others outside the organization, gathering information, and

3) Leader, defining the relationship between the CEO and subordinates, motivating, hiring, etc.

The informational roles:

4) Monitor, identifying the CEO as receiver and collector of information that allows the development of a deep understanding of the organization.

5) Disseminator, or transmitter of information to the organization, and

6) Spokesperson, or transmitter of information to the external environment.

The decisional roles:

7) Entrepreneur, the role when the CEO initiates change and innovation.

8) Disturbance handler, when the CEO must take charge of a threatening situation.

9) Resource allocator, or the final voice in deciding how resources will be expended, and

10) Negotiator, when the CEO is compelled to negotiate on the organization's behalf. 
Table 1

Example activities that describe Mintzberg's 10 CEO Roles, Adapted from Nature of Managerial Work, 1973

\begin{tabular}{|c|c|c|c|}
\hline & Example Activity 1 & Example Activity 2 & Example Activity 3 \\
\hline Figurehead role & $\begin{array}{l}\text { Outgoing mail, for example diplomas } \\
\text { for graduating nurses, letters of } \\
\text { appreciation to retiring employees, } \\
\text { and a proposal letter to a client. }\end{array}$ & $\begin{array}{l}\text { Making a speech to a group of } \\
\text { visitors. }\end{array}$ & $\begin{array}{l}\text { An old friend schedules a meeting with the } \\
\text { CEO in an attempt to sell a product. }\end{array}$ \\
\hline Leader role & $\begin{array}{l}\text { Giving advice to a subordinate on a } \\
\text { personal problem. }\end{array}$ & $\begin{array}{l}\text { Using authority to encourage a } \\
\text { subordinate to follow up on a } \\
\text { project. }\end{array}$ & $\begin{array}{l}\text { Complimenting an employee on a recent } \\
\text { achievement. }\end{array}$ \\
\hline Liaison role & Handling a request for a report. & $\begin{array}{l}\text { Writing to congratulate a peer on a } \\
\text { promotion. }\end{array}$ & $\begin{array}{l}\text { Writing to thank an official of another } \\
\text { company for assistance in arranging a } \\
\text { meeting. }\end{array}$ \\
\hline Monitor role & $\begin{array}{l}\text { Requesting information on internal } \\
\text { operations in the organization. }\end{array}$ & $\begin{array}{l}\text { Requesting information about a } \\
\text { client or competitor. }\end{array}$ & Analyzing financial reports. \\
\hline $\begin{array}{l}\text { Disseminator } \\
\text { role }\end{array}$ & $\begin{array}{l}\text { Information from a board meeting is } \\
\text { reported to a subordinate. }\end{array}$ & $\begin{array}{l}\text { A telephone conversation with a } \\
\text { client is relayed to a subordinate. }\end{array}$ & $\begin{array}{l}\text { Briefing his staff about a recent business } \\
\text { trip. }\end{array}$ \\
\hline $\begin{array}{l}\text { Spokesperson } \\
\text { role }\end{array}$ & $\begin{array}{l}\text { Opening a board meeting with a report } \\
\text { and then spending time answering } \\
\text { questions. }\end{array}$ & $\begin{array}{l}\text { Appearing in an interview about a } \\
\text { contentious labor issue. }\end{array}$ & $\begin{array}{l}\text { Appearing in an advertisement soliciting } \\
\text { donations for a non-profit group. }\end{array}$ \\
\hline $\begin{array}{l}\text { Entrepreneur } \\
\text { role }\end{array}$ & $\begin{array}{l}\text { Randomly questioning subordinates } \\
\text { about prospective projects. }\end{array}$ & $\begin{array}{l}\text { Taking an unannounced tour of the } \\
\text { manufacturing facilities. }\end{array}$ & $\begin{array}{l}\text { Searching for process improvements by } \\
\text { reviewing financial results. }\end{array}$ \\
\hline $\begin{array}{l}\text { Disturbance } \\
\text { handler role }\end{array}$ & $\begin{array}{l}\text { Holding a meeting with a manager } \\
\text { who has a problem in his department. }\end{array}$ & $\begin{array}{l}\text { Firing an employee who is } \\
\text { underperforming. }\end{array}$ & $\begin{array}{l}\text { Dealing with the media about a problem } \\
\text { product. }\end{array}$ \\
\hline $\begin{array}{l}\text { Resource } \\
\text { allocator role }\end{array}$ & Making capital expenditure decisions. & $\begin{array}{l}\text { Deciding how many employees will } \\
\text { be hired in the next fiscal year. }\end{array}$ & $\begin{array}{l}\text { Deciding whether a new product will be } \\
\text { invested in. }\end{array}$ \\
\hline Negotiator role & Negotiating a large contract. & $\begin{array}{l}\text { Negotiating projects between } \\
\text { subordinates. }\end{array}$ & $\begin{array}{l}\text { Negotiating the acquisition of another } \\
\text { company. }\end{array}$ \\
\hline
\end{tabular}


Each role was described as observable, for example, it is possible to witness a CEO handling a disturbance. Each of the contacts and pieces of mail that Mintzberg observed in his study were accounted for in his role theory. Most importantly, Mintzberg refers to the roles as being separate yet forming an integrated role. The roles were referred to as forming a "gestalt—an integrated whole" (Mintzberg, 1973, p. 58). One role cannot be removed without an impact on the other roles. Of the six categories used in this research study, three categories (Informational, Interpersonal, and Decisional) represent the work of Mintzberg.

Mintzberg's Contingency Theory

In addition to the theory encompassing 10 roles, Mintzberg concluded there is a Contingency Theory of Managerial Work, meaning how the five CEOs spent their time was dependent upon certain contingencies or variables. The four variables described by Mintzberg are:

1) Environment, including external factors like the economy, industry or internal factors specific to the organization.

2) Job, where it is situated in the organizational hierarchy and who is supervised.

3) Person, including personality and management style, and

4) Situation, specifically whether the organization is in a period of stability or change.

The Purpose of Mintzberg's Research

The purpose of Mintzberg's research was to describe the role of CEO in as much detail as possible. He specifically described his book in these terms: 
It is a book about managers---those people formally in charge of organizations or their subunits. This excludes many of those in "middle management," but includes people with titles such as president, prime minister, foreman, dean, department head, and archbishop. This is not a book about what effective managers do or what styles they exhibit. It focuses on the basic question-what do managers do? The aim, in different words, is to develop a job description that will have meaning to those who believe that management can be approached as a science (p. 4).

\section{Six Characteristics of the Work of CEOs}

Mintzberg did not believe management was a science. He was looking for a theory of management that could be operationalized by looking at those who actually performed the work (Mintzberg, 1973). In addition to the roles and variables, Mintzberg described six sets of characteristics in the work of the CEOs he observed. These characteristics are described as "much work at an unrelenting pace" (p. 29), "activity characterized by brevity, variety, and fragmentation" (p. 31), "preference for live action" (p. 35), "attraction to the verbal media" (p. 38), "between his organization and a network of contacts" (p. 44), and a "blend of rights and duties" (p. 48).

The idea that CEOs never stop working was consistent with Carlson's (1951) work and Carlson also commented about the pace of the executives:

For the chief executives themselves this excessive working load has many unpleasant effects. It means that their opportunities to be with their families or to see their private friends are severely curtailed, and it entails travelling in night trains and evenings and weekends spent away from home. In some cases it also causes a certain intellectual isolation ... They seldom have time to read anything but technical and economic literature or to go to a theatre or a concert (p. 75).

The CEOs observed by Mintzberg (1973) and Carlson (1951) appeared to have choices about interruptions or fragmentation, frequently relying upon assistants to serve as barriers to unwanted interruption. However, it was suggested that interruptions were not discouraged by the CEOs in an attempt to keep information flowing in the 
organization (Mintzberg, 1973; 2009). It was also suggested interruptions are the reason why CEOs spend so little time on long-term planning and strategy (Carlson, 1951; Mintzberg, 1973; 2009).

The thirst for constant information was supported by the "preference for live action" or interest in receiving the most up-to-date information when it happens (Mintzberg, 1973, p. 35). It was suggested CEOs prefer verbal communication as opposed to written communication. The CEO was referred to as the individual who bridges the world outside the organization to the world inside the organization and translates changes on the outside into meaning for the employees inside (Mintzberg, 1973).

Finally, the CEO was described as having minimal control over what he must do, that is, the needs of the organization, its employees, and outside stakeholders largely drive the work the CEO performs on a daily basis. On the other hand, the CEO normally has final decision-making authority, a power usually reserved for this position alone (Mintzberg, 1973). One of Mintzberg's final conclusions was “Managers' jobs are remarkably alike. The work of foremen, presidents, government administrators, and other managers can be described in terms of ten basic roles and six sets of working characteristics" (p. 4).

In summarizing the work of Mintzberg the level of detail and effort expended in his study of five CEOs is very impressive. The description of the work performed and the categorization into roles has survived 40 years of research into management work. Mintzberg's research also provided the conceptual framework for a substantial amount of subsequent research on the role of managers, however, for purposes of this literature 
review studies specific to lower and middle-level managers were excluded. The importance of Mintzberg's research to this study is the theory he developed about the role of CEO, specifically, the ten CEO roles he identified, and the three role categories in which Mintzberg cataloged the ten roles.

Following the release of Mintzberg's book in 1973 there were numerous dissertations and journal articles written to further substantiate his theory about CEOs and managers in general. A substantial amount of this research was focused on middle and lower-level managers, however, 20 studies based on Mintzberg's work were selected for this review of literature based on their focus on Chief Executive Officers. Part of the explanation for fewer studies on CEOs may be based on the difficulty in obtaining access to CEOs versus the ease at which access to middle and lower-level managers can be obtained (Beggs \& Doolittle, 1988; Martinko \& Gardner, 1985). It is also possible that interest in the role of CEO and how CEOs spend their time dwindled in the mid-1980s as issues of CEO compensation became more prevalent.

The lack of substantial, empirical research to refine Mintzberg's theory on the role of CEOs has prevented the theory from developing into one that is applicable to CEOs today. According to Lynham (2002), a theory requires a constant process of evaluating, testing, and refining to remain viable and trustworthy. Role theory, organizational role theory, leadership theory, and Mintzberg's theory of the role of CEO provide the important underlying framework for the conduct of this research. From detailed examination of the research on the role of CEO six categories of roles have emerged. These six categories form the basis for this study and are presented in part three 
of this chapter. A summary of the research studies used as the basis for the 31 roles and six role categories is provided in Table 2.

Part two described the underlying theories supporting the discipline of HRD. It followed with a description of role theory, organizational role theory, and leadership theory, and how these foundational theories inform research on the role of CEO. Finally, Mintzberg's seminal research described research and the resulting theory of the role of CEO. Research on the role of CEOs is the focus of part three of this chapter.

Part Three: Research on the Role of CEOs: The Emergence of Six Categories of Roles Part three explores research on the role of CEOs, defining the 31 roles and six role categories that emerge from the research. Definitions of the 31 roles are supported by research that has helped link the roles to CEOs. Contemporary research is described in terms of the influence external complexities have on the role of CEO. This review of the research provides further support for the problem statement of this study: that research on the role of CEO is conflicting and outdated.

The review of literature contributed to this study in two significant ways. From the research emerged 31 roles that are the basis for the survey instrument developed for this research study with the purpose of answering research question \#1: What is the role of $C E O$ in the U.S. ? Furthermore the review of literature and the process of constant comparative analysis resulted in the identification of six major role categories comprising the role of CEO. These six role categories provide a systematic way of synthesizing the research on the 31 roles and create a simplistic system for understanding and thinking 
Table 2

Summary of 20 Studies Using Mintzberg's Theory for the Conceptual Framework

\begin{tabular}{|c|c|c|c|c|c|}
\hline Dates & Researcher & Method & DV & IV & Findings \\
\hline $\begin{array}{l}1968 / \\
1973\end{array}$ & Mintzberg & $\begin{array}{l}\text { Structured } \\
\text { Observation; } \\
\text { Theory } \\
\text { development }\end{array}$ & $\begin{array}{l}\text { CEO work } \\
\text { activities and time } \\
\text { spent in each } \\
\text { activity }\end{array}$ & & $\begin{array}{l}10 \text { Roles of CEO; three categories of roles; } \\
\text { four factors that influence; six } \\
\text { characteristics of work. }\end{array}$ \\
\hline 1978 & Whitely & $\begin{array}{l}\text { Questionnaire/Ti } \\
\text { me Sampling }\end{array}$ & Time in roles & $\begin{array}{l}\text { Fast pace of work } \\
\text { must lead to stress }\end{array}$ & $\begin{array}{l}\text { Receiving and transmitting information } \\
\text { accounts for } 48-91 \% \text { of contacts and } 30- \\
90 \% \text { of time; Decision making accounts for } \\
9-89 \% \text { of contacts and } 18-85 \% \text { of time; } \\
\text { Internal business control and supervision are } \\
\text { most significant content dimensions; } \\
\text { consulting and personnel are minor parts. }\end{array}$ \\
\hline 1981 & Steiner et al. & $\begin{array}{l}\text { Public } \\
\text { interviews/speec } \\
\text { hes }\end{array}$ & $\begin{array}{l}\text { Impact on CEO } \\
\text { Role }\end{array}$ & $\begin{array}{l}\text { External } \\
\text { Environment is } \\
\text { changing: govt } \\
\text { regulation, law, } \\
\text { attitudes of public, } \\
\text { new demands on } \\
\text { corporations, } \\
\text { criticisms of } \\
\text { corporations, } \\
\text { unsettling } \\
\text { conditions in the } \\
\text { world }\end{array}$ & $\begin{array}{l}\text { CEOs spend } 25-50 \% \text { of their time on } \\
\text { external issues; there has been a } \\
\text { fundamental change in society-historians } \\
\text { describe as "axial age" or one of } \\
\text { monumental transition. From strategy } \\
\text { perspective, executives no longer keep a low } \\
\text { profile, they must take an active role in } \\
\text { public policy processes and new programs. } \\
\text { CEOs have new responsibility for } \\
\text { Advocacy, Activism and must be more of } \\
\text { Strategist. }\end{array}$ \\
\hline
\end{tabular}


Table 2

contd.

\begin{tabular}{llllll}
\hline contd. & & & \\
\hline Dates & Researcher & Method & DV & IV & Findings \\
\hline 1982 & Carter & Mailed & Mintzberg's 10 & International CEOs & $\begin{array}{l}\text { CEOs internationally do not differ } \\
\text { Questionnificantly from CEOs in U.S. firms. The } \\
\text { disturbance handler role is more prevalent } \\
\text { internationally; the disseminator and } \\
\text { negotiator roles are less prevalent. }\end{array}$ \\
& & Roles of CEO & &
\end{tabular}

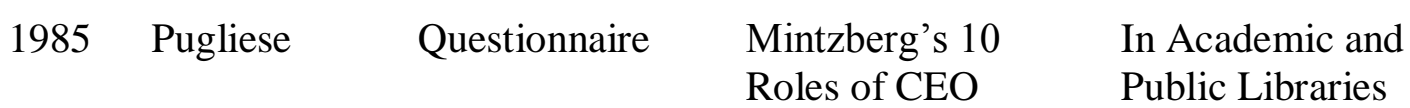

By work activity: resource allocator then disseminator were most frequent roles; liaison, leader and spokesperson were ranked highest by role. Technical expert, disturbance handler and negotiator were least common roles. Job descriptions would be helpful for better performance evaluation and to help CEOs understand their roles better. 
Table 2

contd.

\begin{tabular}{|c|c|c|c|c|c|}
\hline Dates & Researcher & Method & DV & IV & Findings \\
\hline 1986 & Castaldi & $\begin{array}{l}\text { Interview/questi } \\
\text { onnaire } \\
\text { completed at } \\
\text { time of interview }\end{array}$ & Role of CEO. & $\begin{array}{l}\text { Small firms. } \\
\text { Utilized Hemphill's } \\
\text { work roles which } \\
\text { are similar to } \\
\text { Mintzberg's: staff } \\
\text { service, supervision, } \\
\text { business control, } \\
\text { technical concerns, } \\
\text { human, community } \\
\& \text { social affairs, } \\
\text { long-range planning, } \\
\text { business reputation, } \\
\text { preservation of } \\
\text { assets. }\end{array}$ & $\begin{array}{l}\text { All CEOs performed all eight roles. Owner- } \\
\text { manager CEOs perceived the roles } \\
\text { differently than nonowner-managers. Staff } \\
\text { service and supervision was unimportant to } \\
\text { owner-managers, but were significant roles } \\
\text { to nonowner-managers. Technical concerns } \\
\text { were important for owner-managers and not } \\
\text { for nonowner managers. This supports } \\
\text { Mintzberg's proposition that personality } \\
\text { traits impact CEO roles. }\end{array}$ \\
\hline 1987 & $\begin{array}{l}\text { Carroll \& } \\
\text { Gillen }\end{array}$ & $\begin{array}{l}\text { Reviewed } 21 \\
\text { management } \\
\text { textbooks }\end{array}$ & Role of CEO. & $\begin{array}{l}\text { Classical } \\
\text { management } \\
\text { functions. }\end{array}$ & $\begin{array}{l}\text { Classical school is still taught in } \\
\text { management textbooks; Mintzberg's roles } \\
\text { are not integrated into these texts. }\end{array}$ \\
\hline
\end{tabular}


Table 2

contd.

\begin{tabular}{llllll}
\hline Dates & Researcher & Method & DV & IV & Findings \\
\hline 1988 & Howe & Observation & Mintzberg's 10 & $\begin{array}{l}\text { All managers } \\
\text { perform all 10 roles. }\end{array}$ & $\begin{array}{l}\text { CEOs in small companies play an operator } \\
\text { role not identified by Mintzberg. 50\% of } \\
\text { time was spent in informational roles, 36\% } \\
\text { Spent in operator role. Some roles less than } \\
\end{array}$ \\
& & & & $\begin{array}{l}1 \% \text { of time-10 roles is too many. All } \\
\text { managers do not perform all 10 roles. }\end{array}$ \\
& & & & $\begin{array}{l}\text { Figurehead and negotiator were seldom } \\
\text { performed. 22\% of time spent in monitor } \\
\text { role was startling-CEOs need to be able to } \\
\text { process large amounts of information. }\end{array}$ \\
& & & &
\end{tabular}

1988 Greenfeld $\quad \begin{aligned} & \text { Mailed } \\ & \text { Questionnaire }\end{aligned}$

\author{
Impacted by \\ External \\ Environment-as \\ proposed by Steiner \\ et al.?
}

Spokesperson for companies and industry in general is necessary; 57 of 59 CEOs say responsibilities are far broader than before; $85 \%$ say CEO must must have good understanding of political and decision making process in Washington DC.; 68\% say they have changed strategies to deal with social and political forces in the external environment. Work longer hours than ever before; CEOs no longer solely responsible for decision making - $60 \%$ agree CEOs have decentralized authority when it comes to external affairs. 
Table 2

contd.

\begin{tabular}{|c|c|c|c|c|c|}
\hline Dates & Researcher & Method & DV & IV & Findings \\
\hline 1999 & $\begin{array}{l}\text { Ireland \& } \\
\text { Hitt }\end{array}$ & $\begin{array}{l}\text { Literature } \\
\text { Review }\end{array}$ & Role of CEO & $\begin{array}{l}\text { Strategic Leadership } \\
\text { Role }\end{array}$ & $\begin{array}{l}\text { Six components of Strategic Leadership lead } \\
\text { to successful CEOs: setting the vision or } \\
\text { purpose; exploiting \& maintaining core } \\
\text { competencies; developing human capital; } \\
\text { sustaining an effective organizational } \\
\text { culture; emphasizing ethical practices; } \\
\text { establishing balance organizational controls. } \\
\text { There is a strong emphasis now on a "global } \\
\text { mindset" (p. 54). }\end{array}$ \\
\hline
\end{tabular}

2003 Wood \& Interview-Direct Success of CEOS CEO characteristics Characteristics necessary for CEO success Vilkinas Reports of CEOs according to direct reports: achievement orientation (energy, passion, tenacity), humanistic approach (believes in potential and growth of employees), positive thinking (takes responsibility for own thinking, challenges others, is creative), inclusive (participative \& empowering), integrity (clear values, congruent with behavior), balanced approach (work and life), Learning and self-awareness (learns from experience). CEOs play important role in performance of organization. 
Table 2

contd.

\begin{tabular}{|c|c|c|c|c|c|}
\hline Dates & Researcher & Method & DV & IV & Findings \\
\hline 2005 & Ahmed & $\begin{array}{l}\text { CEO Job } \\
\text { Adverstisements }\end{array}$ & Non-profit CEOs. & $\begin{array}{l}\text { Desired } \\
\text { competencies and } \\
\text { job duties }\end{array}$ & $\begin{array}{l}\text { Duties for non-profit CEOs are the same as } \\
\text { for-profit CEOs when using Mintzberg's } \\
\text { three categories and } 10 \text { roles. Strategic } \\
\text { Planning is also very important for non- } \\
\text { profit CEOs, which was a role Mintzberg } \\
\text { said CEOs do not have time for. }\end{array}$ \\
\hline 2005 & Apospori & Interviews & $\begin{array}{l}\text { Roles of } \\
\text { Professional vs. } \\
\text { Entrepreneurial } \\
\text { CEOs. }\end{array}$ & $\begin{array}{l}\text { Achievement } \\
\text { motive, power, } \\
\text { affiliation motive, } \\
\text { concern for others, } \\
\text { moral-legal } \\
\text { standards, sense of } \\
\text { obligation, concern } \\
\text { for consequences of } \\
\text { actions, self- } \\
\text { judgment. }\end{array}$ & $\begin{array}{l}\text { Achievement motivation and obligation } \\
\text { responsibility are two factors that } \\
\text { distinguish entrepreneurial CEOs from } \\
\text { professional CEOs, entrepreneurs are more } \\
\text { motivated by achievement, professional } \\
\text { CEOs by power. }\end{array}$ \\
\hline 2006 & Tengblad & $\begin{array}{l}\text { Structured } \\
\text { Observation }\end{array}$ & $\begin{array}{l}\text { Mintzberg's } 10 \\
\text { Roles are timeless }\end{array}$ & $\begin{array}{l}\text { External } \\
\text { environment } \\
\text { impacts on } \mathrm{CEO} \\
\text { role. }\end{array}$ & $\begin{array}{l}\text { The change in CEO role is "minimal" from } \\
\text { that of administrative management to } \\
\text { institutional leader. }\end{array}$ \\
\hline
\end{tabular}




\begin{tabular}{|c|c|c|c|c|c|}
\hline & $\begin{array}{l}\text { Table } 2 \\
\text { contd. }\end{array}$ & & & & \\
\hline Dates & Researcher & Method & DV & IV & Findings \\
\hline 2009 & Mascarenhas & $\begin{array}{l}\text { Meta- } \\
\text { analysis/surveys } \\
\text { and interviews }\end{array}$ & $\begin{array}{l}\text { Impact on the role } \\
\text { of CEO. }\end{array}$ & $\begin{array}{l}\text { Developing new } \\
\text { growth avenues; } \\
\text { raising productivity; } \\
\text { competing for } \\
\text { talent; managing } \\
\text { diverse risks; } \\
\text { tightening corporate } \\
\text { governance; } \\
\text { incorporating } \\
\text { sustainability; } \\
\text { creating new } \\
\text { innovation models; } \\
\text { building new } \\
\text { infrastructure. }\end{array}$ & $\begin{array}{l}\text { CEOs work is more complex and } \\
\text { challenging. }\end{array}$ \\
\hline 2009 & Mefford & $\begin{array}{l}\text { Literature } \\
\text { Review }\end{array}$ & $\begin{array}{l}\text { Impact on CEO } \\
\text { role. }\end{array}$ & $\begin{array}{l}\text { New Productivity } \\
\text { Paradigm }\end{array}$ & $\begin{array}{l}\text { Increased competition globally requires } \\
\text { focus on productivity of production in the } \\
\text { U.S. to remain competitive. Effective } \\
\text { implementation requires belief in the } \\
\text { process, commitment to implement, } \\
\text { involvement by the CEO and patience to } \\
\text { wait for results. }\end{array}$ \\
\hline
\end{tabular}


about the role of CEO. These role categories are used in the survey instrument to answer research question \#2: How much time do CEOs estimate they spend in six categories of roles?

The six role categories consist of informational, interpersonal, decisional, operational, strategic, and diplomacy roles. They are presented in detail in the following section. The presentation of the role categories begins with Mintzberg's (1973) three categories. The next three categories were described in the research and were developed by utilizing constant comparative analysis. Constant comparative analysis "is an inductive (from specific to broad) data analysis procedure in grounded theory research of generating and connecting categories by comparing incidents in the data to other incidents, incidents to categories, and categories to other categories" (Creswell, 2002, p. 451). This analysis was made by reviewing the detailed descriptions of each role presented in the literature, and then grouping the similar descriptions together, forming the categories of roles. The discussion of the six role categories begins with the informational roles.

The Informational Roles

A significant amount of a CEO's time is spent communicating with others, either receiving or providing information from individuals inside and external to the organization (Carlson, 1951; Mintzberg, 1968; 1973; Tengblad, 2006; Whitely, 1978). It is estimated that CEOs spend between 22 and $91 \%$ of their time either receiving or providing information (Mintzberg, 1973; Rastetter, 1985; Tengblad, 2006; Whitely, 1978). This wide-range in values may be attributed to any number of factors. Three researchers (Mintzberg, Tengblad, and Whitely) used structured observation, so 
differences in methodology are unlikely. The differences may be more related to individual personality, small sample sizes, or organizational characteristics that impact the role.

The informational role category includes the following four roles:

Monitor: The CEO receives and collects information enabling the development of a thorough understanding of the organization (Mintzberg, 1973).

Disseminator: The CEO transmits special information into the organization (Mintzberg, 1973)

Spokesperson: The CEO disseminates the organization's information into the business world (Mintzberg, 1973)

Commander: The CEO gives orders to employees (Gulick, 1937 as cited in Mintzberg, 1973).

The role of monitor was first used by Sayles (1964) but this role was also identified by Mintzberg (1973) and Rastetter (1985). In some cases up to 39\% of a CEO's time was spent in the monitor role (Rastetter, (1985). In the monitor role five different kinds of information were processed (Mintzberg, 1973). Information either pertained to internal operations, external events, analyses, ideas and trends, or pressures. Internal operations and external events are self-explanatory terms. Analyses included information from financial reports and trade organizations that required further explanation. Ideas and trends resulted from attendance at conferences and contact with other executives in similar industries. Pressures come from within the organization as well as from external 
sources and can include a subordinate's request for additional power or requests from outside individuals or organizations for time and/or financial support.

In the disseminator role the CEO provides information from external sources into the organization or coordinates the communication of information within the organization. Research on the spokesperson role has resulted in conflicting results. In some cases it has been considered the least important role (Beggs \& Doolittle, 1988) and others have found it to be the primary focus of the CEO (Greenfeld et al., 1988). As spokesperson for the organization the $\mathrm{CEO}$ is communicating information to individuals outside the organization. This can include the board of directors or what Mintzberg (1973) referred to as “the organization's public” (p. 76). The organization's public may be described today as the organization's stakeholders. Stakeholders are defined as “a person or group having a vested interest in the organization's functioning and objectives" (Cummings \& Worley, 2009, p. 754). This could be a vendor, customer, employee, investor, or others directly or indirectly impacted by the organization's business. Three classes of stakeholder can be identified by one or more of the following characteristics: “(1) the stakeholder's power to influence the firm, (2) the legitimacy of the stakeholder's relationship with the firm, and (3) the urgency of the stakeholder's claim on the firm" (Mitchell, Agle \& Wood, 1997, p. 854).

The final role in the informational category is the commander role derived from Fayol and described as the role in which the CEO gives orders to employees (Fayol, 1916, as cited in Mintzberg, 1973). Fayol recognized five roles: commander, controller, planner, organizer, and controller in his research and these roles became the foundation for on-going research by Gulick (1937), and Mintzberg (1968; 1973). 
The Interpersonal Roles

The interpersonal roles are linked closely with the informational roles because much of the contact a CEO has with others is during the process of either receiving or providing information (Carlson, 1951; Mintzberg, 1973; Tengblad, 2006). Study

participants have indicated they spend between 65 and 90 percent of their time in contact with others (Carlson, 1951; Mintzberg; 1973; Whitely, 1978) and in some cases up to $55 \%$ of a CEO's time is spent in the leader role (Quarterman, Allen, \& Becker, 2005). The interpersonal role category includes the following three roles:

1) Leader: The CEO leads and motivates subordinates (Mintzberg, 1973).

2) Motivator: The CEO creates and sets a sense of excitement and vitality in the organization, challenging people to gain new competencies and achieve higher levels of performance (Hart \& Quinn, 1993).

3) Director: The CEO makes sure the right people are in the right place at the right time doing the right things (Gulick, 1937, as cited in Mintzberg, 1973).

The leader role requires little explanation and may be the most important role of the CEO (Edersheim, 2007; Lafley, 2009; Mintzberg, 1973; Quarterman et al., 2005). The motivator role, described by Hart and Quinn (1993) has an internal, flexible focus, and is described as the role in which the CEO is "managing meaning" (p. 552). In a study of 916 CEOs the motivator role was most strongly associated with organizational effectiveness and had a positive association with business and financial performance, yet it was one of the roles CEOs spent the least amount of time in (Hart \& Quinn, 1993). The director role emerged from Gulick's (1937) work and could also be described as a resource allocator role where human, rather than financial, resources are being directed. 
Managing both financial and human resources is also part of the decisional roles, which are considered next.

The Decisional Roles

Given the complexity of today's competitive environment and the speed at which technology changes, one of the most important characteristics a leader must have is the ability to be ambidextrous. That is, CEOs need to be able to consider two conflicting ideas at the same time, make quick decisions, and be entrepreneurial and innovative at all times (Bodwell \& Chermack, 2010). The decisional and entrepreneurial roles have been suggested to be the most important roles of a CEO (Beggs \& Doolittle, 1988; Mintzberg, 1973). An entrepreneurial approach suggests innovation as a major component of the CEO role with an emphasis on maximizing profit (Galambos, 1995). This emphasis is consistent with the unprogrammed nature of managerial work where the most significant impacts on the organization are those made in the decision theory framework (Mintzberg, 1973). The complexity of the decision making process implies individual characteristics of the person in the role of CEO may be more important than the roles expected of the individual (Hart \& Quinn, 1993; Mintzberg, 1973; Zaccaro, 2001).

Decision making is influenced by existing mental models of individuals in decision making roles (Chermack, 2003). Mental models are defined as the biases, beliefs, experiences, and values of the individual (Ford \& Sterman, 1998; Senge, 1990). Furthermore, "mental models embody how individuals see the world, how individuals know and think about the world, and how individuals act in the world" (Chermack, 2003, p. 410). Thus the decisional roles may be informed more by studying the unique aspects of the individual and not necessarily the role itself. This suggests the importance of 
cognitive and personality aspects of the individual who serves as CEO (Hart \& Quinn, 1993). The decisional role category contains the following eight roles:

1) Entrepreneur: The CEO initiates change within the organization (Mintzberg, 1973).

2) Disturbance handler: The CEO takes charge of the organization when it is threatened (Mintzberg, 1973).

3) Conflict handler: The CEO handles conflicts that arise between individuals and outside organizations (Castaldi, 1986).

4) Resource allocator: The CEO decides where the organization will expend efforts and resources (Mintzberg, 1973).

5) Task master: The CEO has a strong focus on results, or getting the job done (Hart \& Quinn, 1993).

6) Staffer: The CEO makes sure the right people are hired for the right positions (Gulick, 1937).

7) Negotiator: The CEO is compelled to enter negotiations on behalf of the organization (Mintzberg, 1973).

8) Problem solver: The CEO serves to solve the organization's problems (Lau et al., 1979).

Decision making can comprise between 18 and $85 \%$ of a CEO's time and between nine and 89\% of the reasons for interpersonal exchanges (Mintzberg, 1973; Whitely, 1978). Mintzberg estimated that approximately $21 \%$ of the time he observed was spent in decision making roles. Research to "replicate, supplement and extend Mintzberg's findings" focused on seven managers, two were CEOs (Whitely, 1978, p. 
195). The construct of stress was researched as a factor impacting the 10 roles based on Mintzberg's assertion about the fast pace and fragmentation of the CEOs' work (Mintzberg, 1973; Whitely, 1978). The researcher concluded stress did not contribute negatively to the work of the CEO due to the fact managers, especially CEOs, enjoy a great deal of autonomy in their positions. This autonomy provides flexibility that offsets the negative impact of stress, and is consistent with research findings where empowerment was discovered to offset negative impacts of role conflict, and job autonomy contributed to a higher level of job performance (Marginson \& Bui, 2009; Morgeson, Delaney-Klinger, \& Hemingway, 2005).

Hart and Quinn (1993) identified the task master role, with an external, predictable focus, "concerned about firm performance and results" (p. 553). Their findings indicated task master was the role most frequently engaged in, but had the least impact on the three performance indicators they studied (business, organizational, and financial).

The problem solver, conflict handler, and disturbance handler roles seem to conflict with Senge's emphasis on altering mental models in order to make better decisions (Senge, 1994). This suggests that an orientation towards problem solver may be very limiting to a CEO's ability to make effective decisions.

Problem solvers are fundamentally reactive - they wait until a problem is defined, then seek a solution. A problem-solving orientation tends to limit creativity in certain ways. When executives are trying to solve a problem, they focus their efforts on defining the problem, on understanding its extent. By thinking about solving problems, rather than dissolving them, executives often reinforce a problem's existence (Senge, 1994, p. 17). 
The Operational Roles

The role of operator was added to Mintzberg's list while testing the assertion that all managers spend time in the 10 roles identified by Mintzberg (Howe, 1988). Utilizing a combination of structured observation and a questionnaire with CEOs from small and medium-sized insurance companies, the researcher concluded all managers do not perform all roles however CEOs in small companies play an operator role Mintzberg did not recognize. It has been recommended the 10 roles described by Mintzberg be reconstructed in more parsimonious terms (Howe, 1988). Hart \& Quinn (1993) used only four roles, including the analyzer role in their study of the effectiveness of CEOs. Analyzer, with an internal, predictable focus, "sets the context and shapes the decisions made by the operating system" (Hart \& Quinn, 1993, p. 553); The Analyzer role was a strong predictor of business performance, but was found to be only weakly related to organizational performance and not related to financial performance.

Executives in both the private and public sectors were researched by Lau et al., (1979) in The nature of managerial work: A comparison of public and private sector jobs. Using a questionnaire to gather data on the job content described by Mintzberg's 10 roles, an additional role was added, "technical expert" (Lau et al., 1979, p. 340). The technical expert role emerged from an earlier study of Navy civilian executives. The researchers concluded Mintzberg's roles were very similar in terms of job content and the characteristics described by Mintzberg (i.e., fragmented, high pressure, propensity to react quickly) were seen in both the public and private sector CEOs. The suggestion by Mintzberg (1973) that roles might be different for executives working in public versus private sector organizations appears unsupported by this research (Lau et al., 1979). An 
important finding was the roles the CEOs did not have time for, including "reflective, systematic planning" and self-development and learning (Lau et al., 1979, p. 343).

In a study of CEOs in small firms, Castaldi (1986) found large differences in the roles engaged in by CEOs who were owner-managers versus non-owner managers. This finding lends support to Mintzberg's contingency theory that both the person and the job impact the roles a CEO will engage in (Mintzberg, 1973). From the person perspective, the entrepreneur or company owner engaged more in an operational role than the nonowner. From the job perspective the company owner engaged more in technical issues related to product and market and perceived staff supervising as less important. Conversely, non-owner CEOs perceived staff supervision was important and placed less emphasis on operational and technical issues. Long-range planning and asset preservation also received more focus from the owner-CEOs, an idea support by management theory, but rejected by Mintzberg. The Castaldi (1986) study was supported by a similar study of Greek CEOs in which it was concluded achievement motivation and obligationresponsibility are two factors distinguishing entrepreneurial CEOs (owners) from professional CEOs (non-owners) (Apospori, Papalexandris, \& Galanaki, 2005). These studies, along with others that tested Mintzberg's contingency framework, prompted research hypotheses $1,1 \mathrm{a}$ and $1 \mathrm{~b}, 2,5,6$, and 8 , all related to differences due to gender, ownership status of the company, age, years in current job, years as a CEO, and company size. In summary, the operational category consists of six roles:

1) Organizer: The CEO makes sure deadlines are met (Fayol, 1916). 
2) Analyzer: The CEO focuses on efficient management of the internal operating system in the interest of serving existing products/markets (Hart \& Quinn, 1993).

3) Controller: The CEO makes sure projects are completed on time (Fayol, 1916).

4) Operator: The CEO makes sure day-to-day operations are being completed in a satisfactory (Howe, 1988).

5) Technical Expert: The CEO is the expert on product and market (Lau et al., 1979).

6) Consultant: The CEO provides advice on issues that arise within the organization (Lafley, 2009).

While the operating role category focuses on the business today, the strategic

roles focus more on the future. Two of the strategic roles were identified by Fayol (1916) and Gulick (1937): coordinator and planner, but further definition of the strategic roles began to emerge from research beginning in the late 1970s and early 1980s. A description of the strategic role categories follows.

The Strategic Roles

Early research on CEOs suggested they did not have time for long-term strategic planning (Carlson, 1951; Mintzberg, 1973). The lack of time for long-range planning was a result of frequent interruptions during the CEOs day leading to a lack of undisturbed time in which to plan (Carlson, 1951; Mintzberg, 1973). This conflicts with the suggestion that strategy is the role of the CEO, documented in much of the literature about the role of CEO, but with little supporting data (Breene et al., 2007; Ireland \& Hitt, 
1999; Stata, 1988). The vision setter role with an external, flexible focus on "creating a sense of identity and mission — the definition and articulation of the firm's basic purpose and future direction" was included in research focused on CEO performance, effectiveness, and financial performance however, the findings were mixed (p. 551). The vision setter role was associated with business performance and organizational effectiveness, but not with financial performance and was discovered to be one of the roles CEOs worked in the least (Hart \& Quinn, 1993). This suggestion that strategic planning has no impact on financial performance is counter-intuitive and further research to verify or deny this finding is needed.

A focus on strategy as the role of the CEO was suggested by Ireland and Hitt (1999) in their description of six components of effective strategic leadership. These components include: crafting a purpose or vision for the firm; exploiting and maintaining core competencies; developing human capital; sustaining an effective organizational culture; emphasizing ethical practices; and establishing balanced organizational controls. The strategic role category is comprised of the following six roles:

1) Coordinator: The CEO makes sure all efforts are coordinated towards the goals and strategic plan of the organization (Fayol, 1916; Gulick, 1937).

2) Innovator: The CEO guides the organization into new cycles of innovation in U.S. markets and in overseas markets (Galambos, 1995).

3) Planner: The CEO does both short-term and long-term planning for the organization (Fayol, 1916 ; Gulick, 1937).

4) Vision Setter: The CEO creates the sense of identify and mission for the organization (Hart \& Quinn, 1993). 
5) Strategist: The CEO crafts the organization's strategy (Stata, 1988).

6) Transformer: The CEO transforms the organization as markets and the external environment change (Galambos, 1995).

7) Creator and maintainer of culture: The CEO establishes and ensures the organization's culture is consistent with its strategic focus and plan (Sashkin \& Fullmer, 1988).

The strategic roles developed as the business environment became more complex in the late 1970s and early 1980s. The complexity and pressure exerted on CEOs by the external environment along with the size and complexity of multi-national organizations seems to have changed the role of the CEO (Boatright, 2009; Steiner et al., 1981). The diplomacy roles are a result of the responsibility to multiple stakeholders, further delineated as a global citizenship role. While two of the diplomacy roles were conceived by Mintzberg in 1973 as informational roles, the descriptions of these roles align more closely with the link or statesman role identified by Lafley (2009). The diplomacy roles are the topic of the next section.

The Diplomacy Roles

The diplomacy roles emerged from studying impacts of the external environment and the shift in the role of CEO to one of global citizenship. External complexities have led to changes in the way CEOs must interact with the world (Lafley, 2009).

Globalization of businesses, increased complexity, expansion of the corporate stakeholder group, and company economies exceeding those of small countries have resulted in the need for the CEO to be a diplomat or statesperson, linking the outside world to the world inside the organization (Edersheim, 2007; Lafley, 2009). The 
diplomacy role category includes the following three roles, two of which were originally identified by Mintzberg (1973):

1) Link/Statesperson: The CEO links the external world to the world inside the organization (Lafley, 2009).

2) Figurehead: The CEO represents the organization in all formal matters (Mintzberg, 1973).

3) Liaison: The CEO interacts with peers and others outside the organization to gain favors and information (Mintzberg, 1973).

In an effort to understand the impact of external influences proposed by Steiner et al., (1981), Greenfeld et al. (1988) sought to know what priority CEOs were giving to the external environment of their organizations. Specifically the researchers wanted to know if the CEOs in their study would agree with the findings of Steiner et al. (1981) about the influence of external factors on the role of CEO. Questionnaires were sent to 200 CEOs from the 1986 Baltimore Business Journal's Book of Lists, resulting in 59 usable responses. Most of the CEOs surveyed agreed or strongly agreed with the Steiner et al.'s 1981 findings: the requirements put on CEOs are more extensive than they have been in the past and more time is spent on external issues; CEOs must have an understanding of the political process in Washington, DC; strategies have been changed to deal with additional government regulation; and more time is spent working than ever before (Greenfeld et al., 1988; Steiner et al., 1981).

In an editorial, Kanter (1989) supported the findings of Steiner et al. (1981) and Greenfeld et al. (1988) by stating that for "obvious reasons" managers are "reinventing their profession as they go" (p. 85). The obvious reasons included increasing competition 
globally, acquisitions, divestitures, and mergers focused at combining business activities while reducing staff and levels of hierarchy, and a greater focus on compensation packages based on actual performance (Greenfeld et al., 1988; Kanter, 1989; Steiner et al., 1981).

It is not apparent that previous researchers asked CEOs to suggest roles that might have been missing from surveys. Most researchers asked questions about Mintzberg's 10 roles and in one case they developed their own set of roles upon which to base their studies (Ahmed, 2005; Beggs \& Doolittle, 1988; Carter, 1982; Hart \& Quinn, 1993; Howe, 1988; Kurke \& Aldrich, 1983; Lau et al., 1979; Mintzberg, 2009; Pugliese, 1985; Snyder \& Wheelen, 1981; Tengblad, 2006; Whitely, 1978). In some cases the researchers asked CEOs to rank the roles in terms of importance, rather than asking for time estimations of the roles. These strategies employed by other researchers led to the development of research question \#3: What roles are identified by CEOs that were not identified in the literature on the role of $C E O$ ?

The most current research conducted by Tengblad (2006) and Mintzberg (2009) was based on the idea that the CEO role remains timeless and is unaffected by the complexities in the business environment. It seems unlikely that the role of CEO has not been impacted by changes in the business and regulatory environment over the past 40 years. Mintzberg's theory was contextual in nature, as all theories are, thus it is important to understand the perspective from which Mintzberg's research was conducted (Lynham, 2002). These studies, suggesting the role of CEO has not changed, are presented in the following section. 
Contemporary Research: External Complexities and Their Impact on The Role of CEO

Two contemporary studies suggest that complexities in the external environment have not changed the role of CEO. In 2006 Tengblad published a comparative study to inform Mintzberg's theory on the impact of 30 years of change. The purpose of this study was to determine "the extent to which managerial work (at the executive level) is subject to change" (Tengblad, 2006, p. 1438). The problem studied was based on two conflicting views about the role of CEO. Studies by Carlson (1951), Mintzberg (1973), and Kurke and Aldrich (1983) suggested the roles they described would be the same over time. More current research suggests dramatic changes in the structure of organizations, the business environment, and technology has caused changes to the role of CEO. (Edersheim, 2007; Galambos, 1995; Hart \& Quinn, 1993; Lafley, 2009).

Observing four CEOs for a full week during the late 1990s, Tengblad wanted to compare the work behaviors of his participants to those observed by Mintzberg. The findings resulted in the following differences:

1) CEOs worked longer hours, travelled more, and spent less time at their desks.

2) There were more meetings with more people in attendance.

3) There were more meetings with subordinates, fewer with suppliers and clients.

4) More time was spent providing information and communicating expectations, including vision, strategy, intentions, and performance targets.

5) There was more participation in formal ceremonies.

The researcher described these changes as a shift in the role of CEO from administrative management to institutional leadership, but concluded the shift was an insignificant change in the role of CEO (Tengblad, 2006). Cultural and political 
differences between Europe and the U.S. may explain why researchers in the U.S. argue the change from an administrative emphasis to a leadership emphasis does indicate a significant shift has occurred for the role of CEO (Beggs \& Doolittle, 1988; Boatright, 2009; Jensen \& Murphy, 1990; Steiner et al., 1981).

Mintzberg (2009) supported the findings of Tengblad (2006). Defining a manager as "someone responsible for a whole organization or some identifiable part of it" (p. 12), thus expanding the role to individuals in division-level or department-level CEO-like positions, Mintzberg studied an additional 12 CEOs during 2003. His focus was the level of impact changes in the business environment made on the role of CEO. Mintzberg (2009) concluded these changes were not significant. He recognized that many things in the business environment were changing and stressed the importance of the CEO role in linking the organization to the external environment (consistent with Lafley, 2009), however he stood by his earlier conclusions about the role of CEO:

Has any of that changed now? We might like to think so, but the evidence suggests otherwise. Were management a science, even a profession, it would change. (Medical practice changes constantly.) But management is neither. So aside from the fads that come and go, many of them dysfunctional, managing carries merrily along. Even the new information technologies, especially e-mailthe one thing that does seem to be rendering significant change-may actually be reinforcing long-standing characteristics of managerial work ... (p. 14).

The context of these comments is important to consider. Over the years Mintzberg's focus shifted from the work not just of CEOs, but to the work of all managers, even though CEOs comprised a portion of the managers he studied. The argument stands that managers and CEOs are distinctly different in the work they do and the way they think (Zaleznik, 1977). 
Changes in the External Environment

Many researchers disagree with Tengblad (2006) and Mintzberg (2009), arguing that changes in the business environment have caused substantial changes in the role of CEO (Beggs \& Doolittle, 1988; Boatright, 2009; Edersheim, 2007; Jensen \& Murphy, 1990; Lafley, 2009; Steiner et al., 1981). In the years following 1973, the business environment changed rapidly as a result of technology, globalization, excess capacity, increased productivity, and instability (Breene et al., 2007; Boatright, 2009; Jensen \& Murphy, 1990). These changes impacted the expectations for the role of the CEO and contributed to the complexity the CEO was supposed to manage (Breene, et al., 2007; Boatright, 2009; Hart \& Quinn, 1993; Jensen \& Murphy, 1990). It was suggested the role of CEO began to evolve into one of value and wealth creation, where the CEO was expected to operate the business as if he/she owned it. This evolution in roles is a reversal from the belief that the role of CEO was bureaucrat or technocrat (Boatright, 2009). Major changes were also made to executive compensation plans, including the addition of stock options. Stock-based compensation plans are one way of ensuring CEOs have skin in the game (Boatright, 2009). It seems evident that researchers do not agree on the impact the complexity of the external environment has had in changing the role of CEO.

Much of the growth in business during the 1960s and 1970s was due to business expansion that resulted in many of the economic challenges of the 1980s and 1990s, including excess capacity and out-sourcing of jobs (Boatright, 2009; Jensen \& Murphy, 1990). For companies to expand their wealth in the years after 1973, they had to downsize their expenses and their organizations. Too much downsizing created a potential for the CEO to lose their job which was a huge disincentive. Companies that did 
not downsize were vulnerable to hostile takeovers by corporate raiders. To encourage downsizing and to reward downsizing that would put the $\mathrm{CEO}$ job at risk, $\mathrm{CEO}$ compensation plans were structured in a manner to compensate the CEO for sacrificing their own jobs if necessary (Boatright, 2009; Jensen \& Murphy, 1990).

Non-economic pressure from sources external to the organization can be just as important to the complexity of the business environment (Steiner et al., 1981). Social consciousness impacts consumer decisions and CEOs are expected to make corporate social responsibility a priority in their decisions (Lynham, 1998; Waldman, Siegel, \& Javidan, 2006). Additionally CEOs are responsible not only to stockholders but to a much wider group of stakeholders than ever before (Bing, Kehrhahn, \& Short, 2003). This group of stakeholders includes employees whose changes in attitudes, expectations, and demands put additional pressure on the CEO (Steiner et al., 1981)

The complexity of the business landscape remains in place today (Breene et al., 2007; Favaro et al., 2010) while "the CEOs work is becoming more complex and challenging" (Mascarenhas, 2009, p. 250). Included in the challenges are the needs to develop new avenues for corporate growth, increase worker productivity, compete for talented employees, manage unique risk, tighten corporate governance, create sustainable business models along with innovation models, build new infrastructure, and lead in virtual environments (Bennett \& Bierema, 2010; Mascarenhas, 2009). The rapid development of industry in countries like China and India, where labor and other production costs are much lower than in the U.S. adds to the challenge for maintaining competitiveness (Mefford, 2009). Steiner et al. (1981) may have best described the changes occurring after the 1970s causing a significant shift in the role of CEO: 
We may well be in the midst of what cultural historians describe as an 'axial age', or one of monumental transition. At least, so far as business is concerned there is little doubt that the rules of the game have changed dramatically from even a decade ago. The scope of environmental concerns has enormously expanded for the CEO of the large company and his priorities of attention have altered significantly within the past few years (p. 11).

Three decades following these comments academics are being called upon to "reorient their research and teaching agendas towards these pressing, top management concerns" (Mascarenhas, 2009, p. 250). These concerns include the need to increase productivity, develop growth, develop talent, manage risk, tighten corporate governance, and increase sustainability---all representing significant challenges to the role of CEO. Understanding the role of CEO is one aspect of research that may be useful for helping CEOs and their organizations "better navigate the turbulent times ahead" (Mascarenhas, 2009, p. 250).

Large corporations often conduct their own research into CEOs, as evidenced by a recent study of the IBM Institute for Business Value and IBM Strategy and Change. Conducting interviews of 1,541 CEOs from September, 2009, through January, 2010, IBM released the fourth edition of their Global CEO Study series in May, 2010. While not directly focused on the role of CEOs, participants identified three strategies necessary for capitalizing on the complexity of today's business landscape (IBM Institute for Business Value, 2010).

Creativity was identified as the most important leadership aspect of CEOs:

Creative leaders invite disruptive innovation, encourage others to drop outdated approaches and take balanced risks. They are open-minded and inventive in expanding their management and communication styles, particularly to engage with a new generation of employees, partners and customers (p. 10). 
The ability to reinvent customer relationships was identified as a critical strategy for CEO effectiveness:

In a massively interconnected world, CEOs prioritize customer intimacy as never before. Globalization, combined with dramatic increases in the availability of information, has exponentially expanded customer's options. CEOs said that ongoing engagement and co-creation with customers produce differentiation. They consider the information explosion to be their greatest opportunity in developing deep customer insights (p. 10).

To deal with complexity it was suggested that CEOs needed to build operating dexterity:

CEOs are revamping their operations to stay ready to act when opportunities or challenges arise. They simplify and sometimes mask complexity that is within their control and help customers do the same. Flexible cost structures and partnering capabilities allow them to rapidly scale up or down (p. 10).

The CEOs interviewed indicated a degree of doubt in their own abilities to handle the "rapidly escalating complexity" in the business world today (IBM Institute for Business Value, 2010, p. 13).

\section{Summary and Conclusions}

In many ways the work that has been done to clarify the role of CEO is still incomplete (Edersheim, 2007; Hart \& Quinn, 1993). Immediately following the release of Mintzberg's book in 1973 many researchers tried to verify the roles Mintzberg proposed however few attempts have been made to update the 10 roles. Furthermore, there does not appear to be a model or theory that integrates a complete set of roles that contribute to an effective executive (Hart \& Quinn, 1993; Howe, 1988; Mintzberg, 1973, 2009; Snyder \& Wheelen, 1981) and few empirical studies have attempted to make the connection between the role of CEO and the performance of the organizations they lead. Peter Drucker's attraction to the role of CEO "became almost an obsession" in the last years of 
his life, marked by the $21^{\text {st }}$ century—a time when the speed of change left very little room for errors in top management (Edersheim, 2007, p. 40). In a 2003 interview Drucker commented "the CEO role needed to be the next focus of management research" (Edersheim, 2007, p.40). This comment aptly and succinctly underscores the need to research the role of CEO. The majority of studies on the role of CEO date back 40 years and have lost relevance for CEOs today. While CEOs are being studied extensively in other areas, there remains a basic need to understand the role of the CEO. These conclusions support the problem put forth for this study, namely: that research on the role of CEO is conflicting and outdated.

This chapter has presented the methodology used to conduct the review of literature. Additionally, it provided an analysis and synthesis of literature covering a brief overview of the history of CEOs and existing theories that inform research on the role of CEO. From the review of literature six role categories and 31 CEO roles emerged, providing the foundation for this study. From the review of literature the research questions and hypotheses also evolved. The most current research on the complexities of the external environment and their impact on the role of CEO were presented.

The following chapter outlines the methodology for this research study. Specifically, it provides the research questions and hypotheses, research design, research philosophy, population and sample, sampling procedures and external validity, the pilot study, instrumentation, measurement validity and reliability, data collection, and limitations and weaknesses of the study designed to provide evidence of the role of CEO. 


\section{CHAPTER THREE: METHODOLOGY}

Introduction

This study was designed to provide evidence of the role of CEO from the perspective of CEOs and to analyze the amount of time CEOs spend in specific role categories. This study was conducted using a survey design which is considered a form of cross-sectional research. Quantitative data were collected from CEOs using selfadministered surveys through an electronic survey tool Qualtrics. Data were analyzed testing the study's three research questions and eight research hypotheses using both descriptive and inferential statistical methods. This chapter will present the methodology for the study including: identification of the research questions and hypotheses, research design, research philosophy, population and sample, sampling procedures and external validity, the pilot study, instrumentation, measurement validity and reliability, data collection, and limitations and weaknesses.

\section{Research Questions}

The overarching research question to be addressed by this study was:

RQ1) What is the role of CEO in the U.S.?

To gain an understanding about how CEOs allocate their time, the following question was asked:

RQ2) How much time do CEOs estimate they spend in six categories of roles? 
On the survey participants were asked to add roles that were missing in order to explore the following question:

RQ3) What roles are identified by CEOs that were not identified in the literature on the role of CEO?

In addition to the three research questions, the following hypotheses were tested:

H1) There is no difference between gender, agreement with the 31 role descriptions, and time allocated to the six role categories.

H1a) Female CEOs will report they spend more time in interpersonal roles than their male counterparts.

H1b) Female CEOs will report they spend less time in operational roles than their male counterparts.

H2) CEOs from public companies will report they spend less than $10 \%$ of their time in strategic role categories.

H3) Agreement with and time spent in the role categories will not differ depending upon the CEOs degree major or industry background.

H4) There will be no difference in the way CEOs spend their time between CEOs with other C-level executives working for them, and those without C-level executives. H5) There will be an association between age, years in current job, years as a CEO, last degree earned, company size and agreement with each role category.

H6) There will be no difference in the responses on role agreement and time spent in the role categories between CEOs from privately-held versus publicly-held companies.

H7) There will be no difference in the responses on role agreement and time allocations to role categories between a convenience sample of CEOs and a random sample of CEOs. 
H8) There will be no difference in the responses on role agreement and time allocations between CEOs from small companies and CEOs from large companies.

To answer these research questions and test the hypotheses a survey was developed based on 31 role descriptions identified in the review of the literature. These 31 roles were analyzed into six role categories using constant comparative analysis to induce six categories of roles: informational, diplomacy, interpersonal, decisional, strategic, and operational. This analysis was made by reviewing the detailed descriptions of each role presented in the literature, and then grouping the similar descriptions together, forming the categories of roles.

The survey participants were asked to review the 31 roles and report whether or not they agree with the roles as they relate to their role as CEO. A five-point Likert scale was used ranging from strongly agree to strongly disagree. The participants were asked to approximate the number of hours spent in the role categories during an average week. The participants were provided space to write in any roles that were missing from the survey, along with an approximation of the number of hours spent in those roles during an average week. Finally, demographic information about the CEO and their organization were collected for both comparative and associational purposes. The demographic information collected included: age, gender, years in current job, years as CEO, last degree earned, academic major or industry background, company size by employee number, company size by sales revenue, industry, ownership status of company, that is, privately- or publicly-held, whether or not they hold an additional title besides CEO, and if yes, what that title is, and whether or not they have other C-level executives working for them, and if yes, what those titles are. Table 3 provides a summary of the research 
Table 3

Research Questions, Variables, and Appropriate Statistics for Analysis

\begin{tabular}{|c|c|c|c|}
\hline $\mathrm{RQ} / \mathrm{RH}$ & IV & DV & Statistic \\
\hline RQ1 & & Role of CEO & Descriptive/frequency \\
\hline RQ2 & & Time spent in roles & Descriptive/frequency \\
\hline RQ3 & & New roles identified & Descriptive/frequency \\
\hline $\begin{array}{l}\text { RH1, } \\
\text { RH1a \& b }\end{array}$ & Gender & $\begin{array}{l}\text { Agreement with and time } \\
\text { spent in role categories }\end{array}$ & $\begin{array}{l}\text { T-test (role agreement) and Mann- } \\
\text { Whitney U (time) }\end{array}$ \\
\hline RH2 & Public Co. CEOs & Time in Strategic Roles & Descriptive \\
\hline RH3 & Focus of degree & $\begin{array}{l}\text { Agreement with and time } \\
\text { spent in role categories }\end{array}$ & $\begin{array}{l}\text { ANOVA (agreement with) and } \\
\text { Kruskal-Wallis (time spent) }\end{array}$ \\
\hline RH4 & $\begin{array}{l}\text { Other C-level } \\
\text { executives }\end{array}$ & $\begin{array}{l}\text { Time spent in role } \\
\text { categories }\end{array}$ & Mann-Whitney U \\
\hline RH5 & $\begin{array}{l}\text { Age, years in } \\
\text { current job, years } \\
\text { as CEO, last } \\
\text { degree earned, } \\
\text { company size- } \\
\text { employees and } \\
\text { revenues }\end{array}$ & $\begin{array}{l}\text { Agreement with the CEO } \\
\text { role categories }\end{array}$ & Multiple regression \\
\hline RH6 & $\begin{array}{l}\text { Private vs. } \\
\text { Public Company }\end{array}$ & $\begin{array}{l}\text { Agreement with and time } \\
\text { spent in role categories }\end{array}$ & $\begin{array}{l}\text { T-test (agreement with) and Mann- } \\
\text { Whitney U (time spent) }\end{array}$ \\
\hline RH7 & $\begin{array}{l}\text { Responses from } \\
\text { Random Sample; } \\
\text { Responses from } \\
\text { Convenience } \\
\text { Sample }\end{array}$ & $\begin{array}{l}\text { Agreement with and time } \\
\text { spent in role categories }\end{array}$ & $\begin{array}{l}\text { T-test (agreement with) and Mann- } \\
\text { Whitney U (time spent) }\end{array}$ \\
\hline RH8 & $\begin{array}{l}\text { Company size } \\
\text { (small, med, } \\
\text { large, based on } \\
\text { employee } \\
\text { numbers) }\end{array}$ & $\begin{array}{l}\text { Agreement with and time } \\
\text { spent in role categories }\end{array}$ & $\begin{array}{l}\text { T-test (agreement with) and Mann- } \\
\text { Whitney U (time spent) }\end{array}$ \\
\hline
\end{tabular}


questions, dependent and independent variables, and the corresponding statistic used to analyze the data.

\section{Research Design}

The research design used in this study was non-experimental, descriptive, inferential, and utilized quantitative methods. The methodology was a self-reporting survey to collect data for testing comparative and associational questions and hypotheses about the role of CEO. E-mail was selected as the primary method for contacting participants due to the ease of sending large numbers of e-mails at a minimum cost. When compared to the cost of printing and mailing paper surveys along with the resulting manual data entry, e-mail was the most economical and efficient method for conducting the survey. Paper surveys were offered as an alternative to the on-line survey with 11 participants choosing the paper survey method. Of the paper surveys mailed, 4 surveys were returned and included in the sample.

A majority of the research on the role of CEO has been conducted by structured observation, where the role of a limited number of CEOs is described from the perspective of the researcher, not necessarily from the perspective of the CEO. Structured observation, a research method conducted by watching an individual perform work in a natural work environment, is based on categorizing observed events in any number of ways and is dependent upon the researchers' interpretation of the activities into broader categories (Mintzberg, 1973). Certain activities can be observed, however a large portion

of the work performed by CEOs is cognitive work that cannot be observed (Martinko \& Gardner, 1985). Additionally, work performed outside the office is not likely to be observed by the researcher; therefore, the structured observation method may miss some 
critical activities or aspects of the role of CEO (Martinko \& Gardner, 1985). Structured observation has been criticized for its small sample sizes (evidenced by Mintzberg's research on five CEOs), lack of reliability and validity, inconsistent coding methodologies, narrow perspective of the studies, failure to identify effective versus ineffective CEOs, lack of theory, and failure to identify the epistemological orientation of the researcher (Martinko \& Gardner, 1985).

Use of work diaries, interviews, in-basket simulation, and time sampling are other research methods employed to study the role of CEO (Carlson, 1951; Lau et al., 1979; Mintzberg, 1973; Shapira \& Dunbar, 1980; Snyder \& Wheelen, 1981; Whitely, 1978). A few studies have surveyed CEOs directly using Mintzberg's 10 roles or Hart and Quinn's four roles, however these surveys limited the roles the CEOs could choose from and did not appear to ask the CEOs to add roles they thought were missing from the survey. Assumptions

Certain assumptions are important to consider in this research study which utilized a survey methodology. First, it is assumed the survey instrument developed and used provided accurate and reliable data and provided roles and descriptions from research the survey participants identified with. Second, it is assumed CEOs who participated in this study accurately completed the survey instrument. Finally, it is assumed the responses provided by the CEOs reflected accurate representations of CEO roles and the estimated amount of time spent in these roles on a weekly basis. This study incorporated sampling procedures consistent with a post-positivist research philosophy, as outlined in the following section. 


\section{Research Philosophy}

Based on an underlying post-positivist philosophy, the epistemology, or the "nature of the relationship between the knower (the inquirer) and the known (or knowable)" (Guba, 1990, p. 18) is modified objectivist, with an understanding that

objectivity is an ideal that may never be entirely comprehended. The ontology or "nature of reality" (Guba, 1990, p. 18) is a critical realist perspective in which it is believed that reality exists, although humans may never completely comprehend it. The researcher believes that the role of CEO can be known, and the best way to discover the role of CEO is to ask CEOs. The researcher also believes there is value in this knowledge for HRD practitioners, CEOs, and Boards of Directors. It is hoped that the researcher can publish several articles as a result of this research and that dissemination of the knowledge gained about the role of CEO will encourage further empirical research on CEOs.

Knowledge accumulation was accomplished using a survey of CEOs with hopes that the response rate was large enough to make generalizations about the total population of CEOs. The conventional benchmarks of rigor include internal and external validity, reliability, and objectivity. The post-positivist paradigm emphasizes objectivity and thus the values of the researcher were not considered for this study. Ethics were maintained by utilizing random sampling and maintaining anonymity of study participants. The voice of the study is that of the researcher objectively reporting the research findings from the perspective of working CEOs. Certain limitations exist because of the willingness or ability for a random selection of CEOs to respond to surveys. 


\section{Population and Sample}

There are an estimated 400,000 CEOs in the U.S. (Martelli \& Abels, 2010). This was considered the theoretical population for purposes of this study. The total number of accessible CEOs was limited by the availability of CEO e-mail addresses in a purchased database and from the researcher's professional contacts. This number was approximately 28,000 CEOs. Internet surveys are a relatively new method of data collection and best practices for conducting this type of research is evolving (Leong \& Austin, 2006). The entire accessible population became the selected sample due to the difficulty in estimating response rates. Expected response rates for internet surveys "have ranged wildly from $0 \%$. . . to $85.3 \% "$ (Leong \& Austin, 2006, p. 190). InfoServices, a division of RefUSA estimated the response rates would range from $.25 \%$ to $2.0 \%$ based on their experience collecting data from executives using e-mail surveys.

The accessible population was identified using a variety of sources. The first source of CEOs was a convenience sample of 127 CEOs who were professional contacts of the researcher. This sample was expanded from 50 by asking the CEOs to recommend other CEOs, by accessing CEO contacts from the CSU Alumni website, and by accessing CEOs from the Linked-In database of a colleague at Colorado State University. The second source was a random sample of approximately 250 CEOs obtained from the Lexis-Nexis database at Morgan Library at Colorado State University. The final and major source of CEO e-mail addresses were obtained from a purchased database.

Several alternative sources for accessing CEO e-mail addresses were identified. These sources included the Mergent database accessible for free through the Morgan Library at Colorado State University and a variety of databases available for sale. Several 
companies selling databases were identified, including Lead411.net, InfoServices (a division of RefUSA), rsalists.com, and thedatasupplier.com. An attempt was made to partner with business organizations offering study data in exchange for help accessing CEOs. The organizations contacted included The Academy of Management, The American Management Association, Chief Executive Magazine, Vistage, IBM, PriceWaterhouse-Coopers, Business Roundtable, strategy+business, and CEOsurvey.org. These organizations either did not express interest in this partnering opportunity or did not respond to the request.

The survey was conducted using Qualtrics software implemented by The School of Education at Colorado State University during the summer, 2010. This software allows the creation of a confidential, on-line survey that can be sent as a link to a large number of e-mail addresses. It provides a back-end tool that tracks responses and collects data in a form that can be automatically downloaded into IBM SPSS software. Data collection began on October 28, 2010. Surveys were e-mailed over a three week period of time, either on Tuesday or Thursday. Reminder e-mails were sent one week following the original e-mail. Data collection ended on November 23, 2010.

Sampling Procedures and External Validity

The sampling procedures for this study were conducted in phases aimed at maximizing the number of study participants. The first phase was comprised of a convenience sample of 127 CEOs. The advantage of using a convenience sample is that it is believed CEOs are more likely to respond to surveys when they are conducted by someone they know or trust (Bartholomew \& Smith, 2006). The second phase of sampling was based on an accessible population of CEOs from a purchased database. The 
entire accessible population was contacted. A large sample was necessary due to the expected low response rate.

\section{External Validity}

The goal of sampling is to select a sample that is representative of the total population so inferences can be made from the sample to the population (Gall, Gall, \& Borg, 2005; Gliner, Morgan \& Leech, 2009). Having a sample that is representative is more important than overall sample size and is an important aspect in evaluating external validity, specifically population external validity (Gliner et al., 2009). Ecological external validity, a second aspect of external validity, is considered adequate when the study is conducted in a natural setting for the participants (Gliner et al., 2009). Due to the nature of a mailed or e-mailed survey, it is assumed CEOs who choose to participate will do so from their homes or their offices--a natural setting for them as opposed to a laboratory or classroom. To ensure the random and convenience samples used were mutually exclusive a complete listing of e-mail addresses was checked for duplicates using Microsoft Excel. For purposes of this study internal validity will not be evaluated because the research is not designed to infer a causal relationship (Gliner et al., 2009).

One potential problem with a random sample of CEOs is the sample may be heavily weighted by male CEOs, based on the actual proportion of female to male CEOs, especially in publicly-traded companies (Adams, Gupta, \& Leeth, 2009). Stratified random sampling could have been used to address this issue. Stratified random sampling is a "probability technique in which the population is divided into segments based on key variables, sampling from each value of the key variable" (Gliner et al., 2009, p. 437). In an attempt to maximize sample size stratified random sampling was not used. 
The total desired sample size was 400 , a response rate of $1.4 \%$. It is suggested that five times as many responses as items on a survey will provide optimal data for factor analysis and for practical purposes (Leong \& Austin, 2006) making the minimum desired number of responses 155. Dillman recommends 383 respondents for a population of 100,000, +/- 5\% sampling error, with a 50/50 split (Dillman, 2007). The recommended sample size increases to 384 , or by only one respondent, for a population of $1,000,000$ and thus, while the population size increases dramatically, the recommended sample size does not. The total actual sample size of 1,202 exceeded the recommendations of Leong \& Austin (2006) and Dillman (2007) and was believed to be a reasonable response rate when studying CEOs and when collecting data via e-mail (Beggs \& Doolittle, 1988). Table 4 provides sample sizes from previous studies on CEOs.

\section{The Pilot Study}

After receiving Colorado State University Institutional Review Board approval (Appendix C), a pilot study using paper (mailed) surveys was conducted in May, 2010 on a random sample of 100 CEOs from the accessible population. An accessible population of CEOs from companies in the U.S. was selected using Reference USA (RefUSA) from the Fort Collins Public Library website: http://www. poudrelibraries.org and accessed from the Morgan Library at Colorado State University. RefUSA is a leading provider of business and consumer research and is a service of InfoGroup, an internet-based reference service founded in 1992. RefUSA was designed to be used as a reference and research tool for students, job seekers, and researchers. The data are continuously updated from over 5,000 public sources and examined by hand for quality and 
Table 4

Research Conducted on the Role of CEO: Sample Size

\begin{tabular}{|c|c|c|c|c|}
\hline Dates & Researcher & Method & $\mathrm{N}$ & Number of Roles \\
\hline 1930s & Gulick & & & 7 \\
\hline $1938 / 1968$ & Barnard & & & 3 \\
\hline 1951 & Carlson & Diaries & 9 & 4 \\
\hline 1957 & Selznick & & & 4 \\
\hline $1968 / 1973$ & Mintzberg & Structured Observation & 5 & 10 \\
\hline 1978 & Whitely & Questionnaire/Time Sampling & 7 & 13 \\
\hline 1979 & Lau et al. & Questionnaire & 220 & Mintzberg's 10 \\
\hline 1981 & Snyder & Observation & 2 & Mintzberg's 10 \\
\hline 1981 & Steiner et al. & Public interviews/speeches & 47 & $\mathrm{CEO}$ is strategist \\
\hline 1982 & Carter & Mailed Questionnaire & 93 & Mintzberg's 10 \\
\hline 1983 & Kurke \& Aldrich & Observation & 4 & Mintzberg's 10 \\
\hline 1985 & Pugliese & Questionnaire & $55 / 66$ & Mintzberg's $10+1$ \\
\hline 1986 & Castaldi & $\begin{array}{l}\text { Interview/questionnaire completed at time of } \\
\text { interview }\end{array}$ & 8 & 8 \\
\hline 1987 & Carroll \& Gillen & Reviewed 21 management textbooks & 21 & $\begin{array}{l}\text { Classical school } \\
\text { approach is still used }\end{array}$ \\
\hline
\end{tabular}


Table 4 contd.

\begin{tabular}{|c|c|c|c|c|}
\hline Dates & Researcher & Method & $\mathrm{N}$ & Number of Roles \\
\hline 1988 & $\begin{array}{l}\text { Beggs \& } \\
\text { Doolittle }\end{array}$ & Mailed Questionnaire & $92 / 400$ & Mintzberg's 10 \\
\hline 1988 & Howe & Observation & 12 & Mintzberg's 10 \\
\hline 1988 & Greenfeld & Mailed Questionnaire & $59 / 200$ & Agreed with Steiner \\
\hline 1993 & Hart \& Quinn & 16 item Questionnaire & $916 / 3546$ & $\begin{array}{l}4 \text { roles of "Top } \\
\text { Managers" These were } \\
\text { CEOs or Presidents }\end{array}$ \\
\hline 1999 & Ireland \& Hitt & Literature Review & $\mathrm{n} / \mathrm{a}$ & $\mathrm{n} / \mathrm{a}$ \\
\hline 2003 & $\begin{array}{l}\text { Wood \& } \\
\text { Vilkinas }\end{array}$ & Interview-Direct Reports of CEOs & 34 & $\mathrm{n} / \mathrm{a}$ \\
\hline 2005 & Ahmed & CEO Job Advertisements & 242 & 15 \\
\hline 2005 & Apospori & Interviews & 47 & \\
\hline 2006 & Tengblad & Structured Observation & 4 & Mintzberg's 10 \\
\hline 2009 & Mascarenhas & Meta-analysis/surveys and interviews & 6 & 8 \\
\hline 2009 & Mefford & Literature Review & $\mathrm{n} / \mathrm{a}$ & $\mathrm{n} / \mathrm{a}$ \\
\hline
\end{tabular}


completeness by a staff of over 700 database specialists. RefUSA has information available on over 14 million businesses in the U.S.

Utilizing RefUSA lists of approximately 7,300 publicly-traded and 101,000 privately-traded companies in the U.S. were created. A complete description of data available from the RefUSA database is listed in Appendix E; however, not all data are complete for every company, especially those companies that are privately-held. The information that was utilized for this study included: company name, CEO first and last name, and mailing address.

A draft of the survey instrument (Appendix A) with a letter describing the purpose for the pilot test was mailed May 17, 2010 to participants, along with a selfaddressed, stamped envelope for returning the survey. The purpose of the pilot study was to test response rates on a mailed survey to a random selection of participants. A sample of the letter to pilot study participants appears in Appendix B. A follow-up postcard was mailed June 3, 2010, to encourage responses and to offer an electronic version of the survey via e-mail (Appendix E). As of June 30, 2010, eight surveys were returned, a disappointing response rate of $8 \%$. Only two of the eight respondents estimated their time spent in each role. This indicated the survey took too long to complete and led to changes in the way these data were collected on the final survey. The final survey categorized the 31 roles into six role categories for purposes of approximating the amount of time spent each week by the participants.

Responses from the pilot study included four CEOs from privately-held companies, two from publicly-held companies, one from a private-public venture, and one from a non-profit, home health care business. Seven of the respondents were male 
and one did not respond to gender. Three CEOs ranged in age from 41-50 and four ranged in age from 51-60. Three respondents had spent over 20 years in their current job and over 20 years as CEO. Additionally, three participants were in their current job between two and five years, two between six and ten years. One had been a CEO between two and five years, three between six and ten years, and one between 11 and 20 years. Four participants indicated they had Bachelor of Arts degrees, three had Bachelor of Science degrees, and one had a PhD.

The company sizes were as follows: three between zero and 50 employees, one between 51 and 100 employees, two between 101 and 500 employees, and one had over 500 employees. In terms of sales revenues, four companies were less than $\$ 10$ million, one was between $\$ 11$ and $\$ 50$ million, one was between $\$ 51$ and $\$ 150$ million, and one was greater than $\$ 500$ million. The industries were all different, including: wholesale beverage, economic development, internet security, CPG (no further description was provided), home health care, retail, insurance, and granite memorial manufacturer.

It is difficult to draw any conclusions from a sample size of eight however there were some interesting findings in the eight responses. The role category with the most variance in response was the operational category. Of the six operational roles, four roles resulted in conflicting responses. See Table 5 for these results. Howe (1988) suggested that operational roles would be more prevalent in smaller companies. Of the four neutral responses to the analyzer role, two were from small companies in terms of employees and sales revenues, conflicting with Howe's (1988) results. Of the three disagree responses to the operator role one was from a small company in terms of employees and sales revenues. Of the two neutral responses to the technical expert role, one was from a small 
company and one was from a large company, and the one disagree response was from a small company. The responses to the organizer role were consistent with Howe's (1988) findings, that is, the CEOs from large organizations disagreed that this was a CEO role.

Table 5

Frequency Table - Responses to Operational Roles

\begin{tabular}{|c|c|c|c|c|}
\hline & $\begin{array}{l}\text { Strongly } \\
\text { Agree }\end{array}$ & Agree & Neutral & Disagree \\
\hline & \multicolumn{4}{|c|}{ Frequency of Responses } \\
\hline $\begin{array}{l}\text { Analyzer: I focus on efficient management of } \\
\text { the internal operating system in the interest of } \\
\text { serving existing products/markets. }\end{array}$ & 2 & 2 & 4 & 0 \\
\hline $\begin{array}{l}\text { Operator: I make sure that day-to-day } \\
\text { operations are being completed in a satisfactory } \\
\text { manner. }\end{array}$ & 1 & 4 & 0 & 3 \\
\hline $\begin{array}{l}\text { Technical expert: I am the expert on product } \\
\text { and market. }\end{array}$ & 1 & 4 & 2 & 1 \\
\hline Organizer: I make sure deadlines are met. & 1 & 4 & 2 & 1 \\
\hline
\end{tabular}

The informational roles had similar variation with $50 \%$ of the responses indicating agreement with the roles and 50\% neutral or did not agree that the roles were roles of CEOs. Three of eight decisional roles also had conflicting results. The eight responses from the pilot study did not provide enough data to test the research questions or hypotheses proposed by this study using inferential statistics. Of the eight responses, only two made estimates of their time. The method for collecting time estimates was changed on the survey instrument after the pilot study was conducted. Another significant change from the pilot study to the final study was the method for sending the surveys. 
Rather than mailing the surveys, the surveys were sent via e-mail so that a much larger population could be reached at a much lower cost.

\section{Instrumentation}

The purpose of using a survey is to enable the researcher to make generalizations about a population by surveying a sample of that population (Fink, 2006). A search for instruments to survey CEOs about their perspectives on the role of $\mathrm{CEO}$ was not successful and resulted in the development of a survey for this study's purpose. The selfadministered survey includes a list of role descriptions created by utilizing a review of the literature. The list of roles appears in Table 6 and a list of role categories appears in Table 7.

\section{Measurement Validity and Reliability}

Measurement validity establishes evidence for using a particular instrument in a "particular setting with a particular population for a specific purpose" (Gliner et al., 2009, p. 165). Validity is based on the scores obtained from the instrument. There are three types of evidence supporting measurement validity of an instrument: content validity, criterion-related validity, and construct validity (Gall et al., 2005; Gliner et al., 2009). Measurement validity is more difficult to obtain than measurement reliability. Both reliability and consistency are necessary for measurement validity (Gliner et al., 2009). Content evidence can be provided by using an instrument that has already been used or by having experts review an instrument to verify its' content represents what the instrument is trying to measure. This instrument has not been used previously; however, these roles emerged from research over the past 40 years and, therefore, it is believed there is some level of content evidence for the roles on the survey. The use of expert 
Table 6

Role of CEO as Described by Previous Studies

\begin{tabular}{|c|c|c|}
\hline $\begin{array}{l}\text { Roles of CEO as described by } \\
\text { previous studies }\end{array}$ & References (theoretical) & References (empirical) In Chronological Order \\
\hline $\begin{array}{l}\text { Planning, organizing, } \\
\text { commanding, coordinating, } \\
\text { control }\end{array}$ & Classical school: Fayol, 1916 & Castaldi, 1986; Howe, 1988 \\
\hline $\begin{array}{l}\text { Planning, organizing, } \\
\text { controlling }\end{array}$ & Classical school: Davis, 1935, 1951 & \\
\hline $\begin{array}{l}\text { Planning, organizing, staffing, } \\
\text { coordinating, reporting, } \\
\text { budgeting, directing }\end{array}$ & Classical school: Gulick, 1937. & \\
\hline $\begin{array}{l}\text { Planning, organizing, } \\
\text { assembling resources, } \\
\text { directing, controlling }\end{array}$ & Classical school: Newman, 1951, 1960 & \\
\hline $\begin{array}{l}\text { Planning, organizing, } \\
\text { actuating, controlling }\end{array}$ & Classical school: Terry, 1953, 1956 & \\
\hline $\begin{array}{l}\text { Manage the business, manage } \\
\text { the workers \& manage the } \\
\text { work }\end{array}$ & Drucker, 1954 & \\
\hline
\end{tabular}




\begin{tabular}{|c|c|c|}
\hline \multicolumn{3}{|l|}{ Table 6 contd. } \\
\hline $\begin{array}{l}\text { Roles of CEO as described by } \\
\text { previous studies }\end{array}$ & References (theoretical) & References (empirical) In Chronological Order \\
\hline $\begin{array}{l}\text { Contact with people \& } \\
\text { organizations, communicating, } \\
\text { issue handling \& taking action }\end{array}$ & & Carlson, 1951 \\
\hline $\begin{array}{l}\text { Three interpersonal roles: } \\
\text { figurehead, liaison, and leader; } \\
\text { three informational roles: } \\
\text { monitor, disseminator, and } \\
\text { spokesperson; and four } \\
\text { decisional roles: entrepreneur, } \\
\text { disturbance handler, resource } \\
\text { allocator, and negotiator }\end{array}$ & & $\begin{array}{l}\text { Mintzberg, 1973; Lau, et al., 1979; Snyder \& Wheelen, } \\
\text { 1981; Carter, 1982; Kurke \& Aldrich, 1983; Howe, } \\
1988 \text {; Beggs \& Doolittle, 1988; Tengblad, } 2006\end{array}$ \\
\hline Creating culture & & Sashkin \& Fulmer, 1988 \\
\hline Technical expert & & Lau, et al., 1979; Pugliese, 1985 \\
\hline $\begin{array}{l}\text { Strategist } \\
\text { Motivator, analyzer, vision } \\
\text { setter, task master }\end{array}$ & $\begin{array}{l}\text { Steiner, et al., } 1981 \\
\text { Hart \& Quinn, } 1993\end{array}$ & Snyder \& Wheelen, 1981; Greenfeld, 1988 \\
\hline Innovator & Galambos, 1995. & \\
\hline $\begin{array}{l}\text { Linking organization to outside } \\
\text { world }\end{array}$ & Lafley, 2009; Drucker, 2004 & \\
\hline
\end{tabular}


Table 7

Six Role Categories Described Through Constant Comparative Analysis

\begin{tabular}{lllllll}
\hline $\begin{array}{l}\text { Role } \\
\text { Categories: }\end{array}$ & Informational & Interpersonal & Decisional & Operational & Strategic & Diplomacy \\
\hline \multirow{2}{*}{ Roles: } & $\begin{array}{l}\text { Monitor } \\
\text { Disseminator }\end{array}$ & $\begin{array}{l}\text { Leader } \\
\text { Motivator }\end{array}$ & $\begin{array}{l}\text { Entrepreneur } \\
\text { Disturbance } \\
\text { handler }\end{array}$ & $\begin{array}{l}\text { Organizer } \\
\text { Analyzer }\end{array}$ & $\begin{array}{l}\text { Coordinator } \\
\text { Innovator }\end{array}$ & $\begin{array}{l}\text { Link } \\
\text { Figurehead }\end{array}$ \\
& Spokesperson & Director & Conflict handler & Controller & Planner & Liaison \\
& Commander & & Resource allocator & Operator & Vision Setter & \\
& & & Taskmaster & Technical Expert & Strategist \\
& & & Consultant & Transformer \\
& & & Creator/maintainer \\
& & & Negotiator & & of culture \\
\end{tabular}


CEOs to review the instrument also provides content validity. The process of content analysis was used to induce the six categories of roles by analyzing the descriptions of the roles and grouping the descriptions that were most similar into the categories described in the literature.

Construct validity evidence can be provided by response processes in which participants do not answer with responses they believe to be socially desirable. It can also be provided with evidence based on internal structure, which is tested via factor analysis. For purposes of this study Cronbach's alpha was used to assess internal consistency reliability of the roles within the major categories: informational, interpersonal, decisional, operational, strategic, and diplomacy. Specifically, factor analysis and Cronbach's coefficient alpha are used for testing internal consistency reliability by measuring consistency in a multiple-item scale when enough responses are received (Leech, Barrett, \& Morgan, 2005). Cronbach's alpha is usually used “when the researcher has several Likert-type items (ratings from strongly disagree to strongly agree) that are summed or averaged to make a composite score or summated scale" (Gliner et al., 2009).

This instrument was tested using factor analysis. Factor analysis helps determine which items result in consistent responses from survey participants. Consistency in responses suggests certain items are measuring the same construct and fit the categories (Gall et al., 2005). The alpha is then based on the average correlation of each item with every other item and is used because it provides a measure of reliability based on one administration of a questionnaire or survey (Gliner et al., 2009). In this respect the use of alpha could significantly reduce the number of items on the survey for future use by removal of an item one at a time to examine the change in alpha. 


\section{Data Collection}

Data were downloaded from Qualtrics directly into SPSS for statistical analysis, eliminating the potential for human error from data input. All surveys with responses to the 31 roles were considered complete. Ideally, respondents allocated their time to each role category on a weekly basis. If this portion of the survey was skipped but the 31 role questions and demographic data were complete, the survey was still used. The five-point Likert scale items of strongly agree (one) to strongly disagree (five) were assigned numerical values of one to five. The number of hours spent in each role category was recorded as the actual number of hours indicated on the survey by the CEOs. A blank response was not recorded with any numerical value. Demographic information was coded using numerical values between one and five, depending on the number of levels the variables contained. Qualitative data in the form of text were also gathered, however, these data were not analyzed for this study due to IRB restrictions. These restrictions included obtaining written permission from each CEO to use e-mails and other nonsolicited comments.

Upon completion of data collection exploratory data analysis was conducted to review the responses for completeness and skewness, to look for outliers, to understand the descriptive nature of the data, and to clean the data (Gliner et al., 2009; Leong \& Austin, 2006).

\section{Research Questions and Data Analysis}

To answer the first two research questions, "what is the role of CEO in the U.S.?" and "how much time do CEOs estimate they spend in each role category?" descriptive statistics were used to identify the roles most strongly agreed with by the participants and 
the average amount of time spent in each role category, when available. The third question, "what roles are identified by CEOs that were not identified by a review of literature on the role of CEO" was answered using qualitative data provided by the study participants.

RH1 was tested using an independent samples t-test on the 31 role descriptions and Mann-Whitney $U$ for the role categories due to the skewness of these data. The appropriate statistic for evaluating two levels of the independent variable (gender) with a normal or scale dependent variable, when assumptions are not markedly violated is the independent samples t-test. The independent t-test provides the statistical significance of the difference in gender on the independent variable. Effect size was also calculated. If the assumptions are markedly violated the appropriate statistic is Mann-Whitney U (Morgan, Leech, Gloeckner, \& Barrett, 2011).

RH1a and RH1b were tested with descriptive statistics by comparing the time approximations in the interpersonal and operational role categories between males and females.

RH2 was tested using descriptive statistics.

RH3 was tested using a one-way ANOVA and Kruskal-Wallis, which was appropriate for testing time spent in role categories as this data were skewed.

RH4 was tested using Mann Whitney-U due to the skewness of the data.

RH5 was tested using multiple regression. The statistic used to compare several independent variables with the purpose of predicting a dependent, criterion variable is multiple linear regression (Morgan et al., 2011). While none of the demographic independent variables can be considered causal for the role of CEO, they may impact the 
roles that CEOs identify and spend the majority of their time in. It may also be useful to make comparisons to prior studies using more current data. These statistics help in understanding the associations of multiple independent variables with the independent variables (Morgan et al., 2011). The dependent variables considered were the agreement with the CEO roles and the amount of time allocated to the role categories.

RH6 was tested using an independent sample t-test for the agreement with roles and Mann-Whitney $\mathrm{U}$ for the approximations to role categories.

RH7 was tested using an independent sample t-test for the agreement with roles and Mann-Whitney $\mathrm{U}$ for the approximations to role categories.

RH8 was tested using a one-way ANOVA, Kruskal-Wallis, and Mann-Whitney U.

\section{Limitations and Weaknesses}

This study was delimited to CEOs in the U.S., the result of which the following limitation is likely to ensue: the study cannot be considered applicable to middle or lower-level managers or to CEOs in other countries.

This study was limited by the response rate ultimately achieved, impacting the ability to generalize the results to the total population of CEOs in the U.S., or external validity. The confidential nature of the survey is a limitation in that who chose to complete the survey is unknown. The honesty in the time estimations are unknown and the difference between the time allocations made on the survey and the actual effort expended in the roles is also unknown. This study utilized a survey instrument designed specifically for the study and therefore validity and reliability of the instrument may be interpreted as weaknesses of the research. 


\section{Summary}

This chapter has outlined the methodology and underlying philosophy for conducting the research study on the role of CEO. It has described the methods used for sampling and collecting data and has highlighted the limitations and weaknesses in the study. The following chapter will present the sample and the results of the survey. 


\section{CHAPTER FOUR: RESULTS}

This chapter presents the results of the survey conducted to answer the research questions and to test the research hypotheses. This chapter describes the sample, explains the exploratory factor analysis conducted on the survey instrument, and presents the statistical results in the order the research questions and hypotheses were presented in Chapter Three.

\section{Description of Sample}

The sample for this study was obtained through professional relationships and two databases of U.S. companies containing CEO e-mail addresses. The accessible population comprised 28,018 possible study participants however 2 e-mails were returned due to invalid e-mail addresses. After receiving IRB approval (Appendix F), CEOs were emailed a link to the survey (Appendix G) along with the appropriate IRB consent information (Appendix H). A total of 1,768 surveys were started, 1,237 were completed, and 1,202 were considered usable, for a total response rate of $4.29 \%$. Table 8 is a summary of the response rates. 
Table 8

Role of CEO Survey Response Rates

\begin{tabular}{|c|c|c|c|c|c|c|}
\hline Sample & $\begin{array}{r}\text { Total E- } \\
\text { mails } \\
\text { Sent } \\
\end{array}$ & $\begin{array}{l}\text { Invalid } \\
\text { E-mail }\end{array}$ & $\begin{array}{r}\text { Total E- } \\
\text { mails } \\
\text { Sent } \\
\end{array}$ & $\begin{array}{r}\text { Surveys } \\
\text { Started }\end{array}$ & $\begin{array}{r}\text { Surveys } \\
\text { Finished }\end{array}$ & $\begin{array}{r}\text { Response } \\
\text { Rate \% }\end{array}$ \\
\hline $\begin{array}{l}\text { Convenience/ } \\
\text { Professional } \\
\text { Contacts }\end{array}$ & 47 & 0 & 47 & 28 & 25 & 53.19 \\
\hline $\begin{array}{l}\text { Convenience/ } \\
\text { Schuster } \\
\text { Linked-In } \\
\text { Contacts }\end{array}$ & 40 & 0 & 40 & 7 & 6 & 15.00 \\
\hline $\begin{array}{l}\text { Convenience/ } \\
\text { CSU Alumni } \\
\text { website } \\
\text { Contacts }\end{array}$ & 40 & 0 & 40 & 4 & 4 & 15.00 \\
\hline $\begin{array}{l}\text { Random/ } \\
\text { Lexis-Nexis } \\
\text { Database }\end{array}$ & 245 & 0 & 245 & 4 & 1 & .41 \\
\hline $\begin{array}{l}\text { Random/ } \\
\text { Purchased } \\
\text { Database }\end{array}$ & 27,646 & 2 & 27,644 & 1,725 & 1,201 & 4.34 \\
\hline $\begin{array}{l}\text { Unusable } \\
\text { Surveys }\end{array}$ & & & & & נכנ & \\
\hline TOTAL & 28,018 & 2 & 28,016 & 1,768 & 1,202 & 4.29 \\
\hline
\end{tabular}

Non-respondents

Non-respondents totaled 26,784. This is a substantial, but not unexpected, number of non-responders. According to Dillman (2007) non-response error is one source of error that results from survey research. Other errors include sampling error, coverage error, and measurement error. An increase in any one of these types of error may cause the results of a study to "become increasingly suspect and decreasingly valuable as evidence of the 
characteristics in other audiences" (Dooley \& Lindner, 2003, p. 100). There are several recommended solutions for controlling for nonresponse error after follow-up procedures have been used. These include "ignore nonrespondents; compare respondents to population on characteristics known before the study; compare respondents to nonrespondents on characteristics known before the study; compare early to late respondents; and 'double-dip,' or sample, nonrespondents” (Dooley \& Lindner, 2003, p. 102).

Lindner, Murphy, and Briers (2001) have suggested comparing the last wave of 30 respondents to early respondents as one defensible and "generally accepted procedure(s) for handling nonresponse error as a threat to external validity of research findings" (Dooley \& Lindner, 2003, p. 103). In an independent sample t-test of the first 30 and last 30 responses received there were no statistically significant differences on agreement with role categories or time spent in the role categories between the two groups sampled.

Demographics

The sample is comprised of 1,048 males (87.5\%) and 150 females (12.5\%). The S\&P Fortune 500 (2008) contained approximately $13.5 \%$ female CEOs, making this sample seem fairly representative in terms of gender. The majority of respondents range in age from 45 to 64 , with $21.3 \%$ between 50 and 54, 20.9\% between 55 and 59, and $18.7 \%$ between 60 and 64 . The age distribution was also similar to the age distribution of CEOs in S\&P Fortune 500 companies. Average tenure in current job is 12.4 years and the average tenure as a CEO is 11.6 years. Current turnover rates of CEOs suggest this sample of CEOs has longer tenure on average. Average company size was 962 employees 
and \$253 million in sales revenues. The U.S. Census Bureau estimates that $99 \%$ of companies in the U.S. have fewer than 500 employees. This implies that this sample of CEOs come from a more diverse range of company sizes. Additional demographic data are provided in Tables 9 and 10.

\section{Exploratory Factor Analysis}

The primary research focus was not instrument development, however since the survey instrument utilized was designed specifically for this study, it is appropriate to run exploratory factor analysis (EFA) to examine the reliability and validity of the instrument (Yang, 2005). The purpose of EFA is "to discover the common factors that drive interrelationships among the observable variables" (Yang, 2005, p. 184). EFA is preferable over confirmatory factor analysis (CFA) "in early stages of scale development ... to explore the underlying factor structure and to determine how measurement items load on factors that have not been clearly revealed" (Yang, 2005, p. 185). Principal component factor analysis (PCA) was run with Varimax (orthogonal) rotation. Rotation can be described as "mathematical alignment" of variables in which "variables that cluster closely together on some axis are presumably related to each other" (Leong \& Austin, 2006, p. 251). Rotation is used "to improve the psychometric properties (i.e., reliability and validity) and substantive meanings of extracted factors" (Yang, 2005, p. 192). Principal axis factor analysis (PAA) was also run with Promax (oblique) rotation and the results were not substantially different. PCA was used for this study since PCA is the most commonly used form of factor analysis (Leong \& Austin, 2006). 
Table 9

Demographic Data Provided by Survey Respondents

\begin{tabular}{|c|c|c|c|c|}
\hline Participant Demographics & Mean & $\begin{array}{r}\text { Standard } \\
\text { Deviation }\end{array}$ & Frequency & $\%$ \\
\hline Age: & 54.02 & 8.58 & & \\
\hline$<39$ & & & 56 & 5.00 \\
\hline $40-44$ & & & 92 & 8.20 \\
\hline $45-49$ & & & 180 & 16.10 \\
\hline $50-54$ & & & 238 & 21.30 \\
\hline $55-59$ & & & 234 & 20.90 \\
\hline $60-64$ & & & 209 & 18.70 \\
\hline $65-69$ & & & 85 & 7.60 \\
\hline$>70$ & & & 23 & 2.10 \\
\hline \multicolumn{5}{|l|}{ Gender: } \\
\hline M & & & 1,048 & 87.50 \\
\hline $\mathrm{F}$ & & & 150 & 12.50 \\
\hline Years in Current Job: & 12.43 & 10.10 & & \\
\hline$<1$ & & & 6 & .50 \\
\hline $1-5$ & & & 296 & 25.02 \\
\hline $6-10$ & & & 284 & 24.01 \\
\hline $11-15$ & & & 171 & 14.45 \\
\hline $16-20$ & & & 178 & 15.05 \\
\hline $21-25$ & & & 96 & 8.11 \\
\hline$>25$ & & & 152 & 12.86 \\
\hline
\end{tabular}




\begin{tabular}{|c|c|c|c|c|}
\hline \multicolumn{5}{|l|}{ Table 9 contd. } \\
\hline Participant Demographics & Mean & $\begin{array}{r}\text { Standard } \\
\text { Deviation }\end{array}$ & Frequency & $\%$ \\
\hline Years as a CEO: & 11.63 & 8.61 & & \\
\hline$<1$ & & & 6 & .50 \\
\hline $1-5$ & & & 339 & 28.71 \\
\hline $6-10$ & & & 326 & 27.60 \\
\hline $11-15$ & & & 222 & 18.80 \\
\hline $16-20$ & & & 117 & 9.91 \\
\hline $21-25$ & & & 73 & 6.18 \\
\hline$>25$ & & & 98 & 8.30 \\
\hline \multicolumn{5}{|l|}{ Last Degree Earned: } \\
\hline High School & & & 56 & 4.70 \\
\hline Associates Degree & & & 28 & 2.30 \\
\hline Bachelors Degree & & & 430 & 35.90 \\
\hline Masters Degree & & & 479 & 40.00 \\
\hline $\mathrm{PhD}$ & & & 95 & 7.90 \\
\hline Other & & & 110 & 9.20 \\
\hline \multicolumn{5}{|c|}{ Major of Last Degree or Industry Focus: } \\
\hline Operations & & & 124 & $10.7 \%$ \\
\hline Finance & & & 204 & $17.6 \%$ \\
\hline Public Relations & & & 14 & $1.2 \%$ \\
\hline Technical/Engineering & & & 236 & $20.4 \%$ \\
\hline Other & & & 580 & $50.1 \%$ \\
\hline
\end{tabular}


Table 10

Demographics of Companies Included in Survey

\begin{tabular}{|c|c|c|c|c|}
\hline $\begin{array}{l}\text { Company } \\
\text { Demographics }\end{array}$ & Mean & $\begin{array}{l}\text { Standard } \\
\text { Deviation } \\
\end{array}$ & Frequency & $\%$ \\
\hline $\begin{array}{l}\text { Company } \\
\text { Size/Employees: }\end{array}$ & 962.0 & 10,487 & & \\
\hline $\begin{array}{l}\text { Small }(<100) \\
\text { Medium }(100<500) \\
\text { Large }(<500)\end{array}$ & & & $\begin{array}{l}646 \\
302 \\
196\end{array}$ & $\begin{array}{l}56.5 \\
26.4 \\
17.1\end{array}$ \\
\hline $\begin{array}{l}\text { Total } \\
\text { Missing } \\
\mathrm{N}\end{array}$ & & & $\begin{array}{r}1,144 \\
58 \\
1,202\end{array}$ & \\
\hline $\begin{array}{l}\text { Company Size/Sales } \\
\text { Revenue: }\end{array}$ & $\$ 252.6 \mathrm{M}$ & $\$ 2.5 B$ & & \\
\hline $\begin{array}{l}\$<100 \mathrm{~K} \\
\$ 100 \mathrm{~K}-\$ 499 \mathrm{~K} \\
\$ 500 \mathrm{~K}-\$ 999 \mathrm{~K} \\
\$ 1 \mathrm{M}-\$ 4.9 \mathrm{M} \\
\$ 5 \mathrm{M}-\$ 9.9 \mathrm{M} \\
\$ 10 \mathrm{M}-\$ 49.9 \mathrm{M} \\
\$ 50 \mathrm{M}-\$ 99.9 \mathrm{M} \\
\$ 100 \mathrm{M}-\$ 249.9 \mathrm{M} \\
\$ 250 \mathrm{M}-\$ 499.9 \mathrm{M} \\
\$ 500 \mathrm{M}-\$ 999.9 \mathrm{M} \\
\$ 1 \mathrm{~B}-\$ 2.499 \mathrm{~B} \\
>\$ 2.5 \mathrm{~B}\end{array}$ & & & $\begin{array}{r}5 \\
21 \\
26 \\
175 \\
140 \\
334 \\
95 \\
99 \\
46 \\
41 \\
21 \\
16\end{array}$ & $\begin{array}{r}.5 \\
2.1 \\
2.6 \\
17.2 \\
13.7 \\
32.8 \\
9.3 \\
9.7 \\
4.5 \\
4.0 \\
2.1 \\
1.6\end{array}$ \\
\hline $\begin{array}{l}\text { Total } \\
\text { Missing } \\
\mathrm{N}\end{array}$ & & & $\begin{array}{r}1,019 \\
183 \\
1,202\end{array}$ & \\
\hline $\begin{array}{l}\text { Privately-held } \\
\text { Publicly-held }\end{array}$ & & & $\begin{array}{r}1,015 \\
164\end{array}$ & $\begin{array}{l}86.1 \\
13.9\end{array}$ \\
\hline
\end{tabular}


The sample size was adequate for factor analysis. Leong and Austin (2006) recommend giving a survey to at least five times as many people as there are questions on the survey. The KMO (Kaiser-Meyer-Olkin) measure of sampling adequacy should be evaluated prior to running factor analysis. This statistic "reflects the degree to which it is likely that the common factors explain the observed correlations among the variables" (Leong \& Austin, 2006, p. 250). A small value (less than .50) of the KMO statistic indicates correlations between variables are not accounted for by common factors. A score of .80 is described as "meritorious" (Leong \& Austin, 2006, p. 250) and the score for this survey was .892 .

Principal component analysis revealed seven components comprising $52.4 \%$ of the total variance explained (Table 11). Using a loading of .40, appropriate for a new survey (Yang, 2005) the 31 items sorted into seven components with 27 items retained. Three of the roles, entrepreneur, conflict handler, and consultant did not load. The fourth excluded role, commander, did not fit logically with the diplomacy roles and the decision was made to exclude the role.

Three role categories did not change as a result of PCA. The interpersonal (component \#5), strategic (component \#2), and diplomacy (component \#4) role categories remained intact. The decisional (component \#6) role category decreased from eight to four roles. Previously considered decisional roles, entrepreneur and conflict handler did not load, and problem solver and negotiator loaded with spokesperson and technical expert to create the new informational (component \#3) role category. The operational (component \#1) role category decreased from six to four roles, the consultant role did not 
Table 11

Rotated Component Matrix ${ }^{a}$

\begin{tabular}{|c|c|c|c|c|c|c|c|}
\hline Role & & & & ompo & & & \\
\hline & 1 & 2 & 3 & 4 & 5 & 6 & 7 \\
\hline Monitor & & & & & & & .768 \\
\hline Disseminator & & & & & & & .756 \\
\hline Spokesperson & & & .713 & & & & \\
\hline Negotiator & & & .501 & & & & \\
\hline Problem Solver & & & .646 & & & & \\
\hline Technical Expert & & . & .524 & & & & \\
\hline Commander & & & & .567 & & & \\
\hline Link & & & & .714 & & & \\
\hline Figurehead & & & & .683 & & & \\
\hline Liaison & & & & .617 & & & \\
\hline Coordinator & & .463 & & & & & \\
\hline Innovator & & .626 & & & & & \\
\hline Planner & & .477 & & & & & \\
\hline Vision Setter & & .517 & & & & & \\
\hline Strategist & & .563 & & & & & \\
\hline Transformer & & .697 & & & & & \\
\hline $\begin{array}{l}\text { Creator/Maintainer } \\
\text { of Culture }\end{array}$ & & .484 & & & & & \\
\hline Leader & & & & & .739 & & \\
\hline Motivator & & & & & .805 & & \\
\hline Director & & & & & .448 & & \\
\hline Entrepreneur & & & & & & & \\
\hline Disturbance & & & & & & .430 & \\
\hline Handler & & & & & & & \\
\hline Conflict Handler & & & & & & & \\
\hline Resource & & & & & & .521 & \\
\hline Allocator & & & & & & & \\
\hline Task Master & & & & & & .521 & \\
\hline Staffer & & & & & & .531 & \\
\hline Organizer & .749 & & & & & & \\
\hline Analyzer & .683 & & & & & & \\
\hline Controller & .819 & & & & & & \\
\hline Operator & .720 & & & & & & \\
\hline Consultant & & & & & & & \\
\hline
\end{tabular}

${ }^{\text {a }}$ Rotation converged in 13 iterations. 
load and the technical expert role moved. Component seven was eliminated as it contained two items that contributed $3.4 \%$ of the variance (Table 12). All seven components had eigenvalues greater than 1.0, meaning that the component is useful. A value less than 1.0 indicates the factor "explains less information than a single item would have explained" (Leech et al., 2005, p. 82). Elimination of the seventh category left six categories consisting of 25 roles, closely reflecting the original six role categories. It is important to note that data collected pertaining to time approximations were made according to the original six role categories and this data remains intact.

Table 12

Eigenvalues and Variances Explained

\begin{tabular}{llclll}
\hline \multirow{2}{*}{$\begin{array}{l}\text { Component } \\
\end{array}$} & \# of Items & Total & $\begin{array}{c}\text { Initial Eigenvalues } \\
\text { \% of } \\
\text { Variance }\end{array}$ & $\begin{array}{l}\text { Cumulative } \\
\%\end{array}$ & $\begin{array}{l}\text { Rotation } \\
\text { Total }\end{array}$ \\
\hline 1 & 4 & 6.869 & 22.157 & 22.157 & 3.178 \\
2 & 8 & 2.631 & 8.488 & 30.645 & 2.849 \\
3 & 4 & 1.821 & 5.875 & 36.520 & 2.406 \\
4 & 4 & 1.413 & 4.558 & 41.078 & 2.399 \\
5 & 3 & 1.341 & 4.327 & 45.405 & 1.962 \\
6 & 5 & 1.138 & 3.672 & 49.077 & 1.894 \\
7 & 2 & 1.040 & 3.356 & 52.433 & 1.567 \\
& & & & & \\
\hline
\end{tabular}

Note: Extraction method: Principal component analysis.

There were no research questions or hypotheses specifically addressing the validity or reliability of the instrument. Cronbach's alpha is the normal test of reliability and was calculated at .88 for all 31 components. Alpha should be positive and is usually .70 or larger to provide support for internal consistency reliability (Morgan et al., 2011). Cronbach's alpha by component ranged from .43 to .82 (Table 13). 
Table 13

Component Means, Standard Deviations, Reliabilities, Variances, and Item Loadings for the CEO Role Survey

\begin{tabular}{|c|c|c|c|c|c|}
\hline Factors and Items & $\mathrm{M}$ & $\mathrm{SD}$ & $\alpha$ & Item Loading & $\begin{array}{c}\text { Variance } \\
\text { Explained \% }\end{array}$ \\
\hline Factor 1 - Operational Roles & 2.49 & .74 & .82 & & 22.16 \\
\hline Organizer: I make sure deadlines are met & & & & .75 & \\
\hline $\begin{array}{l}\text { Analyzer: I focus on efficient management of the internal } \\
\text { operating system in the interest of serving existing } \\
\text { products/markets. }\end{array}$ & & & & .68 & \\
\hline Controller: I make sure projects are completed on time. & & & & .82 & \\
\hline $\begin{array}{l}\text { Operator: I make sure that day-to-day operations are being } \\
\text { completed in a satisfactory manner. }\end{array}$ & & & & .72 & \\
\hline Factor 2 - Strategic Roles & 1.78 & .47 & .75 & & 8.49 \\
\hline $\begin{array}{l}\text { Coordinator: I make sure all efforts are coordinated towards } \\
\text { the goals and strategic plan of the organization. }\end{array}$ & & & & .46 & \\
\hline $\begin{array}{l}\text { Innovator: I guide the organization into new cycles of } \\
\text { innovation. }\end{array}$ & & & & .63 & \\
\hline Planner: I do both short-term and long-term planning. & & & & .48 & \\
\hline $\begin{array}{l}\text { Vision Setter: I create a sense of identity and mission for my } \\
\text { organization. }\end{array}$ & & & & .52 & \\
\hline Strategist: I craft the organization's strategy. & & & & .56 & \\
\hline $\begin{array}{l}\text { Transformer: I transform the organization as markets and } \\
\text { the external environment change. }\end{array}$ & & & & .70 & \\
\hline
\end{tabular}


Factor 3 - Informational Roles

Spokesperson: I disseminate the organization's information into the business world.

Negotiator: I am compelled to enter negotiations on behalf of my organization.

Problem solver: I am the person who solves the organization's problems.

Technical expert: I am the expert on product and market.

Factor 4 - Diplomacy Roles

Link: I link the external world to the world inside the organization.

Figurehead: I represent the organization in formal matters.

Liaison: I interact with peers and others outside the organization to gain favors and information.

Factor 5 - Interpersonal Roles

Leader: I lead and motivate my subordinates.

Motivator: I create and set a sense of excitement and vitality in the organization, challenging people to gain new competencies and achieve higher levels of performance. Director: I make sure the right people are in the right place at the right time doing the right things. 


\begin{tabular}{|c|c|c|c|c|c|}
\hline $\begin{array}{l}\text { Table } 13 \text { contd. } \\
\text { Factors and Items }\end{array}$ & M & SD & $\alpha$ & Item Loading & $\begin{array}{c}\text { Variance } \\
\text { Explained \% }\end{array}$ \\
\hline Factor 6 - Decisional Roles & 1.54 & .41 & .57 & & 3.67 \\
\hline $\begin{array}{l}\text { Disturbance handler: I take charge when my organization is } \\
\text { threatened. }\end{array}$ & & & & .43 & \\
\hline $\begin{array}{l}\text { Resource allocator: I decide where my organization will } \\
\text { expend efforts and resources. }\end{array}$ & & & & .52 & \\
\hline $\begin{array}{l}\text { Task Master: I have a strong focus on results or getting the } \\
\text { job done. }\end{array}$ & & & & .52 & \\
\hline $\begin{array}{l}\text { Staffer: I make sure the right people are hired for the right } \\
\text { positions. }\end{array}$ & & & & .53 & \\
\hline
\end{tabular}

Note: Response scale for the CEO Role Survey (strongly agree $=1$, agree $=2$, neither agree nor disagree $=3$, disagree $=4$, strongly disagree $=5$ ) . 


\section{Research Questions}

\section{Research Question One}

Research question one comprises the overarching research question for this study, what is the role of CEO in the U.S.? Tables 14 through 19 summarize the frequencies associated with the six role categories and 31 roles. The informational role category changed substantially as a result of PCA retaining only one original role. Less than $40 \%$ of participants strongly agreed or agreed that the problem solver (Lau et al., 1979) and technical expert roles (Lau et al., 1979) comprise CEO roles. Less than $50 \%$ of the participants strongly agree or agree that spokesperson (Mintzberg, 1973) was a CEO role.

Table 14

Agreement with Informational Role Categories

\begin{tabular}{|c|c|c|c|c|c|c|c|c|}
\hline Role & $\mathrm{SA}$ & $\mathrm{A}$ & $\begin{array}{l}\text { Neither } \\
\text { A nor D }\end{array}$ & $\mathrm{D}$ & $\mathrm{SD}$ & $\mathrm{SA} / \mathrm{A}$ & Neither & $\mathrm{D} / \mathrm{SD}$ \\
\hline Spokesperson & 172 & 389 & 280 & 282 & 77 & $46.8 \%$ & $23.3 \%$ & $29.9 \%$ \\
\hline Negotiator & 322 & 458 & 291 & 116 & 6 & $65.4 \%$ & $24.4 \%$ & $10.2 \%$ \\
\hline $\begin{array}{l}\text { Problem } \\
\text { Solver }\end{array}$ & 118 & 316 & 469 & 254 & 43 & $36.1 \%$ & $39.1 \%$ & $24.8 \%$ \\
\hline $\begin{array}{l}\text { Technical } \\
\text { Expert }\end{array}$ & 169 & 290 & 387 & 306 & 43 & $38.4 \%$ & $32.4 \%$ & $29.2 \%$ \\
\hline
\end{tabular}

There was strong agreement across the interpersonal role category consisting of leader, motivator, and director (Table 15). Over $90 \%$ of all participants strongly agreed or agreed that these were roles of a CEO. This role category remained intact after PCA. 
Table 15

Agreement with Interpersonal Role Categories

\begin{tabular}{lcclccccc}
\hline Role & SA & A & $\begin{array}{l}\text { Neither } \\
\text { A nor } \\
\text { D }\end{array}$ & D & SD & SA/A & Neither & D/SD \\
\hline Leader & 743 & 440 & 12 & 3 & 0 & $98.7 \%$ & $1.0 \%$ & $0.3 \%$ \\
Motivator & 696 & 457 & 44 & 4 & 0 & $96.0 \%$ & $3.7 \%$ & $0.3 \%$ \\
Director & 537 & 546 & 97 & 16 & 3 & $90.3 \%$ & $8.1 \%$ & $1.6 \%$ \\
\hline
\end{tabular}

There was also strong agreement with the decisional role categories with $87.7 \%$ or more participants with a strongly agree or agree response to all four roles. PCA decreased the number of roles in this category from eight to four.

Table 16

Agreement with Decisional Role Categories

\begin{tabular}{lcccccccc}
\hline Role & SA & A & $\begin{array}{l}\text { Neither } \\
\text { A nor } \\
\text { D }\end{array}$ & D & SD & SA/A & Neither & D/SD \\
\hline $\begin{array}{l}\text { Disturbance } \\
\text { Handler }\end{array}$ & 887 & 272 & 37 & 3 & 0 & $96.7 \%$ & $3.0 \%$ & $0.3 \%$ \\
$\begin{array}{l}\text { Resource } \\
\text { Allocator }\end{array}$ & 485 & 609 & 79 & 23 & 0 & $91.5 \%$ & $6.6 \%$ & $1.9 \%$ \\
$\begin{array}{l}\text { Task } \\
\text { Master }\end{array}$ & 725 & 427 & 37 & 4 & 0 & $96.6 \%$ & $3.1 \%$ & $0.3 \%$ \\
Staffer & 470 & 574 & 130 & 16 & 1 & $87.7 \%$ & $10.9 \%$ & $1.4 \%$ \\
& & & & & & & & \\
\hline
\end{tabular}


The operational role categories received between $47.4 \%$ and $65.6 \%$ of strongly agree/agree responses. Clearly $25 \%$ of respondent neither agreed nor disagreed that operational roles represent roles of a CEO. Almost 30\% disagreed or strongly disagreed that operator is a CEO role. These findings are consistent with the pilot study but conflict with prior research (Howe, 1988). This category was reduced by two roles as a result of PCA.

Table 17

Agreement with Operational Role Categories

\begin{tabular}{lcclccccc}
\hline Role & SA & A & $\begin{array}{l}\text { Neither } \\
\text { A nor } \\
\text { D }\end{array}$ & D & SD & SA/A & Neither & D/SD \\
\hline Organizer & 164 & 621 & 290 & 118 & 4 & $65.6 \%$ & $24.2 \%$ & $10.2 \%$ \\
Analyzer & 162 & 564 & 304 & 155 & 9 & $60.8 \%$ & $25.5 \%$ & $13.7 \%$ \\
Controller & 142 & 518 & 354 & 173 & 10 & $55.1 \%$ & $29.6 \%$ & $15.3 \%$ \\
Operator & 96 & 468 & 300 & 292 & 39 & $47.2 \%$ & $25.1 \%$ & $27.7 \%$ \\
& & & & & & & & \\
\hline
\end{tabular}

The strategic role category was left intact by PCA. Participants' responses ranged from $80.0 \%$ to $93.5 \%$ in the strongly agree or agree category. The lowest response, $80.0 \%$ was the planner role in which $11.8 \%$ of participants neither agreed nor disagreed, and $8.2 \%$ disagreed or strongly disagreed that this is a role of the CEO. 
Table 18

Agreement with Strategic Role Categories

\begin{tabular}{|c|c|c|c|c|c|c|c|c|}
\hline Role & SA & $\mathrm{A}$ & $\begin{array}{l}\text { Neither } \\
\text { A nor } \\
\text { D }\end{array}$ & D & $\mathrm{SD}$ & $\overline{\mathrm{SA} / \mathrm{A}}$ & Neither & $\mathrm{D} / \mathrm{SD}$ \\
\hline Coordinator & 447 & 640 & 89 & 21 & 0 & $90.8 \%$ & $7.4 \%$ & $1.8 \%$ \\
\hline Innovator & 438 & 613 & 127 & 16 & 2 & $87.9 \%$ & $10.6 \%$ & $1.5 \%$ \\
\hline Planner & 357 & 599 & 141 & 94 & 4 & $80.0 \%$ & $11.8 \%$ & $8.2 \%$ \\
\hline Vision Setter & 610 & 502 & 60 & 17 & 0 & $93.5 \%$ & $5.1 \%$ & $1.4 \%$ \\
\hline Strategist & 406 & 584 & 159 & 40 & 3 & $83.1 \%$ & $13.3 \%$ & $3.6 \%$ \\
\hline Transformer & 364 & 629 & 162 & 34 & 1 & $83.4 \%$ & $13.6 \%$ & $3.0 \%$ \\
\hline $\begin{array}{l}\text { Creator/Maintainer } \\
\text { of Culture }\end{array}$ & 532 & 554 & 78 & 20 & 2 & $91.6 \%$ & $6.6 \%$ & $1.8 \%$ \\
\hline
\end{tabular}

The diplomacy role categories were also left intact by PCA. The newest role in this category, link, only received a strongly agree/agree score of $66.9 \%$ while $26 \%$ of participants neither agreed nor disagreed that this is a CEO role.

Table 19

Agreement with Diplomacy Role Categories

\begin{tabular}{lcclccccc}
\hline Role & SA & A & $\begin{array}{l}\text { Neither } \\
\text { A nor } \\
\text { D }\end{array}$ & D & SD & SA/A & Neither & D/SD \\
\hline Link & 223 & 578 & 311 & 77 & 9 & $66.9 \%$ & $26.0 \%$ & $7.1 \%$ \\
Figurehead & 504 & 545 & 122 & 25 & 3 & $87.5 \%$ & $10.2 \%$ & $2.3 \%$ \\
Liaison & 321 & 564 & 215 & 68 & 24 & $74.2 \%$ & $18.0 \%$ & $7.8 \%$ \\
& & & & & & & & \\
\hline
\end{tabular}


Table 20 presents the frequencies associated with the six roles that were eliminated through the factor analysis procedure. Four of these roles, monitor, disseminator, entrepreneur, and consultant received strongly agree or agree scores of $90 \%$ or higher. Table 21 summarizes the descriptive statistics associated with the 31 roles.

Table 20

Agreement With the Six Roles Eliminated Through Factor Analysis

\begin{tabular}{lcccccccc}
\hline Role & SA & A & $\begin{array}{l}\text { Neither } \\
\text { A nor } \\
\text { D }\end{array}$ & D & SD & SA/A & Neither & D/SD \\
\hline Monitor & 777 & 395 & 19 & 8 & 3 & $97.5 \%$ & $1.5 \%$ & $1.0 \%$ \\
Disseminator & 650 & 500 & 44 & 7 & 0 & $95.7 \%$ & $3.7 \%$ & $0.6 \%$ \\
Commander & 205 & 533 & 292 & 152 & 9 & $62.0 \%$ & $24.5 \%$ & $13.5 \%$ \\
Entrepreneur & 680 & 467 & 45 & 6 & 0 & $95.7 \%$ & $3.8 \%$ & $0.5 \%$ \\
Conflict & 347 & 568 & 213 & 62 & 5 & $76.6 \%$ & $17.8 \%$ & $5.6 \%$ \\
Handler & & & & & & & & \\
Consultant & 372 & 712 & 87 & 14 & 2 & $91.3 \%$ & $7.3 \%$ & $1.4 \%$ \\
& & & & & & & & \\
\hline
\end{tabular}


Table 21

Descriptive Statistics, Agreement with 31 Roles ( 1 = Strongly Agree, $5=$ Strongly

Disagree)

\begin{tabular}{|c|c|c|c|c|c|c|c|}
\hline & $\mathrm{N}$ & Minimum & Maximum & Mean & $\begin{array}{l}\text { Standard } \\
\text { Deviation }\end{array}$ & $\begin{array}{l}\text { Skewness } \\
\text { Statistic } \\
\end{array}$ & $\begin{array}{l}\text { Standard } \\
\text { Error }\end{array}$ \\
\hline $\begin{array}{l}\text { Disturbance } \\
\text { Handler }\end{array}$ & 1199 & 1 & 4 & 1.30 & 0.534 & 1.723 & .071 \\
\hline Monitor & 1202 & 1 & 5 & 1.39 & 0.583 & 1.710 & .071 \\
\hline Leader & 1198 & 1 & 4 & 1.39 & 0.524 & 0.900 & .071 \\
\hline Task Master & 1193 & 1 & 4 & 1.43 & 0.572 & 1.042 & .071 \\
\hline Motivator & 1201 & 1 & 4 & 1.46 & 0.585 & 0.941 & .071 \\
\hline Entrepreneur & 1198 & 1 & 4 & 1.48 & 0.596 & 0.967 & .071 \\
\hline Disseminator & 1201 & 1 & 4 & 1.51 & 0.599 & 0.894 & .071 \\
\hline Vision Setter & 1189 & 1 & 4 & 1.57 & 0.658 & 1.044 & .071 \\
\hline $\begin{array}{l}\text { Creator- } \\
\text { Maintainer of } \\
\text { Culture }\end{array}$ & 1186 & 1 & 5 & 1.66 & 0.692 & 1.005 & .071 \\
\hline Director & 1199 & 1 & 5 & 1.67 & 0.703 & 0.973 & .071 \\
\hline $\begin{array}{l}\text { Resource } \\
\text { Allocator }\end{array}$ & 1196 & 1 & 4 & 1.70 & 0.677 & 0.824 & .071 \\
\hline Figurehead & 1199 & 1 & 5 & 1.73 & 0.746 & 0.929 & .071 \\
\hline Coordinator & 1197 & 1 & 4 & 1.74 & 0.670 & 0.716 & .071 \\
\hline Staffer & 1191 & 1 & 5 & 1.74 & 0.707 & 0.695 & .071 \\
\hline Innovator & 1196 & 1 & 5 & 1.77 & 0.699 & 0.700 & .071 \\
\hline Consultant & 1187 & 1 & 5 & 1.79 & 0.636 & 0.645 & .071 \\
\hline Strategist & 1192 & 1 & 5 & 1.87 & 0.783 & 0.783 & .071 \\
\hline Transformer & 1190 & 1 & 5 & 1.89 & 0.743 & 0.648 & .071 \\
\hline Planner & 1195 & 1 & 5 & 1.99 & 0.873 & 0.858 & .071 \\
\hline $\begin{array}{l}\text { Conflict } \\
\text { Handler }\end{array}$ & 1195 & 1 & 5 & 2.00 & 0.845 & 0.676 & .071 \\
\hline Liaison & 1192 & 1 & 5 & 2.09 & 0.923 & 0.881 & .071 \\
\hline Negotiator & 1193 & 1 & 5 & 2.18 & 0.957 & 0.433 & .071 \\
\hline Link & 1198 & 1 & 5 & 2.22 & 0.849 & 0.482 & .071 \\
\hline Organizer & 1197 & 1 & 5 & 2.31 & 0.841 & 0.492 & .071 \\
\hline Commander & 1191 & 1 & 5 & 2.35 & 0.935 & 0.413 & .071 \\
\hline Analyzer & 1194 & 1 & 5 & 2.40 & 0.904 & 0.426 & .071 \\
\hline Controller & 1197 & 1 & 5 & 2.49 & 0.909 & 0.297 & .071 \\
\hline Spokesperson & 1200 & 1 & 5 & 2.75 & 1.153 & 0.182 & .071 \\
\hline Operator & 1195 & 1 & 5 & 2.76 & 1.015 & 0.225 & .071 \\
\hline $\begin{array}{l}\text { Technical } \\
\text { Expert }\end{array}$ & 1195 & 1 & 5 & 2.80 & 1.082 & -.103 & .071 \\
\hline $\begin{array}{l}\text { Problem } \\
\text { Solver }\end{array}$ & 1200 & 1 & 5 & 2.82 & 0.991 & -.027 & .071 \\
\hline
\end{tabular}




\section{Research Question Two}

Research question two addressed the question of time allocation, how much time do CEOs approximate they spend in six categories of roles? Table 22 summarizes the frequencies associated with the six role categories and Table 23 summarizes the descriptive statistics associated with the six role categories.

Table 22

Frequencies - Hours Reported in the Six Role Categories During an Average Week Role Informational Interpersonal Decisional Operational Strategic Diplomacy Category:

\begin{tabular}{|c|c|c|c|c|c|c|}
\hline $\begin{array}{l}\text { Total } \\
\text { Hours } \\
\text { Reported }\end{array}$ & 9,028 & 10,806 & 11,219 & 11,121 & 12,967 & 6,696 \\
\hline $\begin{array}{l}\% \text { of } \\
\text { Total }\end{array}$ & 14.6 & 17.5 & 18.1 & 18.0 & 21.0 & 10.8 \\
\hline
\end{tabular}

Table 23

Descriptive Statistics: Hours Reported in Six Role Categories During an Average Week

\begin{tabular}{lccrrrrr}
\hline & $\mathrm{N}$ & Minimum & Maximum & Mean & $\begin{array}{l}\text { Standard } \\
\text { Deviation }\end{array}$ & $\begin{array}{l}\text { Skewness } \\
\text { Statistic }\end{array}$ & $\begin{array}{l}\text { Standard } \\
\text { Error }\end{array}$ \\
\hline Strategic & 1199 & 0 & 70 & 10.76 & 8.607 & 1.718 & .071 \\
Decisional & 1199 & 0 & 60 & 9.31 & 6.892 & 1.538 & .071 \\
Operational & 1199 & 0 & 60 & 9.25 & 8.042 & 1.703 & .071 \\
Interpersonal & 1199 & 0 & 60 & 8.99 & 7.275 & 1.748 & .071 \\
Informational & 1194 & 0 & 30 & 7.54 & 5.562 & 1.269 & .071 \\
Diplomacy & 1198 & 0 & 50 & 5.58 & 4.899 & 2.166 & .071 \\
\hline
\end{tabular}




\section{Research Question Three}

Research question three asked what roles are identified by CEOs that were not identified in the literature on the role of $C E O$ ?

The following roles were identified by the survey participants: coach, mentor, cheerleader, succession planner, consensus builder, liaison with Board of Directors, community involvement and outreach, driver of sustainability, investor relations, financial oversight, fund raising, enabler, chief storyteller, recruiter, thought leader, industry positioner, and chief embodiment of the values of the organization. Many other roles were identified that reflected the roles on the survey. Many CEOs emphasized spending a significant amount of their time in financial roles due to the current economic condition. This finding may imply that economic context is important in determining the role of CEO at any given time.

Research Hypotheses Testing

\section{Research Hypothesis One}

Research hypothesis one in null form, there is no difference between gender, agreement with the 31 role descriptions, and time allocated to the six role categories was tested using an independent-samples t-test (role agreement) and Mann-Whitney U (time allocated to the six role categories). Two different statistics were necessary due to skewness of the data related to time. Table 24 indicates there were statistically significant differences in role agreement between male and female CEOs on the operational, strategic, and diplomacy role categories. The group means for the operational role category indicates the average score for female CEOs $(\mathrm{M}=2.3418)$ is lower than the average score $(\mathrm{M}=2.5097)$ for males. The effect size $d$ is approximately .23 which is 
small or smaller than typical. The lower scores for female CEOs indicate slightly more agreement that these are roles of a $\mathrm{CEO}$, as the score of 1 indicated a response of strongly agree on the five-point Likert scale.

The group means for the strategic role category indicates the average score for female CEOs $(M=1.6643)$ is lower than the average score $(M=1.7979)$ for males. The effect size $d$ is approximately .29 which is between a small (.20) and medium or typical effect size (.50) (Gliner et al., 2009). The group means for the diplomacy role category indicated the average score for female CEOs $(\mathrm{M}=1.8073)$ is lower than the average score $(\mathrm{M}=2.0402)$ for males. The effect size $d$ is .37 which is between a small and medium or typical effect size. Effect size indicates "the strength of the relationship between the independent variable and the dependent variable, and/or the magnitude of the difference between levels of the independent variable with respect to the dependent variable" (Morgan et al., 2011, p. 99). 
Table 24

Differences Between Males and Females on Role Agreement

\begin{tabular}{|c|c|c|c|c|c|c|}
\hline Role & $\mathrm{M}$ & $\mathrm{SD}$ & $\mathrm{t}$ & $\mathrm{df}$ & $p$ & $d$ \\
\hline Informational/Males & 2.6532 & .74222 & & & & \\
\hline Informational/Females & 2.5544 & .80374 & 1.408 & 1,176 & .161 & .13 \\
\hline $\begin{array}{l}\text { Interpersonal } \\
\text { Roles/Males }\end{array}$ & 1.5106 & .45864 & & & & \\
\hline $\begin{array}{l}\text { Interpersonal } \\
\text { Roles/Females }\end{array}$ & 1.4933 & .41544 & .469 & 1,188 & .640 & .04 \\
\hline $\begin{array}{l}\text { Decisional } \\
\text { Roles/Males }\end{array}$ & 1.5412 & .40724 & & & & \\
\hline $\begin{array}{l}\text { Decisional } \\
\text { Roles/Females }\end{array}$ & 1.5397 & .45708 & .039 & 1,168 & .969 & .00 \\
\hline $\begin{array}{l}\text { Operational } \\
\text { Roles/Males }\end{array}$ & 2.5097 & .72738 & & & & \\
\hline $\begin{array}{l}\text { Operational } \\
\text { Roles/Females }\end{array}$ & 2.3418 & .82558 & 2.339 & 1,174 & $.020 *$ & .23 \\
\hline $\begin{array}{l}\text { Strategic Roles/Males } \\
\text { Strategic } \\
\text { Roles/Females }\end{array}$ & $\begin{array}{l}1.7979 \\
1.6643\end{array}$ & $\begin{array}{l}.46495 \\
.45722\end{array}$ & 3.231 & 1,134 & $.001 *$ & .29 \\
\hline $\begin{array}{l}\text { Diplomacy } \\
\text { Roles/Males } \\
\text { Diplomacy } \\
\text { Roles/Females }\end{array}$ & 2.0402 & .57857 & 4.508 & 1,181 & $.001 *$ & .39 \\
\hline
\end{tabular}

The difference between male and female CEOs in terms of time spent in six role categories was tested using Mann-Whitney U. There were no statistically significant differences between male and female CEOs in time approximations (Table 25). 
Table 25

Differences Between Male and Female CEOs in Time Spent in Six Role Categories

\begin{tabular}{|c|c|c|c|c|c|c|}
\hline & Informational & Interpersonal & Decisional & Operational & Strategic & Diplomacy \\
\hline $\begin{array}{l}\text { Mann- } \\
\text { Whitney } \\
\text { U }\end{array}$ & 74,824 & 74,032 & 78,172 & 77,531 & 75,303 & 72,145 \\
\hline Z & -.631 & -1.149 & -.090 & -.254 & -.823 & -1.621 \\
\hline $\begin{array}{l}\text { Asymp. } \\
\text { Sig. (2- } \\
\text { tailed) }\end{array}$ & .528 & .251 & .928 & .800 & .410 & .105 \\
\hline$r$ & .018 & .033 & .003 & .007 & .024 & .047 \\
\hline
\end{tabular}

Research Hypotheses one (a) and (b)

Research hypothesis one (a) stated that female CEOs will spend more time in interpersonal roles than their male counterparts. Research hypothesis one (b) stated that female CEOs will spend less time in operational roles than their male counterparts. Table 26 presents the data for RH one (a) and RH one (b). In both cases the data provide support for the hypotheses however, the differences are very, very small. This would be expected after computing the Mann-Whitney U statistic in H1. Female CEOs spent $17.6 \%$ of their time in interpersonal roles compared to $17.4 \%$ for male CEOs, and $17.1 \%$ of their time in operational roles, compared to $18.2 \%$ for males. 
Table 26

Majority of Time Spent in the Role Categories - Males and Females

\begin{tabular}{lcccc}
\hline Role Category & $\begin{array}{l}\text { Males }- \\
\text { Frequency }\end{array}$ & $\begin{array}{l}\text { Males \% of } \\
\text { Total }\end{array}$ & $\begin{array}{l}\text { Females }- \\
\text { Frequency }\end{array}$ & $\begin{array}{l}\text { Females \% of } \\
\text { Total }\end{array}$ \\
\hline Informational & 7,806 & 14.7 & 1,177 & 14.0 \\
Interpersonal* & 9,260 & 17.4 & 1,481 & 17.6 \\
Decisional & 9,665 & 18.2 & 1,484 & 17.7 \\
Operational* & 9,637 & 18.2 & 1,439 & 17.1 \\
Strategic & 11,013 & 20.8 & 1,843 & 22.0 \\
Diplomacy & 5,693 & 10.7 & 970 & 11.6 \\
& & & & \\
\hline
\end{tabular}

$*=$ roles of interest in $R H 1(a)$ and $(b)$

Research Hypothesis Two

Research hypothesis two, CEOs from public companies will spend less than $10 \%$

of their time in strategic role categories, was tested using descriptive statistics. Table 27

reports the frequency and percent of responses by role category for both private and

public companies. The data do not indicate support for hypothesis two revealing that

CEOs from public companies approximate they spend $20.5 \%$ of their time in the strategic

role category. This is comparable to CEOs from private companies at $21.0 \%$. 
Table 27

Majority of Time Approximations in the Role Categories - Private versus Public Companies

\begin{tabular}{lclll}
\hline Role Category & $\begin{array}{l}\text { Private }- \\
\text { Frequency }\end{array}$ & $\begin{array}{l}\text { Private \% of } \\
\text { Total }\end{array}$ & $\begin{array}{l}\text { Public }- \\
\text { Frequency }\end{array}$ & $\begin{array}{l}\text { Public \% of } \\
\text { Total }\end{array}$ \\
\hline Informational & 7,543 & $14.5 \%$ & 1,352 & $15.4 \%$ \\
Interpersonal & 8,980 & $17.3 \%$ & 1,636 & $18.6 \%$ \\
Decisional & 9,437 & $18.2 \%$ & 1,592 & $18.1 \%$ \\
Operational & 9,548 & $18.4 \%$ & 1,365 & $15.6 \%$ \\
Strategic* & 10,866 & $21.0 \%$ & 1,797 & $20.5 \%$ \\
Diplomacy & 5,499 & $10.6 \%$ & 1,035 & $11.8 \%$ \\
& & & & \\
\hline
\end{tabular}

Research Hypothesis Three

Research hypothesis three, agreement with and time spent in the role categories will not differ depending upon the CEOs degree major or industry background, was tested using ANOVA (agreement with) and Kruskal-Wallis (time spent). A statistically significant difference was found among the four levels of degree major or industry background on agreement with informational roles, $F(3,568)=3.25, p=.021$, and with decisional roles, $F(3,566)=2.92, p=.033$. Table 28 shows that the mean response in informational roles is 2.77 for finance majors and 2.58 for technical/engineering majors, these means indicate less agreement with these roles. The mean response in decisional roles was 1.62 for operations majors and 1.53 for technical/engineering majors, these means indicate stronger agreement with these roles. Post hoc Tukey HSD tests indicate that the finance and technical/engineering majors differed significantly in their agreement 
with informational roles, yet the effect size is small or smaller than typical $(p<.026, d=$ .27). Post hoc Tukey HSD also indicated there were statistically significant mean differences for operations majors and technical/engineering majors on the decisional roles, and again the effect size is small or smaller than typical $(p<.036, d=.29)$. 
Table 28

Means and Standard Deviations Comparing Four Degree Majors or Industry Focus of CEO Participants and Agreement with Role Categories

\begin{tabular}{|c|c|c|c|c|c|c|c|c|c|c|c|c|c|c|c|c|c|c|}
\hline \multirow[b]{2}{*}{$\begin{array}{l}\text { Major or } \\
\text { Industry } \\
\text { Focus }\end{array}$} & \multirow[b]{2}{*}{$n$} & \multicolumn{2}{|c|}{ Informational } & \multirow[b]{2}{*}{$n$} & \multicolumn{2}{|c|}{ Interpersonal } & \multirow[b]{2}{*}{$n$} & \multicolumn{2}{|c|}{ Decisional } & \multirow[b]{2}{*}{$n$} & \multicolumn{2}{|c|}{ Operational } & \multirow[b]{2}{*}{$n$} & \multicolumn{2}{|c|}{ Strategic } & \multirow[b]{2}{*}{$n$} & \multicolumn{2}{|c|}{ Diplomacy } \\
\hline & & $M$ & $S D$ & & $M$ & $S D$ & & $M$ & $S D$ & & $M$ & $S D$ & & $M$ & $S D$ & & $M$ & $S D$ \\
\hline Operations & 123 & 2.76 & .75 & 123 & 1.58 & .49 & 123 & 1.62 & .44 & 122 & 2.44 & .68 & 119 & 1.86 & .45 & 124 & 2.02 & .62 \\
\hline Finance & 201 & 2.77 & .70 & 202 & 1.50 & .42 & 202 & 1.53 & .38 & 197 & 2.56 & .70 & 191 & 1.77 & .45 & 202 & 2.03 & .69 \\
\hline $\begin{array}{l}\text { Public } \\
\text { Relations }\end{array}$ & 14 & 2.75 & .74 & 14 & 1.62 & .54 & 14 & 1.66 & .54 & 14 & 2.66 & 1.00 & 13 & 2.02 & .58 & 14 & 1.86 & .41 \\
\hline $\begin{array}{l}\text { Technical or } \\
\text { Engineering }\end{array}$ & 234 & 2.58 & .69 & 235 & 1.48 & .46 & 231 & 1.50 & .39 & 233 & 2.55 & .75 & 225 & 1.77 & .45 & 229 & 2.01 & .66 \\
\hline Total & 572 & 2.69 & .71 & 574 & 1.51 & .46 & 570 & 1.54 & .40 & 566 & 2.53 & .72 & 548 & 1.80 & .45 & 569 & 2.02 & .66 \\
\hline
\end{tabular}


Table 29

One-Way Analysis of Variance Summary Table Comparing a CEOs Degree Major or Industry Background on Agreement with Six Role Categories

\begin{tabular}{|c|c|c|c|c|c|c|}
\hline Source & & df & SS & MS & $\mathrm{F}$ & $p$ \\
\hline \multirow{5}{*}{$\begin{array}{l}\text { Informational } \\
\text { Roles }\end{array}$} & Between & 3 & 4.876 & 1.625 & 3.254 & $.021 *$ \\
\hline & Groups & & & & & \\
\hline & Within & 568 & 283.695 & .499 & & \\
\hline & Groups & & & & & \\
\hline & Total & 571 & 288.571 & & & \\
\hline & Between & 3 & 1.145 & .382 & 1.842 & .138 \\
\hline \multirow{4}{*}{$\begin{array}{l}\text { Interpersonal } \\
\text { Roles }\end{array}$} & Groups & & & & & \\
\hline & Within & 570 & 118.089 & .207 & & \\
\hline & Groups & & & & & \\
\hline & Total & 573 & 119.234 & & & \\
\hline \multirow{5}{*}{$\begin{array}{l}\text { Decisional } \\
\text { Roles }\end{array}$} & Between & 3 & 1.393 & .464 & 2.921 & $.033^{*}$ \\
\hline & Groups & & & & & \\
\hline & Within & 566 & 89.958 & .159 & & \\
\hline & Groups & & & & & \\
\hline & Total & 569 & 91.351 & & & \\
\hline \multirow{5}{*}{$\begin{array}{l}\text { Operational } \\
\text { Roles }\end{array}$} & Between & 3 & 1.584 & .528 & 1.012 & .387 \\
\hline & Groups & & & & & \\
\hline & Within & 562 & 293.390 & .522 & & \\
\hline & Groups & & & & & \\
\hline & Total & 565 & 294.974 & & & \\
\hline \multirow{5}{*}{$\begin{array}{l}\text { Strategic } \\
\text { Roles }\end{array}$} & Between & 3 & 1.458 & .486 & 2.374 & .069 \\
\hline & Groups & & & & & \\
\hline & Within & 544 & 111.388 & .205 & & \\
\hline & Groups & & & & & \\
\hline & Total & 547 & 112.846 & & & \\
\hline \multirow{5}{*}{$\begin{array}{l}\text { Diplomacy } \\
\text { Roles }\end{array}$} & Between & 3 & .422 & .141 & .322 & .810 \\
\hline & Groups & & & & & \\
\hline & Within & 565 & 246.588 & .436 & & \\
\hline & Groups & & & & & \\
\hline & Total & 568 & 247.010 & & & \\
\hline
\end{tabular}


A Kruskal-Wallis nonparametric test was conducted to test for significant differences between time spent in the role categories based on major or focus of industry because the data were skewed. The test indicated that the four majors differed significantly on operational roles, $\mathrm{X}^{2}(3, \mathrm{~N}=578)=12.33, p=.006$. Post hoc MannWhitney tests compared the four majors/focus of industry, using a Bonferonni corrected $p$ value of .0125 to indicate statistical significance. Bonferonni provides a more conservative analysis of significance (Gliner et al., 2009). The mean rank for time spent in the operational role category between operations majors $(185.03, n=124)$ was significantly higher than finance majors $(152.02, n=204), z=-3.092, p=.002, r=.17$, a small to medium effect size.

Research Hypothesis Four Research hypothesis four, there will be no difference in the way CEOs spend their time between CEOs with other $C$-level executives working for them, and those without $C$ level executives, was tested using Mann-Whitney U because the dependent variables were ordinal and the variances were unequal. In four role categories there is some evidence against this hypothesis as shown in Table 30. The 907 CEOs with other C-level executives working for them have significantly higher mean ranks (606.66) than CEOs without other C-level executives (517.50) on the interpersonal role category, $U=$ $101,892, p<.001, r=.112$. According to Cohen (1988) this is a small or smaller than typical effect size. There was a significant difference in mean ranks of CEOs with (568.59) and without (647.79) for the operational role category, $U=103,936, p<.001, r$ $=.099$, this is a small or smaller than typical effect size according to Cohen (1988). There was a significant difference in mean ranks of CEOs with (606.18) and without (519.14) 
for the strategic role category, $U=102,327, p<.001, r=.109$, a small or smaller than typical effect size. Finally, there was a significant difference in mean ranks of CEOs with (602.21) and without (532.72) for the diplomacy role category, $U=105,927, p=.003, r$ $=.087$, which is slightly less than a small or smaller than typical effect size.

Table 30

Differences Between CEOs With and Without other C-level Executives and Their Approximations of Time in the Six Role Categories

\begin{tabular}{|c|c|c|c|c|c|c|}
\hline & Informational & Interpersonal & Decisional & Operational & Strategic & Diplomacy \\
\hline $\begin{array}{l}\text { Mann- } \\
\text { Whitney } \\
\text { U }\end{array}$ & 112,117 & 101,892 & 118,555 & 103,936 & 102,327 & 105,927 \\
\hline Z & -1.559 & -3.818 & -.340 & -3.383 & -3.724 & -2.990 \\
\hline $\begin{array}{l}\text { Asymp. } \\
\text { Sig. (2- } \\
\text { tailed) }\end{array}$ & .119 & .000 & .734 & .001 & .000 & .003 \\
\hline$r$ & .046 & .112 & .010 & .099 & .109 & .087 \\
\hline
\end{tabular}

Research Hypothesis Five

Research hypothesis five, there will be an association between age, years in current job, years as a CEO, last degree earned, company size, and agreement with each role category, was tested using simultaneous multiple regression. The means, standard deviations, and intercorrelations for the informational role category can be found in Table 31. The combination of variables predicting role agreement including age, years in current job, years as CEO, last degree earned, and company size in employees and sales revenues were statistically significant, $F(6,927)=5.631, p<.001$. The beta coefficients are presented in Table 32. Age and years in current job significantly predicted agreement 
in the informational role category when all six variables were included however, it is important to note that because there is an inverse relationship between sample size and the size of the coefficient needed to recognize statistical significance it is likely that this result occurred due to chance (Gliner et al., 2009). This is further supported by the adjusted $R^{2}$ value of .03 , suggesting that only $3 \%$ of the variance in role agreement was explained by this model. This is a small effect size according to Cohen (1988).

Table 31

Means, Standard Deviations, and Intercorrelations for the Informational Roles and Predictor Variables $(N=934)$

\begin{tabular}{|c|c|c|c|c|c|c|c|c|}
\hline Variable & M & SD & Age** & $\begin{array}{r}\text { Yrs. } \\
\text { Curr. } \\
\text { Job }\end{array}$ & $\begin{array}{l}\text { Yrs. } \\
\text { CEO }\end{array}$ & $\begin{array}{r}\text { Last } \\
\text { Degree* }\end{array}$ & $\begin{array}{r}\text { Co. } \\
\text { Size } \\
\text { (emp.) }\end{array}$ & $\begin{array}{r}\text { Co. } \\
\text { Size } \\
\text { (sales) }\end{array}$ \\
\hline $\begin{array}{l}\text { Info. } \\
\text { Roles }\end{array}$ & 2.66 & .76 & .14 & -.05 & -.01 & .06 & .05 & .05 \\
\hline $\begin{array}{l}\text { Predictor } \\
\text { variables }\end{array}$ & & & & & & & & \\
\hline Age & 54.09 & 8.34 & -- & $.37 * *$ & $.45 * *$ & $.09 * *$ & .04 & .05 \\
\hline $\begin{array}{l}\text { Yrs. } \\
\text { Curr. } \\
\text { Job }\end{array}$ & 12.41 & 9.98 & & -- & $.56 * *$ & $-.10 * *$ & -.03 & -.02 \\
\hline $\begin{array}{l}\text { Yrs. } \\
\text { CEO }\end{array}$ & 11.47 & 8.51 & & & -- & $-.06 *$ & -.03 & -.02 \\
\hline $\begin{array}{l}\text { Last } \\
\text { Degree }\end{array}$ & 3.74 & 1.23 & & & & -- & $.10 * *$ & $.10 * *$ \\
\hline $\begin{array}{l}\text { Co. Size } \\
\text { (emp.) }\end{array}$ & 1,016 & 11,447 & & & & & -- & $.96 * *$ \\
\hline $\begin{array}{l}\text { Co. Size } \\
\text { (sales) }\end{array}$ & $\$ 254 \mathrm{M}$ & $\$ 2.7 \mathrm{~B}$ & & & & & & -- \\
\hline
\end{tabular}


Table 32

Simultaneous Multiple Regression Analysis Summary for Age, Yrs. In Current Job, Yrs. As CEO, Last Degree Earned, and Company Size in Predicting Agreement with the Informational Role Category

\begin{tabular}{lrrrrr}
\hline Variable & B & SE B & $\beta$ & $t$ & $p$ \\
\hline & & & & & \\
Age & .017 & .003 & .191 & 5.517 & .000 \\
Yrs. Curr. & -.007 & .003 & -.092 & -2.326 & .020 \\
Yrs. CEO & -.004 & .004 & -.041 & -1.005 & .315 \\
Last Degree & .016 & .020 & .026 & .783 & .434 \\
Co. Size- & $-1.836 \mathrm{E}-6$ & .000 & -.028 & .234 & .815 \\
Emp. & & & & & .600 \\
Co. Size- & $1.744 \mathrm{E}-11$ & .000 & .062 & & \\
Sales & & & & & \\
& & & & &
\end{tabular}

Note: $R^{2}=.03 ; F(6,927)=5.63, p<.001$.

The means, standard deviations, and intercorrelations for the interpersonal role category can be found in Table 33. The combination of variables predicting role agreement including age, years in current job, years as CEO, last degree earned, and company size in employees and sales revenues were statistically significant, $F(6,937)=$ 3.148, $p<.005$. The beta coefficients are presented in Table 34. Years in current job and years as a CEO significantly predict agreement in the informational role category when all six variables were included. However, the adjusted $R^{2}$ value was only .01 , suggesting that only $1 \%$ of the variance in role agreement was explained by this model. It is likely that statistical significance occurred only as a result of chance. 
Table 33

Means, Standard Deviations, and Intercorrelations for the Interpersonal Roles and Predictor Variables $(N=944)$

\begin{tabular}{|c|c|c|c|c|c|c|c|c|}
\hline Variable & $\mathrm{M}$ & $\mathrm{SD}$ & Age** & $\begin{array}{r}\text { Yrs. } \\
\text { Curr. } \\
\text { Job }\end{array}$ & $\begin{array}{l}\text { Yrs. } \\
\text { CEO }\end{array}$ & $\begin{array}{r}\text { Last } \\
\text { Degree } \\
*\end{array}$ & $\begin{array}{r}\text { Co. } \\
\text { Size } \\
\text { (emp.) }\end{array}$ & $\begin{array}{r}\text { Co. } \\
\text { Size } \\
\text { (sales) }\end{array}$ \\
\hline $\begin{array}{l}\text { Interp. } \\
\text { Roles }\end{array}$ & 1.50 & .44 & -.016 & .10 & -.02 & .01 & -.01 & -.01 \\
\hline \multicolumn{9}{|l|}{$\begin{array}{l}\text { Predictor } \\
\text { variables }\end{array}$} \\
\hline Age & 54.13 & 8.35 & -- & $.37 * *$ & $.45^{* *}$ & $.09 * *$ & .04 & .05 \\
\hline $\begin{array}{l}\text { Yrs. Curr. } \\
\text { Job }\end{array}$ & 12.36 & 9.99 & & -- & $.56 * *$ & $-.10 * *$ & -.03 & -.02 \\
\hline Yrs. CEO & 11.46 & 8.47 & & & -- & $-.06 *$ & -.03 & -.02 \\
\hline $\begin{array}{l}\text { Last } \\
\text { Degree }\end{array}$ & 3.76 & 1.24 & & & & -- & $.10 * *$ & $.10 * *$ \\
\hline $\begin{array}{l}\text { Co. Size } \\
\text { (emp.) }\end{array}$ & 1,005 & 11,387 & & & & & -- & $.96 * *$ \\
\hline $\begin{array}{l}\text { Co. Size } \\
\text { (sales) }\end{array}$ & $\$ 254 \mathrm{M}$ & $\$ 2.7 \mathrm{~B}$ & & & & & & -- \\
\hline
\end{tabular}


Table 34

Simultaneous Multiple Regression Analysis Summary for Age, Yrs. In Current Job, Yrs. As CEO, Last Degree Earned, and Company Size in Predicting Agreement with the Interpersonal Role Category

\begin{tabular}{lrrrrr}
\hline Variable & B & SE B & $\beta$ & $t$ & $p$ \\
\hline & & & & & \\
Age & -.002 & .002 & -.034 & -.926 & .355 \\
Yrs. Curr. & .008 & .002 & .170 & 4.261 & .000 \\
Yrs. CEO & -.005 & .002 & -.105 & -2.533 & .011 \\
Last Degree & .006 & .012 & .018 & .542 & .588 \\
Co. Size- & $-1.169 \mathrm{E}-6$ & .000 & -.030 & -.252 & .801 \\
Emp. & & & & & .196 \\
Co. Size- & $3.832 \mathrm{E}-12$ & .000 & .023 & & .845 \\
Sales & & & & &
\end{tabular}

Note: $R^{2}=.01 ; F(6,937)=3.148, p=.005$.

The combination of variables predicting role agreement for the decisional role category including age, years in current job, years as CEO, last degree earned, and company size in employees and sales revenues were not statistically significant, $F$ (6, 922) $=1.778, p<.10$.

The combination of variables predicting role agreement for the operational role category including age, years in current job, years as CEO, last degree earned, and company size in employees and sales revenues were not statistically significant, $F$ (6, $928)=1.062, p<.384$.

The means, standard deviations, and intercorrelations for the strategic role category can be found in Table 35. The combination of variables predicting role agreement including age, years in current job, years as CEO, last degree earned, and company size in employees and sales revenues were statistically significant, $F(6,901)=$ 3.293, $p<.01$. The beta coefficients are presented in Table 32b. Years in current job and 
years as a CEO significantly predict agreement in the strategic role category when all six variables are included. However, the adjusted $R^{2}$ value was only .02, suggesting that only $2 \%$ of the variance in role agreement was explained by this model. Again, it is likely that statistical significance occurred as a result of chance.

Table 35

Means, Standard Deviations, and Intercorrelations for the Strategic Roles and Predictor Variables $(N=908)$

\begin{tabular}{|c|c|c|c|c|c|c|c|c|}
\hline Variable & M & SD & $\mathrm{Age}^{* *}$ & $\begin{array}{r}\text { Yrs. } \\
\text { Curr. } \\
\text { Job } \\
\end{array}$ & $\begin{array}{l}\text { Yrs. } \\
\text { CEO }\end{array}$ & $\begin{array}{r}\text { Last } \\
\text { Degree }\end{array}$ & $\begin{array}{r}\text { Co. } \\
\text { Size } \\
\text { (emp.) } \\
\end{array}$ & $\begin{array}{r}\text { Co. } \\
\text { Size } \\
\text { (sales) } \\
\end{array}$ \\
\hline $\begin{array}{l}\text { Strategic } \\
\text { Roles }\end{array}$ & 1.77 & .45 & $.14 * *$ & $.08 * *$ & $.08 * *$ & .10 & -.00 & -.01 \\
\hline \multicolumn{9}{|l|}{$\begin{array}{l}\text { Predictor } \\
\text { variables }\end{array}$} \\
\hline Age & 54.05 & 8.35 & -- & $.37 * *$ & $.45^{* *}$ & $.09 * *$ & .04 & .05 \\
\hline $\begin{array}{l}\text { Yrs. } \\
\text { Curr. } \\
\text { Job }\end{array}$ & 12.36 & 10.03 & & -- & $.56^{* *}$ & $-.10 * *$ & -.03 & -.02 \\
\hline $\begin{array}{l}\text { Yrs. } \\
\text { CEO }\end{array}$ & 11.43 & 8.51 & & & -- & $-.06 *$ & -.03 & -.02 \\
\hline $\begin{array}{l}\text { Last } \\
\text { Degree }\end{array}$ & 3.76 & 1.25 & & & & -- & $.10 * *$ & $.10 * *$ \\
\hline $\begin{array}{l}\text { Co. Size } \\
\text { (emp.) }\end{array}$ & 1,031 & 11,608 & & & & & -- & $.96 * *$ \\
\hline $\begin{array}{l}\text { Co. Size } \\
\text { (sales) }\end{array}$ & $\$ 260 \mathrm{M}$ & $\$ 2.7 \mathrm{~B}$ & & & & & & -- \\
\hline
\end{tabular}


Table 36

Simultaneous Multiple Regression Analysis Summary for Age, Yrs. In Current Job, Yrs. As CEO, Last Degree Earned, and Company Size in Predicting Agreement with the Strategic Role Category

\begin{tabular}{lrrrrr}
\hline Variable & $\mathrm{B}$ & SE B & $\beta$ & $t$ & $\rho$ \\
\hline & & & & & \\
Age & .007 & .002 & .124 & 3.285 & .001 \\
Yrs. Curr. & .002 & .002 & .035 & .850 & .395 \\
Yrs. CEO & .000 & .002 & .008 & .188 & .851 \\
Last Degree & .001 & .012 & .003 & .101 & .919 \\
Co. Size- & $2.739 \mathrm{E}-6$ & .000 & .070 & .580 & .562 \\
Emp. & & & & & \\
Co. Size- & $-1.336 \mathrm{E}-11$ & .000 & -.081 & -.670 & .503 \\
Sales & & & & &
\end{tabular}

Note: $R^{2}=.02 ; F(6,901)=3.293, p=.003$.

The means, standard deviations, and intercorrelations for the diplomacy role category can be found in Table 37. The combination of variables predicting role agreement including age, years in current job, years as CEO, last degree earned, and company size in employees and sales revenues were statistically significant, $F(6,930)=$ 2.493, $p<.05$. The beta coefficients are presented in Table 34b. Years in current job and years as a CEO significantly predict agreement in the diplomacy role category when all six variables are included. However, the adjusted $R^{2}$ value was only .01 , suggesting that only $1 \%$ of the variance in role agreement was explained by this model, this is a very small effect size according to Cohen (1988). It seems likely that multiple regression may not be the most appropriate model for interpreting these relationships. 
Table 37

Means, Standard Deviations, and Intercorrelations for the Diplomacy Roles and Predictor Variables $(N=937)$

\begin{tabular}{|c|c|c|c|c|c|c|c|c|}
\hline Variable & $\bar{M}$ & $\mathrm{SD}$ & Age** & $\begin{array}{r}\text { Yrs. } \\
\text { Curr. } \\
\text { Job }\end{array}$ & $\begin{array}{l}\text { Yrs. } \\
\text { CEO }\end{array}$ & $\begin{array}{r}\text { Last } \\
\text { Degree }\end{array}$ & $\begin{array}{r}\text { Co. } \\
\text { Size } \\
\text { (emp.) }\end{array}$ & $\begin{array}{r}\text { Co. } \\
\text { Size } \\
\text { (sales) }\end{array}$ \\
\hline $\begin{array}{l}\text { Diplomacy } \\
\text { Roles }\end{array}$ & 1.99 & .62 & $.11 * *$ & $.01 * *$ & $.07 * *$ & $-.01 * *$ & .03 & .02 \\
\hline $\begin{array}{l}\text { Predictor } \\
\text { variables }\end{array}$ & & & & & & & & \\
\hline Age & 54.12 & 8.41 & -- & $.38 * *$ & $.45^{* *}$ & $.09 * *$ & .04 & .04 \\
\hline $\begin{array}{l}\text { Yrs. Curr. } \\
\text { Job }\end{array}$ & 12.40 & 10.02 & & -- & $.56^{* * *}$ & $-.10 * *$ & -.03 & -.02 \\
\hline Yrs. CEO & 11.48 & 8.51 & & & -- & $-.06^{*}$ & -.03 & -.02 \\
\hline $\begin{array}{l}\text { Last } \\
\text { Degree }\end{array}$ & 3.77 & 1.26 & & & & -- & $.10 * *$ & $.10 * *$ \\
\hline $\begin{array}{l}\text { Co. Size } \\
\text { (emp.) }\end{array}$ & 1,004 & 11,428 & & & & & -- & $.96 * *$ \\
\hline $\begin{array}{l}\text { Co. Size } \\
\text { (sales) }\end{array}$ & $\$ 253 \mathrm{M}$ & $\$ 2.7 \mathrm{~B}$ & & & & & & -- \\
\hline
\end{tabular}


Table 38

Simultaneous Multiple Regression Analysis Summary for Age, Yrs. In Current Job, Yrs. As CEO, Last Degree Earned, and Company Size in Predicting Agreement with the Diplomacy Role Category

\begin{tabular}{lrrrrr}
\hline Variable & $\mathrm{B}$ & SE B & $\beta$ & $t$ & $p$ \\
\hline & & & & & \\
Age & .008 & .003 & .109 & 2.900 & .004 \\
Yrs. Curr. & -.004 & .002 & -.059 & -1.468 & .142 \\
Yrs. CEO & .004 & .003 & .053 & 1.278 & .202 \\
Last Degree & -.013 & .016 & -.026 & -.786 & .432 \\
Co. Size- & $4.315 \mathrm{E}-6$ & .000 & .080 & .670 & .503 \\
Emp. & & & & & .624 \\
Co. Size- & $-1.335 \mathrm{E}-11$ & .000 & -.059 & -.491 & \\
Sales & & & & &
\end{tabular}

Note: $R^{2}=.01 ; F(6,937)=2.493, p=.021$.

Research Hypothesis Six

Research hypothesis six, there will be no difference in responses on role agreement and time spent in the role categories between CEOs from privately-held versus publicly-held companies, was tested using an independent samples t-test (role agreement) and Mann-Whitney U (approximations to role categories). Table 39 indicates that differences in responses between CEOs from private companies and CEOs from public companies were statistically significant on the informational role category. The group means for the informational roles indicate the average score for public company CEOs $(M=2.7988)$ was higher than the score $(M=2.6116)$ for private company CEOs. The effect size $d$ is approximately -.25 which is slightly higher than a small or smaller than typical effect size. There were also statistically significant differences on the interpersonal role category. The group means for the interpersonal role category indicates the average score for private company CEOs $(\mathrm{M}=1.5250)$ was higher than the score $(\mathrm{M}$ 
$=1.4126)$ for public company CEOs. The effect size $d$ is approximately .25 which is slightly higher than a small or smaller than typical effect size. Finally, there was a statistically significant difference on the diplomacy role category. The group means for public company CEOs $(\mathrm{M}=2.1070)$ was higher than the score $(\mathrm{M}=1.9990)$ for private company CEOs. The effect size $d$ is approximately -.17 which is considered a small effect size.

Table 39

Differences Between CEOs From Private versus Public Companies on Role Agreement

\begin{tabular}{|c|c|c|c|c|c|c|}
\hline Role & $\mathrm{M}$ & $\mathrm{SD}$ & $\mathrm{t}$ & $\mathrm{df}$ & $p$ & $\bar{a}$ \\
\hline Informational/Private & 2.6116 & .75576 & & & & \\
\hline Informational/Public & 2.7988 & .71029 & -3.099 & 1,157 & $.002 *$ & -.25 \\
\hline $\begin{array}{l}\text { Interpersonal } \\
\text { Roles/Private }\end{array}$ & 1.5250 & .46314 & & & & \\
\hline $\begin{array}{l}\text { Interpersonal } \\
\text { Roles/Public }\end{array}$ & 1.4126 & .37448 & 3.439 & 1,169 & $.001 *$ & .25 \\
\hline $\begin{array}{l}\text { Decisional } \\
\text { Roles/Private } \\
\text { Decisional } \\
\text { Roles/Public }\end{array}$ & 1.5421 & .42027 & .590 & 1,149 & .556 & .05 \\
\hline $\begin{array}{l}\text { Operational } \\
\text { Roles/Private } \\
\text { Operational } \\
\text { Roles/Public }\end{array}$ & 2.4906 & .75220 & .085 & 1,156 & .932 & .01 \\
\hline $\begin{array}{l}\text { Strategic } \\
\text { Roles/Private } \\
\text { Strategic } \\
\text { Roles/Public }\end{array}$ & 1.7706 & .46292 & -1.832 & 1,116 & .068 & -.16 \\
\hline $\begin{array}{l}\text { Diplomacy } \\
\text { Roles/Private } \\
\text { Diplomacy } \\
\text { Roles/Public }\end{array}$ & 2.1070 & .63665 & -2.004 & 1,162 & $.046^{*}$ & -.17 \\
\hline
\end{tabular}

$*=$ significance 
The difference between private and public company CEOs on time spent in six role categories was tested using Mann-Whitney U. There was a statistically significant difference between private and public company CEOs in time spent in the interpersonal role category, $U=70,275, p=.001, r=.09$, a small effect size, the results appear in Table 40.

Table 40

Differences Between Private and Public Company CEOs on Time Spent in the Six Role Categories

\begin{tabular}{|c|c|c|c|c|c|c|}
\hline & Informational & Interpersonal & Decisional & Operational & Strategic & Diplomacy \\
\hline $\begin{array}{l}\text { Mann- } \\
\text { Whitney } \\
\text { U }\end{array}$ & 75,608 & 70,275 & 78,459 & 76,275 & 80,634 & 75,392 \\
\hline Z & -1.801 & -3.224 & -1.177 & -1.717 & -.629 & -1.934 \\
\hline $\begin{array}{l}\text { Asymp. } \\
\text { Sig. (2- } \\
\text { tailed) }\end{array}$ & .072 & .001 & .239 & .086 & .529 & .053 \\
\hline$r$ & .053 & .094 & .034 & .050 & .018 & .056 \\
\hline
\end{tabular}

Research Hypothesis Seven

Research hypothesis seven, there will be no difference in the responses on role agreement and time allocations to role categories between a convenience sample of CEOs and a random sample of CEOs, was tested using an independent samples t-test (role agreement) and Mann-Whitney U (approximation to role categories). As indicated in Table 41 there are no statistically significant differences in role agreement between the random and convenience samples. 
Table 41

Differences Between CEOs From the Random versus Convenience Sample on Role Agreement

\begin{tabular}{|c|c|c|c|c|c|c|}
\hline & $\mathrm{M}$ & $\mathrm{SD}$ & $\mathrm{t}$ & $\mathrm{df}$ & $\rho$ & $d$ \\
\hline Informational/Random & 2.6510 & .75226 & & & & \\
\hline Informational/Conv & 2.4071 & .73286 & 1.938 & 1,180 & .060 & .32 \\
\hline $\begin{array}{l}\text { Interpersonal } \\
\text { Roles/Random }\end{array}$ & 1.5056 & .45095 & & & & \\
\hline $\begin{array}{l}\text { Interpersonal } \\
\text { Roles/Conv. }\end{array}$ & 1.6286 & .50340 & -1.428 & 1,192 & .162 & -.27 \\
\hline $\begin{array}{l}\text { Decisional } \\
\text { Roles/Random }\end{array}$ & 1.5414 & .41414 & & & & \\
\hline $\begin{array}{l}\text { Decisional } \\
\text { Roles/Conv. }\end{array}$ & 1.5515 & .38326 & -.150 & 1,172 & .882 & -.02 \\
\hline $\begin{array}{l}\text { Operational } \\
\text { Roles/Random }\end{array}$ & 2.4969 & .74620 & & & & \\
\hline $\begin{array}{l}\text { Operational } \\
\text { Roles/Conv. }\end{array}$ & 2.3182 & .60037 & 1.674 & 1,178 & .103 & .24 \\
\hline $\begin{array}{l}\text { Strategic } \\
\text { Roles/Random }\end{array}$ & 1.7819 & .46553 & & & & \\
\hline Strategic Roles/Conv. & 1.7633 & .46089 & .235 & 1,138 & .815 & .04 \\
\hline $\begin{array}{l}\text { Diplomacy } \\
\text { Roles/Random }\end{array}$ & 2.0148 & .63877 & & & & \\
\hline $\begin{array}{l}\text { Diplomacy } \\
\text { Roles/Conv. }\end{array}$ & 1.9429 & .59675 & .701 & 1,185 & .488 & .11 \\
\hline $\begin{array}{l}\text { Monitor } \\
\text { Roles/Random }\end{array}$ & 1.4485 & .48973 & & & & \\
\hline Monitor Roles/Conv. & 1.4571 & .49067 & -.102 & 1,199 & 919 & -.02 \\
\hline
\end{tabular}

The difference between the random and convenience sample CEOs on time spent in six role categories was tested using Mann-Whitney U. There were no statistically significant 
differences between the random and convenience sample CEOs in time approximations to the role categories. The results appear in Table 42 .

Table 42

Differences Between CEOs From the Random versus Convenience Sample on Time Spent in Six Role Categories

\begin{tabular}{|c|c|c|c|c|c|c|}
\hline & Informational & Interpersonal & Decisional & Operational & Strategic & Diplomacy \\
\hline $\begin{array}{l}\text { Mann- } \\
\text { Whitney } \\
\text { U }\end{array}$ & 18,053 & 17,920 & 18,805 & 16,828 & 18,008 & 19,775 \\
\hline Z & -1.128 & -1.229 & -.787 & -1.772 & -1.184 & -.291 \\
\hline $\begin{array}{l}\text { Asymp. } \\
\text { Sig. (2- } \\
\text { tailed) }\end{array}$ & .260 & .219 & .431 & .076 & .237 & .771 \\
\hline$r$ & .033 & .035 & .023 & .051 & .034 & .008 \\
\hline
\end{tabular}

Research Hypothesis Eight

Research hypothesis eight, there will be no difference in the responses on role agreement and time allocations between CEOs from small companies and CEOs from large companies was tested using a one-way ANOVA (role agreement) and KruskalWallis (time allocations). A statistically significant difference was found among the three levels of company size on agreement with all categories of role. For informational roles, $F(2,1122)=39.00, p<.001$, interpersonal roles, $F(2,1134)=9.07, p<.001$, decisional roles, $F(2,1113)=6.583, p=.001$, operational roles, $F(2,1121)=9.259, p<.001$, strategic roles $F(2,1085)=4.74, p=.009$, and for diplomacy roles, $F(2,1126)=9.106$, $p<.001$. Table 43 shows that the mean response for informational roles is 2.48 for small 
companies and 2.95 for large companies. The mean response for interpersonal roles is 1.54 for small companies and 1.38 for large companies. The mean response for decisional roles is 1.51 for small companies and 1.62 for medium companies. The mean response for operational roles is 2.41 for small companies and 2.63 for medium companies. The mean response for strategic roles is 1.74 for small companies and 1.84 for medium companies. Finally, the mean response for diplomacy roles is 1.94 for small companies and 2.12 for large companies. Post hoc Tukey HSD tests indicate that the small and large size companies and small and medium size companies differed significantly in their agreement with informational roles with effect size slightly higher than medium and close to medium or typical $(p<.001, d=.65)$ and $(p<.001, d=.43)$, respectively. Post hoc Tukey HSD indicated there were statistically significant mean differences for small and large size companies on the interpersonal roles, the effect size is between a small and a medium, or typical effect size $(p<.001, d=.37)$. There were also statistically significant mean differences for medium and large size companies, the effect size is closer to small $(p=.002, d=.35)$. Post hoc Tukey HSD indicated there were statistically significant mean differences for small and medium size companies in the decisional roles, the effect size is small ( $p=.001, d=.25)$. There were also statistically significant mean differences for medium and large size companies in the decisional roles, the effect size is small $(p<$ $.037, d=.24)$. In the operational roles post hoc Tukey HSD indicated statistically significant mean differences for small and medium size companies, the effect size is small $(p<.001, d=.30)$. In the strategic role categories there were statistically significant mean differences for small and medium size companies, the effect size is small $(p<.007$, $d=.22$ ). Finally, post hoc Tukey HSD revealed statistically significant mean differences 
for small and medium and small and large companies in the diplomacy roles, the effect sizes are small, $(p<.004, d=.21)$, and $(p<.001, d=.29)$, respectively. 
Table 43

Means and Standard Deviations Comparing Three Levels of Company Size

\begin{tabular}{|c|c|c|c|c|c|c|c|c|c|c|c|c|c|c|c|c|c|c|}
\hline \multirow[b]{2}{*}{$\begin{array}{l}\text { Company } \\
\text { Size by } \\
\text { Employee } \\
\text { Numbers }\end{array}$} & \multirow[b]{2}{*}{$\mathrm{n}$} & \multicolumn{2}{|c|}{ Informatinal } & \multirow[b]{2}{*}{$\mathrm{n}$} & \multicolumn{2}{|c|}{ Interpersonal } & \multirow[b]{2}{*}{$\mathrm{n}$} & \multicolumn{2}{|c|}{ Decisional } & \multirow[b]{2}{*}{$\mathrm{n}$} & \multicolumn{2}{|c|}{ Operational } & \multirow[b]{2}{*}{$\mathrm{n}$} & \multicolumn{2}{|c|}{ Strategic } & \multirow[b]{2}{*}{$\mathrm{n}$} & \multicolumn{2}{|c|}{ Diplomacy } \\
\hline & & $\mathrm{M}$ & SD & & $\mathrm{M}$ & SD & & $\mathrm{M}$ & SD & & $\mathrm{M}$ & SD & & $\mathrm{M}$ & $\mathrm{SD}$ & & $\mathrm{M}$ & SD \\
\hline Small & 632 & 2.48 & .73 & 642 & 1.54 & .48 & 634 & 1.51 & .40 & 636 & 2.41 & .76 & 614 & 1.74 & .46 & 638 & 1.94 & .62 \\
\hline Medium & 299 & 2.80 & .74 & 301 & 1.52 & .42 & 290 & 1.62 & .47 & 294 & 2.63 & .71 & 286 & 1.84 & .47 & 298 & 2.07 & .61 \\
\hline Large & 194 & 2.95 & .71 & 194 & 1.38 & .39 & 192 & 1.52 & .35 & 194 & 2.54 & .68 & 188 & 1.79 & .42 & 193 & 2.12 & .63 \\
\hline Total & 1,125 & 2.65 & .76 & 1,137 & 1.51 & .45 & 1,116 & 1.54 & .41 & 1,124 & 2.49 & .74 & 1,088 & 1.79 & .46 & 1,129 & 2.00 & .62 \\
\hline
\end{tabular}


Table 44

One-Way Analysis of Variance Summary Table Comparing a CEOs Company Size on Agreement with Six Role Categories

\begin{tabular}{|c|c|c|c|c|c|c|}
\hline Source & & $\overline{d f}$ & SS & MS & $\mathrm{F}$ & $p$ \\
\hline \multirow{5}{*}{$\begin{array}{l}\text { Informational } \\
\text { Roles }\end{array}$} & Between & 2 & 41.699 & 20.849 & 39.000 & $<.001 *$ \\
\hline & Groups & & & & & \\
\hline & Within & 1,122 & 599.826 & .535 & & \\
\hline & Groups & & & & & \\
\hline & Total & 1,124 & 641.525 & & & \\
\hline \multirow{5}{*}{$\begin{array}{l}\text { Interpersonal } \\
\text { Roles }\end{array}$} & Between & 2 & 3.653 & 1.826 & 9.071 & $<.001 *$ \\
\hline & Groups & & & & & \\
\hline & Within & 1,134 & 228.312 & .201 & & \\
\hline & Groups & & & & & \\
\hline & Total & 1,136 & 231.964 & & & \\
\hline \multirow{5}{*}{$\begin{array}{l}\text { Decisional } \\
\text { Roles }\end{array}$} & Between & 2 & 2.227 & 1.113 & 6.583 & $<.001 *$ \\
\hline & Groups & & & & & \\
\hline & Within & 1,113 & 188.252 & .169 & & \\
\hline & Groups & & & & & \\
\hline & Total & 1,115 & 190.479 & & & \\
\hline \multirow{5}{*}{$\begin{array}{l}\text { Operational } \\
\text { Roles }\end{array}$} & Between & 2 & 10.005 & 5.003 & 9.259 & $<.001 *$ \\
\hline & Groups & & & & & \\
\hline & Within & 1,121 & 605.688 & .540 & & \\
\hline & Groups & & & & & \\
\hline & Total & 1,123 & 615.693 & & & \\
\hline \multirow{5}{*}{$\begin{array}{l}\text { Strategic } \\
\text { Roles }\end{array}$} & Between & 2 & 1.979 & .989 & 4.740 & $.009 *$ \\
\hline & Groups & & & & & \\
\hline & Within & 1,085 & 226.448 & .209 & & \\
\hline & Groups & & & & & \\
\hline & Total & 1,087 & 228.427 & & & \\
\hline \multirow{5}{*}{$\begin{array}{l}\text { Diplomacy } \\
\text { Roles }\end{array}$} & Between & 2 & 7.002 & 3.501 & 9.106 & $<.001 *$ \\
\hline & Groups & & & & & \\
\hline & Within & 1,126 & 432.875 & .384 & & \\
\hline & Groups & & & & & \\
\hline & Total & 1,128 & 439.877 & & & \\
\hline
\end{tabular}

$*=$ significance 
A Kruskal-Wallis nonparametric test was conducted to test for significant differences between time spent in the role categories based on company size because there were unequal variances across groups. The test indicated that the three company sizes differed significantly on interpersonal roles, $\mathrm{X}^{2}(2, \mathrm{~N}=1,143)=30.83, p<.001$, on operational roles, $\mathrm{X}^{2}(2, \mathrm{~N}=1,143)=19.994, p<.001$, on strategic roles, $\mathrm{X}^{2}(2,1,143)=$ $12.479, p=.002$, and on diplomacy roles, $\mathrm{X}^{2}(2, \mathrm{~N}=1,142)=8.028, p=.018$. Post hoc Mann-Whitney tests compared the three levels of company size, using a Bonferonni corrected $p$ value of .017 to indicate statistical significance. Three Mann-Whitney tests were run, comparing small and medium size companies, small and large size companies, and medium and large size companies.

Small and Medium Size Companies. The mean rank for time spent in the interpersonal role category between small companies $(468.05, n=643)$ was significantly lower than medium companies $(482.01, n=302), z=-4.046, p<.001, r=.13$, a small effect size. The mean rank for time spent in the operational role category between small companies $(498.59, n=646)$ was significantly higher than medium companies $(422.96, n$ = 302) $z=-4.000, p<.001, r=.13$, a small effect size.

Small and Large Size Companies. The mean rank for time spent in the interpersonal role category between small companies $(399.28, n=646)$ was significantly lower than large companies $(492.94, n=195), z=-4.777, p<.001, r=.17$, a small effect size. The mean rank for time spent in the operational category between small companies (434.62, $n=646)$ was significantly higher than large companies $(375.88, n=195), z=-$ 2.987, $p=.003, r=.10$, a small effect size. The mean rank for time spent in the strategic 
category between small companies $(405.31, n=646)$ was significantly lower than large companies $(472.97, n=195), z=-3.447, p=.001, r=.12$, a small effect size.

Medium and Large Size Companies. The mean rank for time spent in the strategic role categories between medium companies $(234.17, n=302)$ was significantly lower than large companies $(271.97, n=195), z=-2.905, p=.004, r=.13$, a small effect size.

Summary

This chapter presented the findings of exploratory factor analysis with an instrument used for the first time. The factor analysis resulted in the elimination of six of 31 roles being investigated and left three of the original six role categories intact. Changes were made to three other role categories. A seventh factor was eliminated because it only included two components or roles. This chapter also presented the statistical results of three research questions and eight hypotheses investigated with data obtained from the survey instrument. A summary and discussion of the research findings along with recommendations for future research are presented in the following chapter. 


\section{CHAPTER FIVE: DISCUSSION OF FINDINGS}

The purpose of this study was to address the gap between what is reported in the literature and what is reported in current practice on the role of CEO. A major goal was for CEOs to provide insights and help improve the understanding of their role. In addition this study was intended to further refine and contribute to Mintzberg's theory on the role of CEO. This chapter will first discuss the results related to the three research questions and the eight hypotheses, and provides a summary of the conclusions. Finally, implications of the study and recommendations for future research are presented.

CEOs are a notoriously difficult population to study (Beggs \& Doolittle, 1988; Thomas, 1995). Most are exceedingly busy running their companies and most have at least one level of screening for e-mail messages. A core challenge to the execution of this research project was creating a strategy for accessing CEOs while maximizing the chances they might participate. When asked for advice about how to gain access to CEOs Dr. Mintzberg responded "No secret Maggie. Just call them." He was absolutely correct. The study has shown that CEOs are interested in learning what other CEOs say about their role, and the nature, complexity, and variety of approaches to the position may be a key factor in motivating CEOs to respond. The importance of this study is evidenced by the number of CEOs who participated and by the 80 participants who requested copies of the results. The study has shown that many of the roles described by Mintzberg (1973) have stood the test of time for over 40 years, yet some have not. It has also shown that 
newer roles, like the link role described by Lafley (2009) are not as strongly perceived as CEO roles as we would have believed them to be.

\section{Conclusions}

This chapter describes the conclusions gleaned from participant responses to the research survey. The data were gathered using an instrument developed from an extensive review of the literature. This chapter is divided into four sections. The first section is a discussion of the responses to the three research questions, the second section discusses the results of testing eight research hypotheses, and the third section summarizes the study findings. A fourth and final section discusses the study's implications for theory, research, and practice on the role of CEO.

Discussion - Three Research Questions

Three core research questions framed this study. They were: 1) What is the role of CEO in the U.S.?, 2) How much time do CEOs approximate they spend in six categories of roles?, and 3) What roles are identified by CEOs that were not identified in the literature on the role of CEO? This section discusses each of these questions in detail, interpreting what the data indicated for a generalized conclusion, and analyzing possible explanations for the responses based on the contextual nature of survey research.

\section{Research Question One}

Research question one asked - What is the role of CEO in the U.S.? Almost 99\% of participants strongly agreed or agreed that leader (Mintzberg, 1973) is a role of the CEO. Also considered the most important role of a CEO (Edersheim, 2007; Lafley, 2009; Mintzberg, 1973; Quarterman et al., 2005) this role was described on the survey as I lead and motivate my subordinates. The leader role was part of the interpersonal role 
categories, which included motivator (96\% of respondents strongly agreed or agreed with this description - I create and set a sense of excitement and vitality in the organization, challenging people to gain new competencies and achieve higher levels of performance) (Hart \& Quinn, 1993) and director (90.3\% strongly agreed or agreed with this description - I make sure the right people are in the right place at the right time doing the right things) (Gulick, 1937). The leadership roles resonated with participants because leader may be the image most commonly associated with CEO. In the literature leader was designated as one of the most important roles of a CEO, touching all other roles within an organization (Goleman et al., 2002; Mintzberg, 1973; Steiner et al., 1981). The data obtained in this study support this conclusion. Some participants criticized the survey for the use of "I" in describing the CEO roles, indicating that the role was less focused on the CEO as an individual and more focused on the CEO's ability to lead and motivate the teams making up their organizations.

The decisional roles also received a large percentage of strongly agreed or agreed responses from the participants. These roles include disturbance handler (96.7\% strongly agreed or agreed with this role description - I take charge when my organization is threatened) (Mintzberg, 1973), task master (96.6\% strongly agreed or agreed - I have a strong focus on results or getting the job done) (Hart \& Quinn, 1993), resource allocator (91.5\% strongly agreed or agreed - I decide where my organization will expend efforts and resources) (Mintzberg, 1973), and staffer (87.7\% strongly agreed or agreed - I make sure the right people are hired for the right positions) (Gulick, 1937). Participant alignment with the decisional roles seems natural based on the CEOs unique authority to guide the direction of the organization either through independent decision making or 
through the process of influencing consensual decision making. CEOs are perceived as having the final say in guiding the organization (Breene et al., 2007).

The strategic roles also received strong ratings as CEO roles. Vision Setter (Hart \& Quinn, 1993) received the most strongly agreed/agreed responses (93.5\% of participants) to the description I create a sense of identity and mission for my organization. Also included are creator/maintainer of culture (91.6\% strongly agreed/agreed - I establish and ensure the organization's culture is consistent with its strategic focus and plan) (Sashkin \& Fullmer, 1988), coordinator, (90.8\% strongly agreed/agreed - I make sure all efforts are coordinated towards the goals and strategic plan of the organization) (Fayol, 1916; Gulick, 1937), innovator (87.9\% strongly agreed/agreed - I guide the organization into new cycles of innovation) (Galambos, 1995), transformer (83.4\% strongly agreed/agreed - I transform the organization as markets and the external environment change) (Galambos, 1995), strategist (83.1\% strongly agreed/agreed - I craft the organization's strategy) (Stata, 1988), and planner (80\% strongly agreed/agreed - I do both short-term and long-term planning) (Fayol, 1916; Gulick, 1937).

Strong participant responses to the strategic roles were surprising in light of the suggestions that CEOs do not have time for strategic planning (Carlson, 1951; Mintzberg, 1973) but may suggest a shift in the CEO role based on the challenges of difficult economic times and increasingly complex operating environments. Many of the study participants referred to pre-depression and post-depression sales revenue numbers and employee numbers, suggesting that many of the organizations were deeply impacted by the economic challenges of the past few years. While the addition of Chief Strategy 
Officers to top management teams has been recommended (Breene, et al., 2007), economic realities may be forcing CEOs to fill this role themselves to insure survival of the organizations they lead. Timing of the survey may have also influenced responses to the strategic roles. The survey was sent in late October, 2010, a time when many companies are finalizing projections for the current year and creating financial and operating strategies for the coming year. A strong focus on strategy at the time of taking the survey may have influenced responses to these roles.

The diplomacy role categories were more controversial in terms of agreement by the participants. Figurehead received the majority of strongly agree/agree responses in this category with $87.5 \%$ (I represent the organization in formal matters) (Mintzberg, 1973). Liaison received $74.2 \%$ strongly agreed/agreed responses (I interact with peers and others outside the organization to gain favors and information) (Mintzberg, 1973), and link received $66.9 \%$ strongly agreed/agreed responses (I link the external world to the world inside the organization) (Lafley, 2009). The link role was described by A. G. Lafley, former CEO of Proctor and Gamble in 2009 as the one role that only the CEO can perform. This new role may resonate more strongly with CEOs from large, global organizations like Proctor and Gamble, however, in this study the CEOs from privatelyheld companies actually agreed more strongly with the link role than the CEOs from publicly-held companies.

The operational roles were fairly controversial yet organizer (I make sure deadlines are met) (Fayol, 1916) and analyzer (I focus on efficient management of the internal operating system in the interest of serving existing products/markets) (Hart \& Quinn, 1993) received $65.6 \%$ and $60.8 \%$ strongly agree/agree responses, respectively. 
Controller (I make sure projects are completed on time) (Fayol, 1916) received 55.1\% strongly agree/agree responses while almost $30 \%$ of participants neither agreed nor disagreed that this is a CEO role. Operator (I make sure that day-to-day operations are being completed in a satisfactory manner) (Howe, 1988) was even more controversial. Of the responses, $47.2 \%$ strongly agreed/agreed, $25.1 \%$ neither agreed nor disagreed, and 27.7\% disagreed or strongly disagreed that operator is a CEO role. The controversy in these roles may be the result of organizations that employ COOs (chief operating officers) or other c-level executives responsible for operational activities. It is also possible that many CEOs do not feel it is their role to direct the day-to-day activities of their organizations and in many cases they may not have time to do this. It may be more accurate to view the $\mathrm{CEO}$ role as one that guides the general direction of the organization from a 50,000 foot view, with much less involvement in day-to-day details.

The informational role category, which was changed substantially by factor analysis, was the most controversial. While negotiator (I am compelled to enter negotiations on behalf of my organization) (Mintzberg, 1973) received 65.4\% strongly agree/agree responses, the remaining roles received less than 50\% strongly agree/agree responses. Of responses to the spokesperson role (I disseminate the organization's information into the business world) (Mintzberg, 1973), 46.8\% strongly agreed/agreed, $23.3 \%$ neither agreed nor disagreed, and $29.9 \%$ disagreed or strongly disagreed that this was a CEO role. Technical expert (I am the expert on product and market) (Lau et al., 1979) was split $38.4 \%$ strongly agreed/agreed, $32.4 \%$ neither agreed nor disagreed, and 29.2\% disagreed/strongly disagreed with this role. Finally, problem solver (I am the person who solves the organization's problems) (Lau et al., 1979) was split $36.1 \%$ 
strongly agreed/agreed, $39.1 \%$ neither agreed/disagreed, and $24.8 \%$ of participants disagreed/strongly disagreed that this is a CEO role.

In today's business environment the negotiator role may be delegated to corporate attorneys more qualified to navigate the complexities of legal negotiations. This may be the result of a much more litigious and complicated business environment today than during the 1970s when Mintzberg identified this as a CEO role. The spokesperson role is frequently the responsibility of the investor or public relations department and this may partially explain disagreement with this role. The roles of technical expert and problem solver are likely delegated to individuals more familiar with the day-to-day operations of an organization making these roles more controversial among participants. In hightechnology and biotechnology firms engineers and scientists are frequently the experts in the technical aspects of the business while CEOs are viewed as the experts in business management and leadership.

Factor analysis results indicated that four roles did not load in this category and two that loaded together were not used in the final analysis of data. Four of these roles, monitor (I receive and collect information enabling me to develop a thorough understanding of my organization) (Mintzberg, 1973), disseminator (I transmit special information into the organization (Mintzberg, 1973), entrepreneur (I initiate changes within the organization) (Mintzberg, 1973), and consultant (I provide advice on issues that arise within the organization) (Lafley, 2009) received strongly agreed/agreed responses in excess of 90\%. Conflict handler (I handle conflicts that arise between individuals and outside organizations) (Castaldi, 1986), and commander (I give orders to 
employees) (Gulick, 1937), received strongly agree/agree responses from $76.6 \%$ and $62.0 \%$ of participants, respectively.

In summary, all 31 roles included on the survey received some strongly agree/agree responses and all 31 roles also received neither agree nor disagree, disagree, and strongly disagree responses. Roles with less than 50\% strongly agree/agree responses totaled four. Combined with the six roles rejected by factor analysis the total number of roles could be reduced to 21 . The leader role was the most agreed-upon role and problem solver was the least agreed upon by the study participants. The interpersonal role categories were most agreed-upon by all participants while the informational role categories were least agreed-upon. Many of the CEO roles identified in the twentieth century still reflect the role of the $\mathrm{CEO}$ in the twenty-first century, even though the business environment has changed significantly. In addition, new roles have been identified confirming the complex and evolving nature of the role of CEO (Lafley, 2009).

\section{Research Question Two}

Research question two asked how much time do CEOs approximate they spend in six categories of roles? In direct conflict with Mintzberg's theory the participants indicated they spend $21.0 \%$ of their time in the strategic roles (Table 22). Mintzberg (1973) argued that CEOs do not have time for strategy. There are many possible reasons for the substantial amount of time study participants allocated to the strategic roles. It is possible, but hopefully unlikely, that the responses were based on how CEOs think they should allocate their time. It is also possible that the responses had something to do with the timing of this survey. The survey was sent late October through late November, 2010, which is the time when many companies are finalizing current year projections and 
creating budgets and strategic plans for the following fiscal year. The participants may have been spending more time focused on strategy when they received this particular survey, influencing their responses. It is also possible that in light of the current economic conditions CEOs need to be and indeed are spending more focused time on strategy. It is possible that the complexity and uncertainty of the business environment today has forced CEOs to finally focus their time on strategy while leaving less urgent roles, like operations, to COOs, CFOs, and CIOs.

Interpersonal, decisional, and operational roles received almost equal allocations of time, $17.5 \%, 18.1 \%$, and $18.0 \%$, respectively. One might expect more time to find more time spent in the interpersonal roles (leader, motivator, and director) based on the strong agreement with this role category. Conversely, the controversy within the operational roles would suggest less time might be spent in this category, however, this is not the case. Further exploration of this inconsistency might be best studied using interviews or other qualitative methods to understand why CEOs spend time in roles they may not necessarily believe to be their roles.

Participants spent $14.6 \%$ of their time in the informational roles. This may be due to the use of investor relations and public relations departments today that might not have been used 40 years ago. Participants spent the least amount of time in diplomacy roles (10.8\%), which included link, liaison, and figurehead. The link role did not resonate strongly with participants, perhaps because there were more privately-held company CEOs than publicly-traded company CEOs in this study. 


\section{Research Question Three}

Research question three asked what roles are identified by CEOs that were not identified in the literature on the role of CEO? Other roles suggested by participants that are different from the roles included on the survey include coach, mentor, cheerleader, succession planner, consensus builder, liaison with Board of Directors, community involvement and outreach, driver of sustainability, investor relations, financial oversight, fund raising, enabler, chief storyteller, recruiter, thought leader, industry positioner, and chief embodiment of the values of the organization. The chief storyteller role was also suggested in the pilot study of the survey and included the description telling stories to reinforce the culture. The Board of Directors liaison role was mentioned by several participants as a key role of the CEO, yet participants did not feel the survey reflected this important role.

It is not surprising that the CEOs role as liaison with the Board of Directors was mentioned. In light of scandals like Enron, Boards are now held to higher levels of accountability than ever before and may be more involved with the CEO than they were prior to Sarbannes Oxley (2000). The current focus on corporate social responsibility and increased regulatory pressure created by the Dodd-Frank Wall Street Reform and Consumer Protection Act (the Dodd-Frank Act), intended to enhance corporate governance, market structure, and corporate disclosure (www.BDO.com; Woods, 2011) may increase the difficultly in accessing CEOs from publicly-traded companies. The extensive rule-making and regulation forced upon public companies certainly may influence the complexity of the CEO role, in addition to putting the $\mathrm{CEO}$ in a defensive posture. 
The new roles identified by participants are important for future development of the survey instrument and for theory-building or theory refinement related to the role of CEO. Descriptions of these roles are necessary for refining the survey instrument and may be best obtained through a focus group of CEOs.

\section{Eight Research Hypotheses}

There were eight research hypotheses for this research study, and they were as follows:

H1) There is no difference between gender, agreement with the 31 role descriptions, and time allocated to the six role categories.

HIa) Female CEOs will report they spend more time in interpersonal roles than their male counterparts.

H1b) Female CEOs will report they spend less time in operational roles than their male counterparts.

H2) CEOs from public companies will report they spend less than $10 \%$ of their time in strategic role categories.

H3) Agreement with and time spent in the role categories will not differ depending upon the CEOs degree major or industry background.

H4) There will be no difference in the way CEOs spend their time between CEOs with other C-level executives working for them, and those without $C$-level executives.

H5) There will be an association between age, years in current job, years as a CEO, last degree earned, company size and agreement with each role category.

H6) There will be no difference in the responses on role agreement and time spent in the role categories between CEOs from privately-held versus publicly-held companies. 
H7) There will be no difference in the responses on role agreement and time allocations to role categories between a convenience sample of CEOs and a random sample of CEOs.

H8) There will be no difference in the responses on role agreement and time allocations between CEOs from small companies and CEOs from large companies.

This section discusses the research results and conclusions for each of the eight hypotheses. Possible explanations for the resulting conclusions are provided.

Research Hypothesis One

There is no difference between gender, agreement with the 31 role descriptions, and time allocated to the six role categories was partially supported by the findings. There were no statistically significant differences between male and female CEOs in terms of time spent in the six role categories. Males and females showed statistically significant differences in agreement with the operational, strategic, and diplomacy role categories, however effect sizes were small to medium, $d=.23, .29$ and .39 , respectively, leading to the conclusion that there is very little practical significance in the response differences between male and female CEOs. In all cases the female participants agreed more strongly with the roles than their male counterparts, and female participants agreed more strongly with all of the roles than male participants.

Most empirical research on female CEOs focuses on the glass ceiling or on differences in compensation structure between males and females. The focus of this study, CEO roles and time allocations to roles does not appear in current research on CEOs. The findings of this research suggest that male and females CEOs may not be substantially different in terms of how they execute the role of CEO. It seems logical that 
female CEOs would need to know the role as well as their male counterparts. This is further supported by Research Hypotheses One (a) and (b).

Research Hypotheses One (a) and One (b)

Female CEOs will spend more time in interpersonal roles than their male counterparts and female CEOs will spend less time in operational roles than their male counterparts were supported by the evidence, but the differences were minimal. It seems there are only minor differences in role agreement and time allocated to roles between male and female CEOs and this is not surprising. Female CEOs may hold the CEO position because they understand the expectations of the role just as well as their male counterparts.

Research Hypothesis Two

CEOs from public companies will spend less than $10 \%$ of their time in strategic role categories was not supported by the data. CEOs from public companies were not substantially different than CEOs from private companies in their time allocations (Table 28). This conflicts with the belief that the ownership status of a company impacts the role of the CEO (Mintzberg, 1973). It seems that the impact of publicly-traded ownership may not be as significant today as it was in the past. More likely, today private company CEOs experience similar pressures as their public company counterparts, a result of the complex business environment and strong competition.

Research Hypothesis Three

Agreement with and time spent in the role categories will not differ depending on the CEOs degree major or industry background was not supported. There were small differences in agreement with the informational roles between finance majors and 
technical/engineering majors, with the latter agreeing more strongly that these are CEO roles. There were also small differences in agreement with the decisional role category between operations majors and technical/engineering majors, with the latter agreeing more strongly that these are CEO roles. Overall, there was stronger agreement on the interpersonal and decisional role categories, with means ranging from 1.48 to $1.66(1=$ strongly agree) than the other categories. Time allocations were also different. Operations and technical/engineering majors had higher mean ranks in the operational role category than finance majors. In terms of practical significance, all of the effect sizes were small.

Research Hypothesis Four

There will be no difference in the way CEOs spend their time between CEOs with other $C$-level executives working for them, and those without $C$-level executives was not supported. There were statistically significant differences with small effect sizes in the interpersonal, operational, strategic, and diplomacy categories. In all categories the CEOs with other C-level executives had higher mean ranks than those without other C-level executives, with the exception of the operational roles. This finding may indicate that CEOs who utilize other C-level executives need to spend less time in operational roles than those who do not.

\section{Research Hypothesis Five}

There will be an association between age, years in current job, years as a CEO, last degree earned, company size, and agreement with each role category was not supported by the data. These variables explained a very insignificant amount of the variance in role agreement and time allocations across the participants. This result leads to a very important question, what factors do influence role agreement and time spent in 
roles by CEOs? This question remains unanswered by this research study. One could speculate that the contextual nature of business may influence this role including the economy, the business cycle, and the uniqueness of specific industries. Some have indicated that the CEO's personality influences the role and the way time is allocated (Hart \& Quinn, 1993; Zaccaro, 2001). It is also possible that multiple regression was not the appropriate model for understanding these relationships.

Research Hypothesis Six

There will be no difference in responses on role agreement and time spent in the role categories between CEOs from privately-held versus publicly-held companies was not supported. There were small differences in role agreement in the informational, interpersonal, and diplomacy role categories. Public company CEOs agreed more strongly with the interpersonal roles and private company CEOs agreed more strongly with the informational and diplomacy roles. While the differences were small they seem logical. A CEO in a publicly-traded company is more likely to be known by name than a CEO in a privately-held company therefore, the public company CEO may identify more strongly with the leader role due to his/her notoriety. Private company CEOs are less likely to have investor relations or public relations departments handling information requests; this may make the informational roles resonate more with private company CEOs. There were small differences in time allocations between the CEOs in the interpersonal role category.

Research Hypothesis Seven

There will be no difference in the responses on role agreement and time allocations to role categories between a convenience sample of CEOs and a random 
sample of CEOs was supported by the data. At the beginning of this research project the researcher believed the most productive way to access CEOs would be through personal contacts (Martinko \& Gardner, 1985; Thomas, 1995). The problem with this approach was the limited sample size. Thus, a database of companies that included CEO e-mail addresses was purchased. This random sample was much more fruitful than anticipated and led to a stronger study, yet there were no significant differences between the two groups of respondents.

\section{Research Hypothesis Eight}

There will be no difference in the responses on role agreement and time allocations between CEOs from small companies and CEOs from large companies was not supported by the data. In fact there were statistically significant differences on agreement in all role categories across three levels of company size based on employee numbers, small, medium, and large. Company sizes were defined by the World Bank standards of small (less than 100 employees), medium (between 100 and 500 employees), and large (over 500 employees) (www.worldbank.com).

There were differences in time allocations between small and medium size companies in the informational (medium effect size), operational, decisional, strategic, and diplomacy role categories (small effect size). Small and large size companies differed in the interpersonal (medium effect size), informational, operational, and strategic categories (small effect sizes). Medium and large size companies differed in the interpersonal and decisional categories (small effect sizes). These differences lend support to research on $\mathrm{CEO}$ failure rates and the thesis that "something changes when a company reaches a certain size that makes it somehow different to manage" (Tuck \& 
Earle, 1996, p. 19). This may suggest that CEOs have difficulty transitioning to companies that are substantially larger or smaller than they are accustomed to leading.

\section{Summary of the Findings}

This section will summarize the findings from the research questions and hypotheses by discussing potential factors influencing participant agreement with the roles and time allocated to the role categories. It will also identify questions that remain unanswered and discuss the limitations of this study.

Agreement with Roles

Mintzberg's (1973) theory about the role of CEOs was a foundational theory for the conduct of this research. All ten of the roles identified by Mintzberg received support by the study participants as roles of the Chief Executive Officer. Factor analysis indicated that three of the roles, monitor, disseminator, and entrepreneur, may not be measuring what they were intended to measure. Two roles, spokesperson and negotiator were controversial roles from the CEOs perspectives perhaps because these roles can be delegated to investor relations and legal departments. The data revealed that the informational role category may not be as relevant today as it was during the 1970s.

While Mintzberg (1973) disagreed with Gulick (1937) and Fayol (1916) about the practice of management as science, their seven roles, commander, director, staffer, organizer, controller, coordinator, and planner still received substantial support from CEOs as roles that are reflective of the CEO. Four roles suggested by Hart \& Quinn in 1993 received support as being roles of a CEO: motivator, task master, analyzer, and vision setter. The strategic roles of innovator and transformer (Galambos, 1995), strategist (Stata, 1988) and creator/maintainer of culture (Sashkin \& Fullmer, 1988) also 
received support as CEO roles. Link and consultant (Lafley, 2009) were supported as CEO roles, along with conflict handler (Zaccaro, 2001). Roles receiving less support included: technical expert (Lau et al., 1979), problem solver (Lau et al., 1979), and operator (Howe, 1988). Of the 31 roles suggested by the literature review and used in the survey instrument, 26 roles received strong support as being CEO roles from the study participants.

Though not the purpose of this research it now seems possible to begin the process of updating and refining theory that informs the role of CEO. Roles that no longer resonate with CEOs like technical expert, problem solver, and operator may now be considered the roles of other $\mathrm{C}$-level executives within an organization. New roles including Board of Director liaison and chief embodiment of the values of the organization can be added as roles reflective of the changed nature of the CEO role. Time Allocated to the Role Categories

This study is believed to be one of the first to ask CEOs to allocate their time across role categories. Some researchers have attempted to understand how CEOs spend their time while observing them at work while others have asked CEOs about the importance of the ten roles identified by Mintzberg (Beggs \& Doolittle, 1988; Mintzberg, 1973; Tengblad, 2006). It was surprising to find $21 \%$ of participant's time spent in strategic roles and $18 \%$ of their time spent in operational roles. The operational roles were not strongly agreed upon as the role of CEO. Table 45 provides a summary of the time allocations from this research compared to other studies on CEOs that provided time-related data. 
Table 45

Comparison Data: Time Allocations to Role Categories

\begin{tabular}{|c|c|c|c|c|}
\hline $\begin{array}{l}\text { Role } \\
\text { Categories }\end{array}$ & $\begin{array}{l}\text { Mintzberg } \\
(1973) \\
N=5\end{array}$ & $\begin{array}{l}\text { Whitely } \\
\text { (1978) } \\
\mathrm{N}=7\end{array}$ & $\begin{array}{l}\text { Tengblad } \\
(2006) \\
N=4\end{array}$ & $\begin{array}{l}\text { Glick } \\
(2010) \\
\mathrm{N}= \\
1,202\end{array}$ \\
\hline Informational & $40.0 \%$ & $\begin{array}{l}65.9 \% \\
\text { (includes } \\
\text { interpersonal) }\end{array}$ & $61.0 \%$ & $14.6 \%$ \\
\hline Interpersonal & $39.0 \%$ & & $29.0 \%$ & $17.5 \%$ \\
\hline Decisional & $21.0 \%$ & $34.1 \%$ & $\begin{array}{l}10.0 \% \\
\text { (includes } \\
\text { strategy) }\end{array}$ & $18.1 \%$ \\
\hline Operational & - & - & - & $18.0 \%$ \\
\hline Strategic & - & - & - & $21.0 \%$ \\
\hline Diplomacy & - & - & - & $10.8 \%$ \\
\hline
\end{tabular}

Factors Influencing Role Agreement and Time Spent in Role Categories

Gender, major of last degree or industry focus, having other C-level executives working for them, and company ownership status, i.e., publicly versus privately-held, had only small influences on agreement with CEO roles and time allocations. When combined, age, years in current job, years as a CEO, last degree earned, and company size in sales revenue were not predictive in determining agreement with the CEO roles, nor was there much association between these variables and role agreement. Company size in terms of employee numbers was a factor impacting the most significant differences in the way CEOs responded to role agreement and how they allocated their time. 
It is likely other factors may have more influence on the role of CEO than were considered by this study. These factors include current economic conditions, availability of capital, whether a company has just been sold or is in acquisition mode, and company stability (existing companies versus start-ups). Several CEOs in this study indicated that they were spending more time on financial issues, a direct result of the difficult economic conditions they face. Some CEOs indicated that managing the Board of Directors took a substantial amount of their time yet did not see this role reflected in the categories presented in the survey.

Limitations of the Study

There were many factors that limited this study on CEOs. The database purchased was done so based on the availability of CEO e-mail addresses, however many companies are still able to keep this information confidential. In some cases the e-mail addresses included info as the name so these went to a general e-mail address that most likely never reached the CEO. Many CEOs have their e-mail screened by assistants and it is possible many CEOs never saw the survey. While there were a wide variety of company sizes and industries, private companies outnumbered public companies six to one. As expected, male CEOs outnumbered female CEOs seven to one.

There are many control variables that may have provided additional depth to this study. Industry-specific variables not controlled for in this study include geographic region(s) of the organization, industry sector, products imported or exported by the organization, whether or not the organization is service-oriented, organizational financial health, business life-cycle placement and age of organization, and organizational culture, i.e., whether it is a hierarchical or team-based organization. Individual CEO characteristic 
variables that were not controlled for in this study include schools attended, roles

previously held, and number of job or industry changes. Additional research that controls for these organizational or individual-specific variables may provide new insight into the role of CEO and the way CEOs choose to spend their time.

Many of the comments received by CEOs indicated that the roles on the survey were too limiting and did not cover the breadth of roles that CEOs are expected to engage in. One CEO indicated that if they were doing an optimal job they would be doing all of the roles included on the survey. It is impossible to know whether the participants answered the questions honestly or provided the answers that they believed were most favorable. There is also no way to know how accurate the time allocations were. The study was conducted only from the CEOs perspective. The ability of participants to "selfselect" can lead to errors including undermining "the extent to which the composition of the panel mirrors the composition of the general public and likely leads to biased results" (Dillman et al., 2007, p. 338). The expectations of boards of directors and other C-level executives were not considered for this study. This study was limited to CEOs in the U.S. so the results may not be indicative of CEOs from other countries. Use of the survey instrument was a pilot study_ it was designed specifically for this research, limiting its validity and reliability (Dillman et al., 2007). Other than the data obtained through exploratory factor analysis there are no other measures available to support the instrument's validity and reliability (Gliner et al., 2009). 
Implications and Recommendations for Future Research

This final section will discuss the implications for theory, research, and practice while making recommendations for future research to enhance the body of knowledge about the role of CEO.

Implications for Theory

One goal for this study was further refinement of Mintzberg's theory of the role of CEO. According to Lynham (2002) theory requires an on-going process of refinement and development which "ensures that the relevance and rigor of the theory are continuously attended to and improved on by theorists through further inquiry and application in the real world" (p. 234). Mintzberg's theory was built deductively using a "research-to-theory" strategy (Lynham, 2002, p. 225). During the 1970s and early 1980s many individuals contributed to the theory by using "theory-to-research" strategies, yet many of these theories were not proven to be useful in practice, thus leaving a gap that was the focus of this study (Lynham, 2002, p. 225).

Using the general method of theory building described by Lynham (2002) the ongoing process of theory development requires five phases including, conceptual development (the theory was originally conceived by Mintzberg in 1973), operationalization, confirmation or disconfirmation, and application. The operationalization phase requires testing in real-world situations. Many doctoral students attempted this phase leading to conflicting results, perhaps the result of small sample sizes. Confirmation or disconfirmation is the intentional design of research for this purpose, that is, to confirm or disconfirm a theory. This particular study has provided data that both confirm and disconfirm Mintzberg's original theory. It has also provided 
confirmation and disconfirmation by roles proposed by other researchers, hopefully expanding and updating Mintzberg's original theory about the role of CEO. A next phase for this research is the application phase in which a real-world CEO would test the effectiveness of the time allocations and the role categories within their organization. Finally, all theories require ongoing refinement and development to ensure their applicability to real world situations (Lynham, 2002).

Further refinement and development of a theory of the role of CEO may be beneficial to HRD professionals and HRD directors who are responsible for change interventions and for creating CEO succession plans. A clear understanding of the CEOs role and time spent in roles may be useful in interventions designed at enforcing organizational culture while at the same time making changes necessary for the continuing advancement of the organization. To enable the identification and development of future CEOs a theory that explains the role of CEO under a variety of individual and organizational variables may be extremely practical. Theory-building may also be improved with new research that controls for organizational and individual characteristics not addressed by this study, but discussed in the limitations section. Implications for Research

Data collected during the survey can be utilized to further this study in several ways. One of the unanswered questions resulting from this study is what factors do influence role agreement and time spent in roles by CEOs? While company size based on employee numbers resulted in statistically significant differences in responses to role agreement and time allocations, is there additional influence based on industry? Is there a relationship between industry, company size, and agreement with roles and time 
allocations to role categories? While not part of my original research these findings could be important for CEOs in specific industry categories. This information could be particularly important for a CEO switching jobs in a new industry where roles and time allocations may be significantly different than those in their current job. Perhaps this information could help CEOs transition more efficiently, helping to reduce excessive turnover.

The unsolicited qualitative data collected were not analyzed for this study. The unsolicited insights, remarks, criticisms, and words of encouragement were some of the most interesting data obtained, yet they were not consistent with the quantitative/postpositivist methodological strategy of this study. To deeply understand the factors influencing role and time allocations, in-depth discussions with CEOs are necessary. While the hard, quantitative data are difficult to argue with, it is impossible to delve deeper for more meaning and understanding. For example, while the data showed little differences between male and female CEOs, intuitively it seems there must be interesting and insightful differences in the experiences and expectations of both male and female CEOs. These experiences can only be learned through qualitative methods. Research on the role of CEO has been criticized for its failure to find similarities while only looking for differences (Hales, 1999). The focus on differences may be due to the nature of hypothesis testing. Perhaps qualitative methods would be more appropriate for identifying similarities in the role of CEO.

Further research controlling for different individual and organizational variables may be extremely useful for CEOs, Boards of Directors, HRD professionals, and HR directors. Research focused on the perspective of other C-level executives may be useful 
not only for COOs, CFOs, and CIOs, but also for the CEOs they work for, Boards of Directors, HRD professionals, and HR directors. Especially for CEOs understanding the gaps between their perception of their role and the way employees and Boards perceive their role could be critical for closing the gap between role expectations and actual performance of the role.

Implications for Practice

The results of this study could have practical implications for a variety of stakeholders including HR directors, Boards of Directors, CEOs, and a variety of other stakeholders who are impacted by the leadership of organizations, including employees, investors, and the public.

HR directors could utilize the CEO role information in creating job descriptions or evaluation plans for CEOs within their organizations. The role information could also be used for succession planning purposes. A refined theory of the role of CEO may help to identify roles that are necessary when certain organizational conditions exist. Boards of Directors could use the roles and the time allocations as benchmarks for the CEOs whose performance they evaluate. They may use the time information to compare the role of the $\mathrm{CEO}$ with other $\mathrm{C}$-level executives within the organization, making sure that efforts are not duplicated.

A working CEO could use the results of this research in three different ways. First, the roles identified and agreed-upon could be used as a benchmark for the CEOs own job description. There may be roles identified is this study that the CEO had not considered part of their job. Further, a CEO interested in expanding research on the role of CEO might identify new roles, providing clarity to the role of CEO while contributing 
knowledge that informs continual refinement of the theory. A third practical use of the study findings is the time allocations. A CEO could use the time allocations as a benchmark for how they spend their time at work, potentially identifying areas that are important to the position but that need more concentrated focus. This may prevent a CEO from spending time in roles they are most comfortable in, where they may duplicate efforts of other c-level executives.

Employees, investors, and consumers who depend upon organizations for basic needs as well as creature comforts are also impacted by this research. For example, CEOs who know what the role is and how to allocate their time may be more efficient and effective in leading their organizations. Hopefully this leads to higher quality products and financial returns that benefit investors with direct interests in the organizations as well as the economy in general.

Conclusion

This chapter has described the conclusions from participant responses to the research survey by discussing responses to the three research questions and presenting the results of testing the research hypotheses. The study findings were summarized and the implications for theory, research, and practice were presented. While this study has not revealed significant changes to the role of the CEO it has added new roles, confirmed and disconfirmed CEO roles that are over 40 years old, and has supported the thesis of a complex and evolving nature of the role of CEO. This study has provided data that further refine Mintzberg's theory on the role of CEO. Data on how CEOs allocate their time has been added to the body of knowledge on the role of CEO and have confirmed the impact of company size on the role of CEO. Hopefully this study has created 
opportunity and interest in future research on CEOs and has provided insight on what CEOs today perceive as the role of Chief Executive Officer. 


\section{REFERENCES}

Adams, S. M., Gupta, A., \& Leeth, J. D. (2009). Are female executives over-represented in precarious leadership positions? British Journal of Management, 20, 1-12. doi:10.1111/j.1467-8551.2007.00549.x

Ahmed, S. (2005). Desired competencies and job duties of non-profit CEOs in relation to the current challenges. Journal of Management Development, 24(10), 913-928. doi:10.1108/02621710510627055

Allgood, S. \& Farrell, K. A. (2003). The match between CEO and firm. Journal of Business, 76(2), 317-341. doi:10.1086/367752

Antonioni, D. (2003). Leading with responsibility. Industrial Management, Nov/Dec, 2003, 8-15.

Apospori, E., Papalexandris, N., \& Galanaki, E. (2005). Entrepreneurial and professional CEOs: Differences in motive and responsibility profile. Leadership \& Organization Development Journal, 26(2), 141-162. doi: $10.1108 / 01437730510582572$

Argyris, C., \& Schon, D. (1978). Organizational Learning: A Theory of Action Perspective. Reading, MA: Addison-Wesley.

Bartholomew, S. \& Smith, A. D. (2006). Improving survey response rates from chief executive officers in small firms: The importance of social networks. Entrepreneurship Theory and Practice, Journal of Small Business Management, (January, 2006), 83-96.

Bass, B. M. (1985). Leadership and Performance Beyond Expectations. New York: Free Press.

Bass, B. M. (1990). Bass \& Stogdills's Handbook of Leadership: Theory, Research, and Managerial Applications. ( $3^{\text {rd }}$ ed.) New York, NY: The Free Press.

Bass, B. M. (1998). Transformational leadership: Industry, military, and educational impact. Mahwah, NJ: Lawrence Erlbaum Associates.

BDO Knows: SEC (2011). The Newsletter from BDO's National Assurance Practice. Retrieved from: $\underline{w w w . b d o . c o m}$. 
Beggs, J. M. \& Doolittle, D. C. (1988). Mintzberg revisited: A study of chief executive officers. Leadership and Organization Development Journal, 9(6), 17-21. doi:10.1108/eb053648

Bennett, E. E. \& Bierema, L. L. (2010). The ecology of virtual human resource development. Advances in Developing Human Resources, 12(6), 632-647. doi: $10.1177 / 1523422310394789$

Biddle, B. J. (1986). Recent developments in role theory. Annual Review of Sociology, 12, 67-92. doi:10.1146/annurev.so.12.080186.000435

Biddle, B. J. and Thomas, E. J. (Eds.) (1966). Role theory concepts and research. New York, NY: John Wiley \& Sons.

Bing, J. W., Kehrhahn, M., \& Short, D. C. (2003). Challenges to the field of human resource development. Advances in Developing Human Resources, 5(3), 342-351. doi: $10.1177 / 1523422303254671$

Block, P. (1993). Stewardship: Choosing Service over Self-Interest, San Franciso, CA: Berrett-Koehler.

Bloxham, E. (2010). Should CEO be a team job? Retrieved September 13, 2010 from http://money.cnn.com

Boal, K. B. \& Hooijberg, R. (2001). Strategic leadership research: Moving on. Leadership Quarterly, 11(4), 515-549.

Boatright, J. R. (2009). From hired hands to co-owners: Compensation, team production, and the role of the CEO. Business Ethics Quarterly, 19(4), 471-496.

Bodwell, W., \& Chermack, T. J. (2010). Organizational ambidexterity: Integrating deliberate and emergent strategy with scenario planning. Technological Forecasting and Social Change, 77(2), 193-202. doi:10.1016/j.techfore.2009.07.004

Breene, R. T. S., Nunes, P. F., \& Shill, W. E. (2007). The chief strategy officer. Harvard Business Review, 85(10), 84-93.

Carlson, S. (1951). Executive Behavior. Stockholm, SE: Stromberg's.

Carroll, S.J. \& Gillen, D.J. (1987). Are the classical management functions useful in describing managerial work? The Academy of Management Review, 12(1), 38-51.

Carter, J. E. (1982). Variations among executive role strengths in U.S. firm at different levels of international involvement (Doctoral dissertation). Retrieved from 
Proquest Dissertations and Theses database. (UMI No. 8308819)

Case, T. S. (2009). Millions spent on CEO turnover: A study of learning and sensemaking of new CEO leaders (Doctoral dissertation). Retrieved from ProQuest

Dissertations and Theses database. (UMI No. 3344718)

Castaldi, R. M. (1986). An analysis of the work roles of CEOs of small firms. American Journal of Small Business, 11 (1), 53-64.

Charan, R. (2005). Ending the CEO succession crisis. Harvard Business Review, 83(2), $72-81$.

Chermack, T. J. (2003). Mental models in decision making. Advances in Developing Human Resources, 5(4), 408-422. doi:10.1177/1523422303257373

Collins, J. (2001). Good to Great. New York, NY: HarperCollins Publishers Inc

Coyne, K. \& Rao, B. (2005). A guide for the CEO-elect. McKinsey Quarterly, 3, 46-53.

Creswell, J.W. (2002). Educational Research: Planning, Conducting, and Evaluating Quantitative and Qualitative Research. Upper Saddle River, NJ: Pearson Education, Inc.

Cummings, T. G., \& Worley, C. G. (2009). Organization development and change. Mason, OH: South-Western Cengage Learning.

Cunningham, P. W., Lynham, S. A., \& Weatherly, G. (2006). National human resource development in transitioning societies in the developing world: South Africa. Advances in Developing Human Resources, 8(1), 62-83. doi: $10.1177 / 152342235283059$

Dillman, D. A. (2007). Mail and internet surveys: The tailored design method (2nd ed.). Hoboken, NJ: John Wiley \& Sons, Inc.

Dillman, D. A., Smyth, J. D., \& Christian, L. M. (2009). Internet, mail and mixed-mode surveys: The tailored design method ( ${ }^{\text {rd }}$ ed.). Hoboken, NJ: John Wiley \& Sons.

Dooley, L. M. \& Lindner, J. R. (2003). The handling of nonresponse error. Human Resource Development Quarterly, 14(1), 99-110.

Edersheim, E. H. (2007). Peter Drucker's “unfinished chapter:” The role of the CEO. Leader to Leader, 45, 40-46. doi:10.1002/lt1.242

Ertugrul, M. \& Krishnan, K., (2011). Can CEO dismissals be proactive? Journal of Corporate Finance, 17, 134-151. doi:10.1016/j.jcorpfin.2010.09.008 
Favaro, K., Karlsson, P., \& Neilson, G. L. (2010). CEO succession 2000-2009: A decade of convergence and compression. Retrieved May 26, 2010 from

Strategy+Business website: http://www.strategy-

business.com/article/10208?pg=all\&tid=27782251

Fink, A. (2006). How To Conduct Surveys: A Step-by-Step Guide ( ${ }^{\text {rd }}$ ed.). Thousand Oaks, CA: Sage Publications.

Fisher, C. D. \& Gitelson, R., (1983). A meta-analysis of the correlates of role conflict and ambiguity. Journal of Applied Psychology, 68(2), 320-333. doi:10.1037/0021$\underline{9010.68 .2 .320}$

Ford, D. N. \& Sterman, J. D. (1998). Expert knowledge elicitation to improve formal and mental models. Systems Dynamics Review, 14(4), 309-340. doi:10.1002/(SICI)1099-1727(199824)14:4<309::AID-SDR154>3.0.CO;2-5

Galambos, L. (1995). The authority and responsibility of the chief executive officer: Shifting patterns in large U.S. enterprises in the twentieth century. Industrial and Corporate Change, 4(1), 187-203. doi:10.1093/icc/4.1.187

Gall, J. P., Gall, M. D., \& Borg, W. R. (2006). Applying Educational Research A Practical Guide ( $5^{\text {th }}$ ed.). Boston, MA: Pearson Education, Inc.

Gilley, J. W., Boughton, N.W., \& Maycunich, A. (1999). The Performance Challenge Developing Management Systems to Make Employees Your Organization's Greatest Asset. Cambridge, MA: Perseus Publishing.

Gliner, J. A., Morgan, G. A., and Leech, N. L. (2009). Research Methods in Applied Settings: An Integrated Approach to Design and Analysis ( $2^{\text {nd }}$ ed.). New York, NY: Taylor and Francis Group, LLC.

Goleman, D., Boyatzis, R., \& McKee, A. (2002). Primal Leadership Learning to Lead with Emotional Intelligence. Boston, MA: Harvard Business School Press.

Greenfeld, S., Winder, R. C., \& Williams, G. (1988). The CEO and the external environment. Business Horizons, 31(6), 20-25. doi:10.1016/0007-6813(88)90019$\underline{5}$

Gross, N., Mason, W., \& McEachern, A. (1958). Explorations in role analysis: Studies of the school superintendency role. New York, NY: John Wiley \& Sons.

Guba, E. G. (Ed.). (1990). The Paradigm Dialog. Newbury Park, CA: Sage Publications.

Hales, C. P. (1986). What do managers do? A critical review of the evidence. Journal of Management Studies, 23(1), 88-115. doi:10.1111/j.1467-6486.1986.tb00936.x 
Hales, C. P. (1999). Why do managers do what they do? Reconciling evidence and theory in accounts of managerial work. British Journal of Management, 10, 335-350.

Hall, B. J. \& Murphy, K. J. (2003). The trouble with stock options. The Journal of Economic Perspectives, 17(3), 49-70. doi:10.1257/089533003769204353

Hambrick, D.C. \& Mason, P.A. (1984). Upper echelons: The organization as a reflection of its top managers. The Academy of Management Review, 9(2), 193-206. doi: $10.2307 / 258434$

Harris. J. D. (2009). What's wrong with executive compensation? Journal of Business Ethics, 85(1), 147-156. doi:10.1007/s10551-008-9934-6

Hart, S. L. \& Quinn, R. E. (1993). Roles executives play: CEOs, behavioral complexity, and firm performance. Human Relations, 46(5), 543-574. doi:10.1177/001872679304600501

Hawkins, J. A. (1997). Why investors push for strong corporate boards. The McKinsey Quarterly, 3, 144-148.

Hiller, N. J., Resick, C. J., Weingarden, S. M., \& Whitman, D. S. (2009). The bright-side and the dark-side of CEO personality: Examining core self-evaluations, narcissism, transformational leadership, and strategic influence. Journal of Applied Psychology, 94(6), 1365-1381. doi:10.1037/a0016238

Hofstadter, R. (1948). The American Political Tradition and the Men Who Made It. New York, NY: A.A. Knopf.

Howe, M. (1988). A test of Mintzberg's (1973) assertion that all managers perform all managerial roles, in addition to an investigation of the psychometric properties of the Pavett \& Lau (1983) questionnaire (Doctoral dissertation). University of Toronto, Toronto, Canada.

IBM Institute for Business Value (2010). Capitalizing on complexity: Insights from the Global Chief Executive Officer Study. IBM Corporation.

Ireland, R. D. \& Hitt, M. A. (1999). Achieving and maintaining strategic competitiveness in the $21^{\text {st }}$ century: The role of strategic leadership. Academy of Management Executive, 13(1), 43-57.

Jackson, S. E. \& Schuler, R. S. (1985). A meta-analysis and conceptual critique of research on role ambiguity and role conflict in work settings. Organizational Behavior and Human Decision Processes 36, 16-78. doi:10.1016/0749-5978(85)90020-2 
Jacovitz, R. (2006). C level management churn continues. Retrieved February 11, 2010, from Liberum Research Web Site:

http://www.managementchange@news.twist.com.

Jensen, M. C. \& Murphy, K. J. (1990). CEO Incentives-It's not how much you pay, but how. Harvard Business Review, 68(3), 138-149.

Johansen, B. (2007). Get There Early: Using Foresight to Provoke Strategy and Innovation. San Francisco, CA: Berrett-Koehler Publishers, Inc.

Kahn, R. L., Wolfe, D. M., Quinn, R. P., \& Snoek, J. D. (1964). Organizational stress: Studies in role conflict and ambiguity. New York, NY: John Wiley \& Sons.

Kanter, R. M. (1989). The new managerial work. Harvard Business Review, 67(6), 85-92.

Katz, D., \& Kahn, R. L. (1966). The Social Psychology of Organizations. New York, NY: John Wiley \& Sons.

King, L. A. \& King, D. W. (1990). Role conflict and role ambiguity: A critical assessment of construct validity. Psychological Bulletin 107 (1), 48-64. doi:10.1037/0033-2909.107.1.48

Kleiner, A. (2008). The age of heretics. ( $2^{\text {nd }}$ ed.) San Francisco, CA: Jossey-Bass.

Kurke, L. B. \& Aldrich, H. E. (1983). Mintzberg was right! A replication and extension of the nature of managerial work. Management Science, 29(8), 975-984. doi:10.1287/mnsc.29.8.975

Lafley, A. G. (2009). What only the CEO can do. Harvard Business Review, 87(5), 5462.

Lau, A. W., Pavett, C. M., \& Newman, A. R. (1979). The nature of managerial work: A comparison of public and private sector jobs. Academy of Management Proceedings, Detroit, MI, 339-343.

Leech, N. L., Barrett, K. C., \& Morgan, G. A. (2005). SPSS for Intermediate Statistics $\left(2^{\text {nd }}\right.$ ed.). Mahwah,NJ: Lawrence Erlbaum Associates, Publishers.

Leong, F. T., \& Austin, J. T. (Eds.) (2006). The Psychology Research Handbook. (2 ${ }^{\text {nd }}$ ed.), Thousand Oaks, CA: Sage Publications.

Lindner, J. R., Murphy, T. H., \& Briers, G. H. (2001). Handling nonresponse in social science research. Journal of Agricultural Education, 42(4), 43-53. 
Lynham, S. (1998). The development and evaluation of a model of responsible leadership for performance: Beginning the journey. Human Resource Development International, 1(2), 207-220.

Lynham, S. (2000). The development of "A theory for responsible leadership for performance" (Doctoral dissertation). Retrieved from ProQuest Dissertations and Theses database. (UMI No. 9972991)

Lynham, S. (2002). The general method of theory-building research in applied disciplines. Advances in Developing Human Resources, 4(3), 221-241.

Marginson, D., \& Bui, B. (2009). Examining the human cost of multiple role expectations. Behavioral Research in Accounting, 21 (1), 59-81. doi:10.2308/bria.2009.21.1.59

Martelli, J. \& Abels, P. (2010). The education of a leader: Educational credentials and other characteristics of chief executive officers. Journal of Education for Business, 85, 209-217. doi:10.1080/0883232090349592

Martinko, M. J. \& Gardner, W. I. (1985). Beyond structured observation: Methodological issues and new directions. The Academy of Management Review, 10(4), 676-695. doi: $10.2307 / 258038$

Mascarenhas, B. (2009). The emerging CEO agenda. Journal of International Management, 15(3), 245-250. doi:10.1016/j.intman.2009.02.002

Matsumura, E. M. \& Shin, J. Y. (2005). Corporate governance and CEO compensation: Intended and unintended consequences. Journal of Business Ethics, 62(2), 101113. doi:10.1007/ss10551-005-0175-7

Mefford, R. N. (2009). Increasing productivity in global firms: The CEO challenge. Journal of International Management, 15(3), 262-272. doi:10.1016/j.intman.2008.12.004

Mintzberg, H. (1968). The manager at work—Determining his activities, roles, and programs by structured observation (Doctoral dissertation). Massachusetts Institute of Technology, Cambridge, MA.

Mintzberg, H. (1973). The nature of managerial work. New York, NY: Harper \& Row, Publishers, Inc.

Mintzberg, H. (2009). Managing. San Francisco, CA: Berrett-Koehler Publishers, Inc. 
Mitchell, R. K., Agle, B. R., \& Wood, D. J. (1997). Toward a theory of stakeholder identification and salience: Defining the principle of who and what really counts. Academy of Management, 22(4), 853-866.

Mooney, C. H., Dalton, C. M., Dalton, D. R., \& Certo, S. T. (2007). CEO succession as a funnel: The critical, and changing, role of inside directors. Organizational Dynamics, 36(4), 418-428. doi:10.1016/j.orgdyn.2007.06.007

Morgan, G. A., Leech, N. L., Gloeckner, G. W., \& Barrett, K. C. (2011). SPSS for introductory statistics use and interpretation (4th ed.). New York: NY: Routledge.

Morgeson, F. P., Delaney-Klinger, K., \& Hemingway, M. A. (2005). The importance of job autonomy, cognitive ability, and job-related skill for predicting role breadth and job performance. Journal of Applied Psychology, 90 (2), 399-406. doi:10.1037/0021-9010.90.2.399

Murphy, M. (2005) Why CEOs get fired. Retrieved from www.LeadershipIQ.com

Pugliese, P. J. (1985). The nature of managerial work: The extent Mintzberg's roles are required by the chief executives in academic and public libraries (Doctoral dissertation). Retrieved from ProQuest Dissertations and Theses database. (UMI No. 8603906)

Quarterman, J., Allen, L., \& Becker, A. (2005). Managerial roles of intercollegiate athletic directors for the NAIA: The Mintzberg model. International Journal of Sport Management, 6, 165-182.

Rastetter, A. L. (1985). Managerial activity analysis via Mintzberg's role theory: The effects of person and organization variables (Doctoral dissertation). Retrieved from ProQuest Dissertations and Theses database. (UMI No. 8605787)

Rizzo, J. R., House, R. J., \& Lirtzman, S. I., (1970). Role conflict and ambiguity in complex organizations. Administrative Science Quarterly, 15 (20), 150-163. doi: $10.2307 / 2391486$

Rosser, M. H. (2005). Mentoring from the top: CEO perspectives. Advances in Developing Human Resources, 7(4), 527-539. doi:10.1177/1523422305279685

Ruona, W. E. A. \& Lynham, S. A. (2004). A philosophical framework for thought and practice in human resource development. Human Resource Development International, 7(2), 151-164. doi:10.1080/13678860310001630665

Sashkin, M. \& Fulmer, R. M. (1988). Toward an organizational leadership theory. In Emerging Leadership Vistas (pp. 51-65). 
Senge, P. (1994). Learning to alter mental models. Executive Excellence, 11(3), 16-17.

Shapira, Z. \& Dunbar, R. L. M. (1980). Testing Mintzberg's managerial roles classification using an in-basket simulation. Journal of Applied Psychology, 65(1), 87-95.

Snyder, N. H. \& Wheelen, T. L. (1981). Managerial roles: Mintzberg and the management process theorists. Academy of Management Proceedings, 1981, 249253.

Stata, R. (1988). The role of the chief executive officer in articulating the vision. Interfaces, 18(3), 3-9.

Steiner, G., Kunin, E. \& Kunin H. (1981). The new class of chief executive officer. Long Range Planning, 14(4), 10-20. doi:10.1016/0024-6301(81)90120-5

Stryker, S. (1959). Symbolic interaction as an approach to family research. Marriage and Family Living, (20), 111-119. doi:10.2307/348099

Stryker, S. \& Statham, A. (1985). Symbolic interaction and role theory. In G. Lindzey \& E. Aronson (Eds.) Volume I The Handbook of Social Psychology (pp. 311-378). $3^{\text {rd }}$ ed. New York, NY: Random House.

Swanson, R. A. (2007). Analysis for Improving Performance. $2^{\text {nd }}$ ed. San Francisco, CA: Berrett-Koehler Publishers, Inc.

Swanson, R. A. \& Holton, E. F. (2009). Foundations of Human Resource Development, $2^{\text {nd }}$ ed. San Francisco, CA: Berrett-Koehler Publishers, Inc.

Tedlow, R. S., Bettcher, K. E., \& Purrington, C. A. (2003). The chief executive officer of the large American industrial corporation in 1917. The Business History Review, 77(4), 687-701. doi: $10.2307 / 30041234$

Tengblad, S. (2006). Is there a 'New Managerial Work'? A comparison with Henry Mintzberg's classic study 30 years later. Journal of Management Studies, 43(7), 1437-1461. doi:10.1111/j.1467-6486.2006.00651.x

Thomas, R. J. (1995). Interviewing important people in big companies. In R. Hertz \& J. Imber (Eds.), Studying elites using qualitative methods (pp. 3-17). Thousand Oaks, CA: Sage.

Torraco, R. J. \& Swanson, R. A. (1995). The strategic roles of human resource development. Human Resource Planning, 18(4), 10-21. 
Torraco, R. J., (1997). Theory-building research methods. In R.A. Swanson \& E.F. Holton III (Eds.), Human resource development research handbook: Linking research and practice (pp. 114-137).

Tuck, E. F. \& Earle, T. (1996). Why C.E.O.'s succeed (and why they fail): Hunters and gatherers in the corporate life. Strategy+Business, Q4, 1996, 18-25.

Useem, M. (1995). Reaching corporate executives. In R. Hertz \& J. Imber (Eds.), Studying elites using qualitative methods (pp. 19-39). Thousand Oaks, CA: Sage.

U.S. Bureau of Labor Statistics. Retrieved from www.bls.gov

Vaill, P. B. (1996). Learning as a way of being. San Francisco, CA: Jossey-Bass Publishers.

Vera, D. \& Crossan, M. (2004). Strategic leadership and organizational learning. Academy of Management Review, 29(2), 222-240. doi:10.2307/20159030

Waldman, D. A., Siegel, D. S., \& Javidan, M. (2006). Components of CEO transformational leadership and corporate social responsibility. Journal of Management Studies, 43(8), 1703-1725. doi:10.1111/j.1467-6486.2006.00642.x

Walsh, J. P. (2008). CEO compensation and the responsibilities of the business scholar to society. Academy of Management Perspectives, 22(2), 26-33.

Whitely, W. T. (1978). Nature of managerial work revisited. Academy of Management Proceedings, San Francisco, CA, 195-199.

Wickham, M. \& Parker, M. (2006). Reconceptualising organisational role theory for contemporary organisational contexts. Journal of Managerial Psychology, 22(5), 440-464. doi:10.1108/02683940710757182

Wood, J. S. (2011). Are your directors CEO Material? The Corporate Board, JanuaryFebruary, 2011, 11-15.

Wood, J. \& Vilkinas, T. (2003). Characteristics of chief executive officers: Views of their staff. Journal of Management Development, 23(5), 469-478. doi:10.1108/02621710410537074

Yang, B. (2005). Factor analysis methods. In R. A. Swanson and E. F. Holton (Eds.), Research in organizations: Foundations and methods of inquiry. (pp. 181-199). San Francisco, CA: Berrett-Koehler Publishers, Inc.

Zaccaro, S. J. (2001). Behavioral complexity theories: Conceptual review and evaluations. In The nature of executive leadership A conceptual and empirical 
analysis of success (pp. 123-147). Washington, DC: American Psychological Association. doi:10.1037/10398-004

Zaleznik, A. (1977). Managers and leaders are they different? Harvard Business Review, 55(3), 74-81.

Zhang, Y. \& Wiersema, M. F. (2009). Stock market reaction to CEO certification: The signaling role of CEO background. Strategic Management Journal, 30, 693-710. doi: $10.1002 / \mathrm{smj} .772$ 


\section{APPENDIX A}

\section{THF ROIF OF CHIEF EXFCUTIVE OFEICER}

FROM THE PERSPECTIVE OF THE CEO

Please participate in the short survey below. Your perspective on the role of CEO is important to research about the role of $C E O$.

Please provide some demographic information about yourself and your company.

Next, please respond to the following statements by indicating your level of agreement/disagreement that each role describes a role engaged in by CEOs.

Please estimate the average number of hours per week you spend in the roles that you believe are CEO roles.

You are provided space to describe any roles that are missing. Please estimate the average number of hours per week spent in these roles.

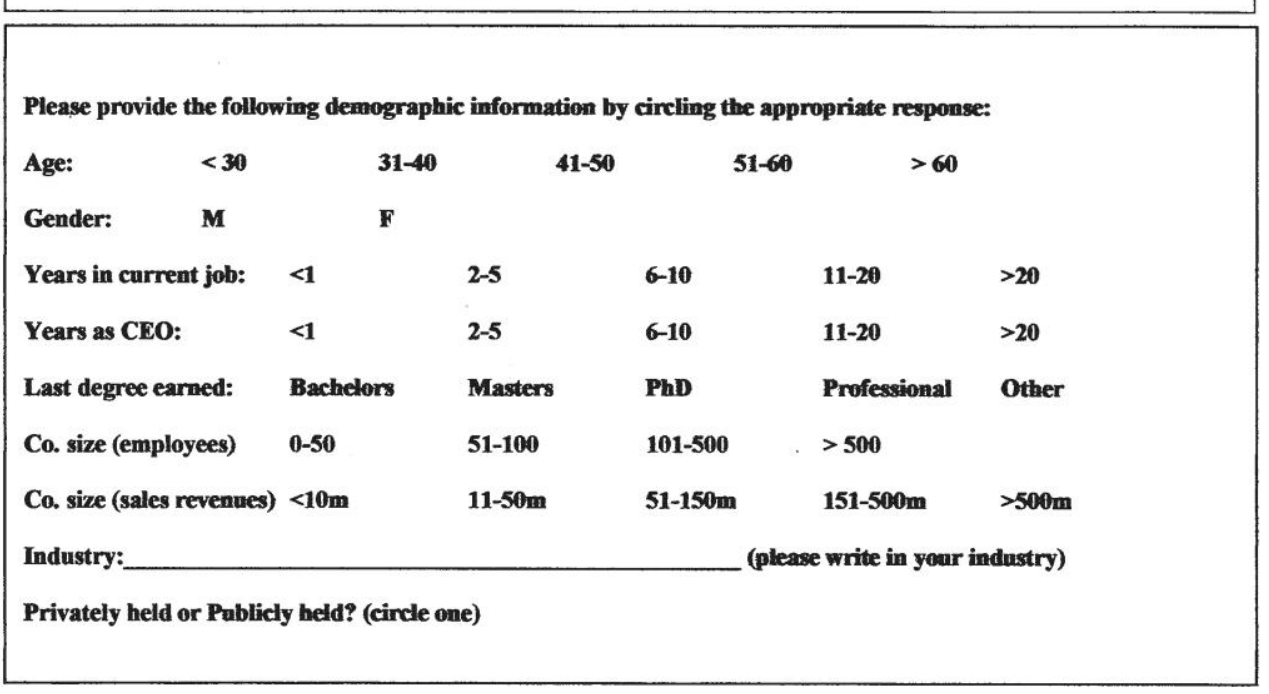

\begin{tabular}{|c|c|c|c|c|c|c|c|}
\hline & & $\begin{array}{c}\text { Stronghy } \\
\text { Agree }\end{array}$ & Agree & Neutral & Dtsagree & $\begin{array}{l}\text { Strongty } \\
\text { Disagree }\end{array}$ & $\begin{array}{l}\text { \# Hours } \\
\text { per week }\end{array}$ \\
\hline 1) & $\begin{array}{l}\text { I focus on efficient management of the internal } \\
\text { operating system in the interest of serving existing } \\
\text { products/markets. }\end{array}$ & 1 & 2 & 3 & 4 & 5 & \\
\hline 2) & I give orders to employees. & $\mathbf{1}$ & 2 & 3 & 4 & 5 & \\
\hline 3) & I make sure projects are completed on time. & 1 & 2 & 3 & 4 & 5 & \\
\hline 4) & $\begin{array}{l}\text { I make sure the right people are in the right place at the } \\
\text { right time doing the right things. }\end{array}$ & $\mathbf{1}$ & 2 & 3 & 4 & $\mathbf{5}$ & \\
\hline 5) & $\begin{array}{l}\text { I make sure that day-to-day operations are being } \\
\text { completed in a satisfactory manner. }\end{array}$ & $\mathbf{1}$ & 2 & 3 & 4 & 5 & \\
\hline 6) & $\begin{array}{l}\text { I decide where my organization will expend efforts and } \\
\text { resources. }\end{array}$ & $\mathbf{1}$ & 2 & 3 & 4 & 5 & \\
\hline 7) & $\begin{array}{l}\text { I make sure the right people are hired for the right } \\
\text { positions. }\end{array}$ & 1 & 2 & 3 & 4 & 5 & \\
\hline 8) & I have a strong focus on results or getting the job done. & 1 & 2 & 3 & 4 & 5 & \\
\hline 9) & I am the expert on product and market. & 1 & 2 & 3 & 4 & 5 & \\
\hline
\end{tabular}




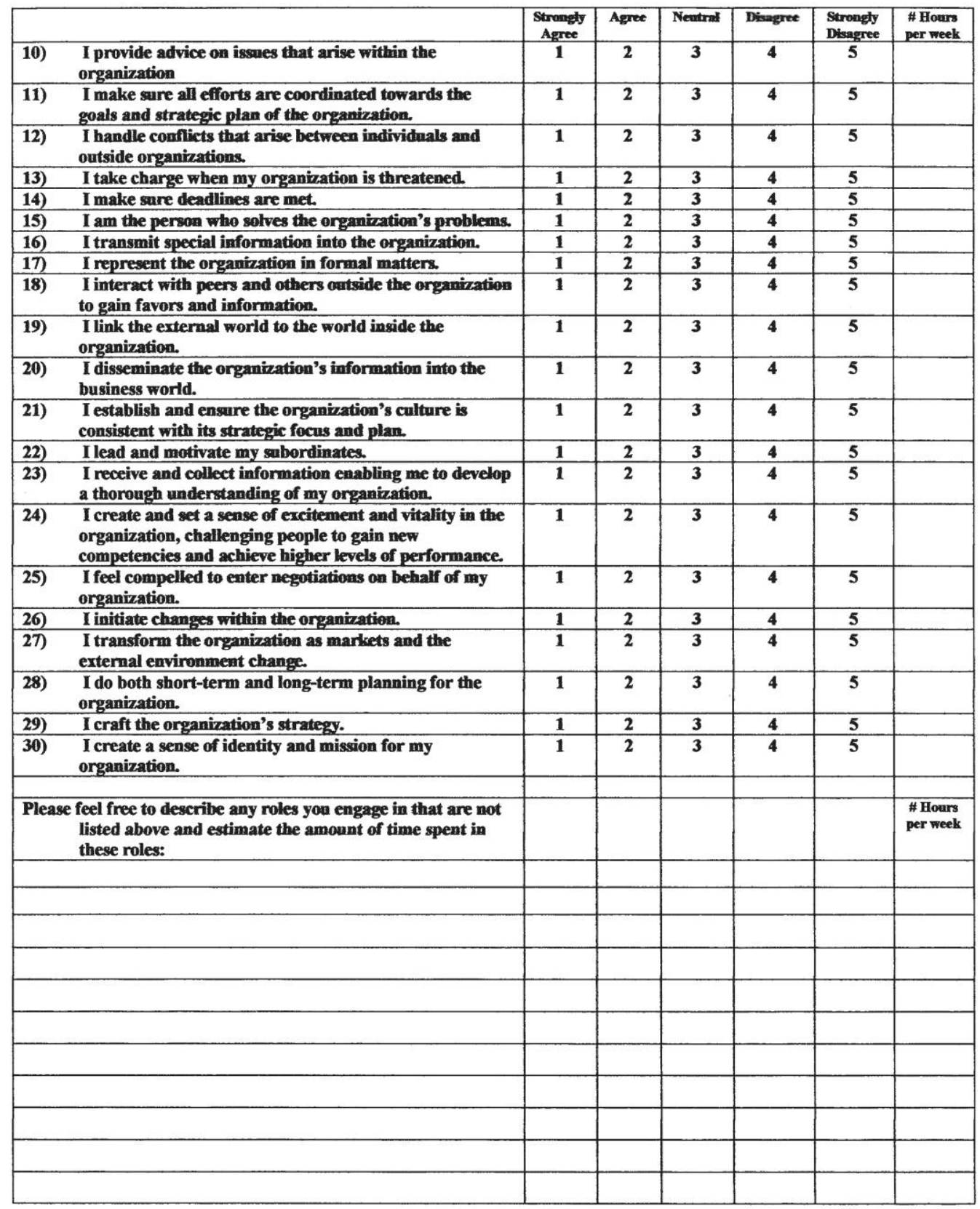




\section{APPENDIX B \\ Consent to Participate in a Research Study \\ Colorado State University}

TITLE OF STUDY: Pilot Test of an instrument designed to measure the role of the Chief Executive Officer (CEO)

PRINCIPAL INVESTIGATOR: Thomas J. Chermack, PhD, Assistant Professor, 612.387.1951; chermack@ colostate.edu .

CO-PRINCIPAL INVESTIGATOR: Maggie Glick, CSU Doctoral Student, 970-4959689; maggie.glick@colostate.edu .

WHY AM I BEING INVITED TO TAKE PART IN THIS RESEARCH? You are being invited to participate in this research because you are a CEO. The survey you are being asked to complete provides information and your opinions about the role of the CEO and how your time is allocated among the various roles. This information will help us to understand what the role of the CEO is.

WHO IS DOING THE STUDY? This study is being conducted by Thomas J. Chermack, $\mathrm{PhD}$, Assistant Professor, Colorado State University, and Maggie Glick, Doctoral Student, Colorado State University. This study is not funded.

WHAT IS THE PURPOSE OF THIS STUDY? The purpose of this study is to research the current role of the CEO.

WHERE IS THE STUDY GOING TO TAKE PLACE AND HOW LONG WILL IT LAST?

The survey will take place at the address of business and will be completed manually and mailed back to Maggie Glick directly upon completion. The estimated time to complete this survey is 10 minutes.

WHAT WILL I BE ASKED TO DO? You are being asked to complete a survey about your role as a CEO. If you want to participate, please complete and return the survey in the envelope provided. For future reference please keep this letter with the researcher's contact information.

\section{ARE THERE REASONS WHY I SHOULD NOT TAKE PART IN THIS STUDY?}

There are no reasons not to participate in this study. 


\section{WHAT ARE THE POSSIBLE RISKS AND DISCOMFORTS?}

There are no known risks associated with this study.

It is not possible to identify all potential risks in research procedures, but the researcher(s) have taken reasonable safeguards to minimize any known and potential, but unknown, risks.

ARE THERE ANY BENEFITS FROM TAKING PART IN THIS STUDY? There are no direct benefits from taking part in this study. However, by participating you will add to the knowledge of the role of CEO. As such, you will extend our understanding of the role providing meaningful data for HRD professionals, boards of directors, and other CEOs. (Please turn this page over for additional information.)

DO I HAVE TO TAKE PART IN THE STUDY? Your participation in this research is voluntary. If you decide to participate in the study, you may withdraw your consent and stop participating at any time without penalty or loss of benefits to which you are otherwise entitled.

\section{WHO WILL SEE THE INFORMATION THAT I GIVE?}

Your name is not required. The name of your organization is not required. The information you provide will be combined with information from other people taking part in the study. When we write about the study to share it with other researchers or publish the results, we will write about the combined information we have gathered. You will not be identified in these written materials.

Only the two members of the research team (listed above) will have access to the survey information.

\section{WHAT IF I HAVE QUESTIONS?}

Before you decide whether to accept this invitation to take part in the study, please ask any questions that might come to mind now. Later, if you have questions about the study, you can contact the principal investigator, Dr. Thomas J. Chermack at 612.387.1951; chermack@colostate.edu , or the co-principle investigator, Maggie Glick at 970-495-9689 or Maggie.glick@ colostate.edu . If you have any questions about your rights as a volunteer in this research, contact Janell Barker, Human Research Administrator at 970-491-1655. This copy of the consent form is yours to keep.

Thank you for your participation in this study.

Sincerely,

Maggie Glick

Doctoral Student

Colorado State University

Thomas J. Chermack, PhD

Assistant Professor

Colorado State University 


\section{APPENDIX C}

\section{Consent to Participate in a Research Study}

\section{Colorado State University}

DATE: May 4, 2010

$$
\begin{array}{r}
\text { Research Integrity \& Compliance Review Office } \\
\text { Office of Vice President for Research } \\
\text { Fort Collins, CO 80523-2011 } \\
\text { (970) 491-1553 }
\end{array}
$$

TO: $\quad$ Thomas Chermack, Education Maggie Glick, Education

FROM: Janell Barker, IRB Administrator Research Integrity \& Compliance Review Office

TITLE: Pilot Test of an Instrument Designed to Survey

IRB ID: 027-10H Review Date: May 4, 2010

The Institutional Review Board (IRB) Administrator has reviewed this project and has declared the study exempt from the requirements of the human subject protections regulations as described in 45 CFR 46.101(b)(2): Research involving the use of educational tests,.... survey procedures, interview procedures or observation of public behavior, unless: a) information obtained is recorded in such a manner that human subjects can be identified, directly or through identifiers linked to the subjects. The IRB determination of exemption means that:

You do not need to submit an application for annual continuing review.

You must carry out the research as proposed in the Exempt application, including obtaining and documenting (signed) informed consent if stated in your application or if required by the IRB.

Any modification of this research should be submitted to the IRB through an e-mail to the IRB Administrator, prior to implementing any changes, to determine if the project still meets the Federal criteria for exemption. If it is determined that exemption is no longer warranted, then an IRB proposal will need to be submitted and approved before proceeding with data collection.

Please notify the IRB if any problems or complaints of the research occur. Please note that you must submit all research involving human participants for review by the IRB. Only the IRB may make the determination of exemption, even if you conduct a similar study in the future. 


\section{APPENDIX D}

The following data are available in the Ref USA database:

Company name, CEO first and last name, CEO title, CEO gender, address, county code, metropolitan area, neighborhood, phone number, fax number, toll free number, company website, company description, primary Standard Industry Code (SIC) code, primary SIC description, primary SIC ad size, primary SIC year appeared (repeated for 1-26 SIC codes), primary North American Industry Code (NAIC), primary NAIC description (repeated for 1-26 NAIC codes), franchise description, location employee size range, location employee size actual, location sales volume range, location sale volume actual, corporate employee size, corporate sale volume range, corporate sales volume actual, holding status, location type, parent company name, parent/USA \#, foreign parent flag, Fortune 1000 ranking, credit score alpha, credit score numeric, credit rating, latitude, longitude, credit cards accepted, year established, year in database, number of Personal Computers (PCs), square footage, home business flag, IUSA number, executive name, title, gender and biographical information (bio) (for 1-20 executives), director name, title, gender and bio (for one to five directors), ticker symbol, stock exchange, expenses: accounting, advertising, contract labor, insurance, legal, office supplies, management/administrative, packing container, payroll and benefits, purchased printing, rent, computer, telecom, utilities, sales history, employee history, brands, and mailing address. 


\section{APPENDIX E}

\section{Dear CEO,}

During the week of May $17^{\text {th }}$ you should have received a request to participate in the pilot study of a survey designed to investigate the Role of CEO. If you have returned that survey, thank you very much for taking your valuable time to do so. If you have not, it is not too late! I would appreciate hearing from you. If you prefer to receive an electronic version, please e-mail me at Maggie.glick@colostate.edu. Thank you! Maggie Glick, CPA

Doctoral Student, Colorado State University 


\title{
APPENDIX F
}

\section{Consent to Participate in a Research Study}

\author{
Colorado State University
}

Research Integrity \& Compliance Review Office

Office of Vice President for Research Fort Collins, CO 80523-2011 (970) $491-1553$

DATE: October 27, 2010

FAX (970) 491-2293
TO: Thomas Chermack, Education Maggie Glick, Education

FROM: Janell Barker, IRB Administrator

Research Integrity \& Compliance Review Office

TITLE: The Role of Chief Executive Office from the Perspective of CEOs

IRB ID: 028-11H Review Date: October 27, 2010

The Institutional Review Board (IRB) Administrator has reviewed this project and has declared the study exempt from the requirements of the human subject protections regulations as described in 45 CFR 46.101(b)(2): Research involving the use of educational tests,....survey procedures, interview procedures or observation of public behavior, unless: a) information obtained is recorded in such a manner that human subjects can be identified, directly or through identifiers linked to the subjects. The IRB determination of exemption means that:

You do not need to submit an application for annual continuing review.

You must carry out the research as proposed in the Exempt application, including obtaining and documenting (signed) informed consent if stated in your application or if required by the IRB.

Any modification of this research should be submitted to the IRB through an e-mail to the IRB Administrator, prior to implementing any changes, to determine if the project still meets the Federal criteria for exemption. If it is determined that exemption is no longer warranted, then an IRB proposal will need to be submitted and approved before proceeding with data collection.

Please notify the IRB if any problems or complaints of the research occur.

Please note that you must submit all research involving human participants for review by the IRB. Only the IRB may make the determination of exemption, even if you conduct a similar study in the future. 


\section{APPENDIX G}

\section{Dear Chief Executive Officer,}

My name is Maggie Glick and I am a doctoral student at Colorado State University. I am writing to you to request your participation in research that supports my dissertation topic, The Role of Chief Executive Officer. You will be doing me a very big favor by taking $10-15$ minutes to complete a survey about the role of the CEO. The survey asks that you review descriptions of 30 roles, and indicate your level of agreement or disagreement that this is a role of the Chief Executive Officer. You are also asked to add any roles that the questionnaire may be missing. The roles are grouped into six role categories and you are asked to estimate the number of hours spent each week in the role categories. Finally, you are asked for some demographic information about yourself and your company. It takes approximately 15 minutes to complete the entire questionnaire. You have indicated your desire to participate in this using an on-line survey, so I am providing a link to the survey below:

This links to a secure server at Colorado State University, utilizing Qualtrics software. You do not need to have the software to complete the survey.

This is an academic project and is not sponsored by any company. Your anonymity is guaranteed and you will not be contacted again (by anyone) for helping me by completing this questionnaire. You can call me at 970-495-9689 or 970-818-1041 if you have any questions. Further, if you would like to see the survey results, I will send them to you. Email me at Maggie.glick@colostate.edu and I will provide you with the results when the study is completed.

Your response is very important to me. Please complete and submit the survey on-line using the link I have provided.

Thank you for your help.

Sincerely,

Maggie Glick, CPA

Doctoral Student

Colorado State University
Thomas J. Chermack, PhD

Assistant Professor

Director, Scenario Planning Institute

Colorado State University 


\section{APPENDIX H}

\section{Role of CEO}

Please participate in this confidential survey. Your perspective on the role of CEO is important to research on this topic. Please read each role description and indicate your level of agreement/disagreement as it relates to your role as a CEO. You are provided a space to add and describe any roles that are missing from the survey. Please indicate the approximate number of hours you spend on each role category per week. As a final step please provide some background demographic information about yourself and your company. Thank you for your participation in this research. 
Informational Roles:

1. I receive and collect information enabling me to develop a thorough understanding of my organization.

Strongly Agree

Agree

Neither Agree nor Disagree

Disagree

Strongly Disagree

2. I transmit special information into the organization.
Strongly Agree
O Agree
Neither Agree nor Disagree
$\bigcirc$ Disagree
Strongly Disagree

3. I give orders to employees.
Strongly Agree
O Agree
Neither Agree nor Disagree
$\bigcirc$ Disagree
Strongly Disagree

4. I disseminate the organization's information into the business world.
Strongly Agree
O Agree
Neither Agree nor Disagree
Disagree
Strongly Disagree

Interpersonal Roles:

5. I lead and motivate my subordinates. 


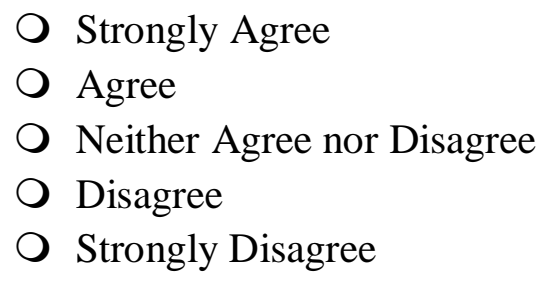

6. I create and set a sense of excitement and vitality in the organization, challenging people to gain new competencies and achieve higher levels of performance.
Strongly Agree
O Agree
Neither Agree nor Disagree
$O$ Disagree
Strongly Disagree

7. I make sure the right people are in the right place at the right time doing the right things.
Strongly Agree
O Agree
Neither Agree nor Disagree
Disagree
Strongly Disagree

Decisional Roles:

8. I initiate changes within the organization.
Strongly Agree
O Agree
Neither Agree nor Disagree
$\bigcirc$ Disagree
O Strongly Disagree

9. I take charge when my organization is threatened.
O Strongly Agree
Agree
Neither Agree nor Disagree 


\title{
O Disagree \\ Strongly Disagree
}

10. I handle conflicts that arise between individuals and outside organizations.

\author{
Strongly Agree \\ O Agree \\ Neither Agree nor Disagree \\ Disagree \\ Strongly Disagree
}

11. I decide where my organization will expend efforts and resources.
O Strongly Agree
Agree
Neither Agree nor Disagree
Disagree
Strongly Disagree

12. I have a strong focus on results or getting the job done.
O Strongly Agree
Agree
Neither Agree nor Disagree
Disagree
Strongly Disagree

13. I make sure the right people are hired for the right positions.
Strongly Agree
Agree
Neither Agree nor Disagree
Disagree
Strongly Disagree

14. I am compelled to enter negotiations on behalf of my organization.
Strongly Agree
Agree
Neither Agree nor Disagree 


\section{Disagree \\ O Strongly Disagree}

15. I am the person who solves the organization's problems.

Strongly Agree

O Agree

Neither Agree nor Disagree

$O$ Disagree

Strongly Disagree

Operational Roles:

16. I make sure deadlines are met.
O Strongly Agree
Agree
Neither Agree nor Disagree
$\bigcirc$ Disagree
O Strongly Disagree

17. I focus on efficient management of the internal operating system in the interest of serving existing products/markets.

\section{Strongly Agree \\ O Agree \\ Neither Agree nor Disagree \\ $O$ Disagree \\ Strongly Disagree}

18. I make sure projects are completed on time.
O Strongly Agree
Agree
Neither Agree nor Disagree
$\bigcirc$ Disagree
Strongly Disagree

19. I make sure that day-to-day operations are being completed in a satisfactory manner. 


\section{O Strongly Agree \\ O Agree \\ Neither Agree nor Disagree \\ Disagree \\ Strongly Disagree}

20. I am the expert on product and market.
O Strongly Agree
O Agree
Neither Agree nor Disagree
O Disagree
O Strongly Disagree

21. I provide advice on issues that arise within the organization.
Strongly Agree
O Agree
Neither Agree nor Disagree
$O$ Disagree
O Strongly Disagree

Strategic Roles:

21. I make sure all efforts are coordinated towards the goals and strategic plan of the organization.
Strongly Agree
O Agree
Neither Agree nor Disagree
$O$ Disagree
O Strongly Disagree

23. I guide the organization into new cycles of innovation.
O Strongly Agree
O Agree
Neither Agree nor Disagree
$\bigcirc$ Disagree 


\title{
O Strongly Disagree
}

24. I do both short-term and long-term planning for the organization.

\author{
O Strongly Agree \\ O Agree \\ Neither Agree nor Disagree \\ O Disagree \\ O Strongly Disagree
}

25. I create a sense of identity and mission for my organization.
O Strongly Agree
O Agree
O Neither Agree nor Disagree
O Disagree
O Strongly Disagree

26. I craft the organization's strategy.
O Strongly Agree
O Agree
O Neither Agree nor Disagree
O Disagree
O Strongly Disagree

27. I transform the organization as markets and the external environment change.
O Strongly Agree
O Agree
O Neither Agree nor Disagree
O Disagree
O Strongly Disagree

28. I establish and ensure the organization's culture is consistent with its strategic focus and plan.
O Strongly Agree
O Agree
O Neither Agree nor Disagree 


\title{
O Disagree \\ O Strongly Disagree
}

Diplomacy Roles:

29. I link the external world to the world inside the organization.

\author{
O Strongly Agree \\ O Agree \\ O Neither Agree nor Disagree \\ O Disagree \\ O Strongly Disagree
}

30. I represent the organization in formal matters.
O Strongly Agree
O Agree
O Neither Agree nor Disagree
O Disagree
O Strongly Disagree

31. I interact with peers and others outside the organization to gain favors and information.
O Strongly Agree
O Agree
O Neither Agree nor Disagree
O Disagree
O Strongly Disagree

Please feel free to describe any roles you engage in that are not listed above and please include an estimate of the time spent in these roles on a weekly basis:

Approximately how many hours do you spend in an average week on the individual role categories?

Informational Roles Interpersonal Roles 
_ Decisional Roles Operational Roles Strategic Roles Diplomacy Roles

Please provide some demographic information about yourself and your organization:

My age is:

My gender is:

O Male

O Female

Years in current job

Years as CEO

Last degree earned
High School
O Associates Degree
O Bachelors Degree
O Masters Degree
$\mathrm{O} \mathrm{PhD}$
Professional
Other

Major of Last degree earned or majority of industry experience
Operations
O Finance
O Public Relations
O Technical/Engineering
Other 


\section{Company Size (Employee Number)}

\section{Company Size (Sales Revenues)}

What industry are you currently working in?

Is your company privately or publicly-held?

\section{O Private}

O Public

Do you have an additional title?

\section{$\mathrm{O}$ Yes}

O No

What other titles do you have?

Do you have other C-level executives working for you?
$\mathrm{O}$ Yes
O No

What are the titles of the other C-level executives that work for you? (for example, COO or $\mathrm{CFO}$ ) 